\title{
SHIP164 is a Chorein Motif Containing Lipid Transport Protein that Controls Membrane Dynamics and Traffic at the Endosome-Golgi Interface.
}

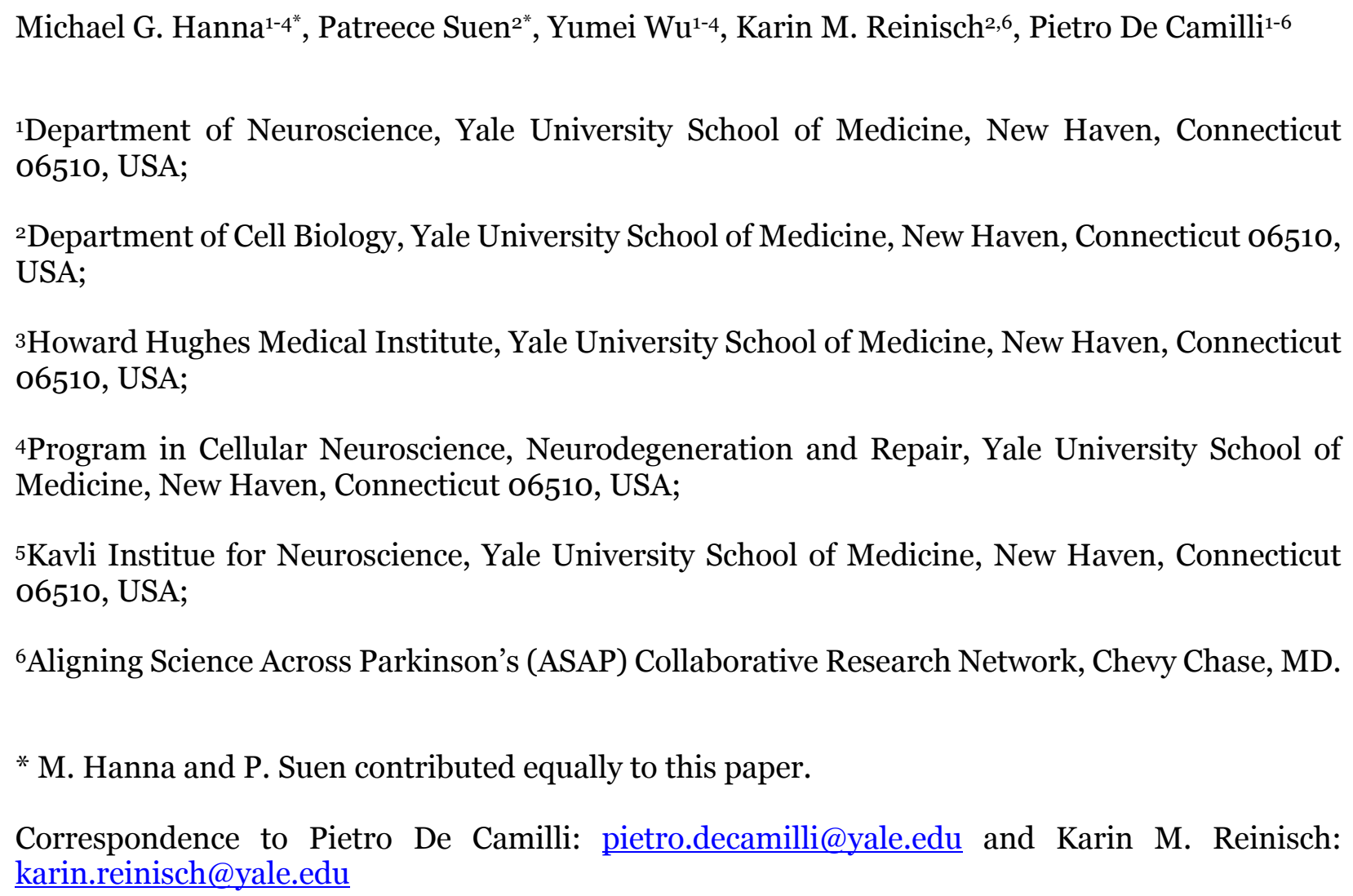




\section{ABSTRACT}

31 Cellular membranes differ in protein and lipid composition as well as in the protein-lipid ratio. Thus, progression of membranous organelles along traffic routes requires mechanisms to control bilayer lipid chemistry and their abundance relative to proteins. The recent structural and functional characterization of VPS13-family proteins has suggested a mechanism through which lipids can be transferred in bulk from one membrane to another at membrane contact sites, and thus independently of vesicular traffic. Here we show that SHIP164 (UHRF1BP1L) shares structural and lipid transfer properties with these proteins and is localized on a subpopulation of vesicle clusters in the early endocytic pathway whose membrane cargo includes the cationindependent mannose-6-phosphate receptor (MPR) and ATG9. Loss of SHIP164 disrupts retrograde traffic of these organelles to the Golgi complex. Our findings raise the possibility that bulk transfer of lipids to endocytic membranes may play a role in their traffic. 


\section{INTRODUCTION}

The homeostasis of intracellular membranes and their adaptation to changes in the functional state of the cell requires the coordination of protein and lipid transport. While much has been learned about protein traffic, less is known about the dynamics and transport of bilayer lipids. A significant fraction of such lipids move between organelles as part of the membranes of vesicular carriers. However, lipids also move via transport proteins that harbor them in hydrophobic cavities as they travel through the aqueous environment of the cytosol. This mode of transport has been known for decades, but has been increasingly appreciated over the last several years with the discovery of many new lipid transport proteins. Moreover, it has also become clear that many such proteins function at membrane contact sites, thus facilitating specificity and speed of lipid transport. Typically, these proteins contain modules or motifs that tether them to the two apposed membranes while lipid transfer modules move back and forth between them to extract and deliver lipids by a shuttling mechanism ${ }^{1-5}$.

Recently, the characterization of VPS13 and its distant paralogue ATG2 has suggested a new mode of transport involving the flow of lipids along a protein bridge that connects the two membranes in eukaryotic cells ${ }^{6-10}$. A defining feature of these proteins is the presence of a conserved Nterminal region, 125 residues long, referred to as the chorein-N motif6,11-13. In VPS13 and ATG2, this motif caps one end of an elongated rod (extended chorein domain). The rod comprises an extended $B$-sheet that is highly curved to resemble a taco shell harboring a groove along its length 78 . A hydrophobic cavity in the chorein motif is continuous with the groove, whose floor is lined by hydrophobic amino acids, and so suited to accommodate many lipids at once and to allow their flow from one end of the rod to the other. In ATG2, the rod represents the bulk of the protein, while in VPS13 there are additional folded C-terminal domains that function in localization. Lipids are thought to flow unidirectionally along the rod, producing a net flow of lipids to the acceptor membrane and allowing for its expansion independent of contribution of new membrane lipids by vesicle fusion'. Accordingly, both the VPS13 paralogues and ATG2 have been implicated in membrane growth ${ }^{14-17}$. Many questions remain, however, about the precise mechanisms of action of these proteins. In some cases, the earliest stages of membrane growth mediated by VPS13 and ATG2 are characterized by the presence of clusters of small vesicles, raising questions about a potential interplay between the lipid transport properties of these proteins and vesicle fusion ${ }^{14-16}$. As studies of VPS13 have informed regarding ATG2 function and vice versa, characterization of other family members should yield further insights both as to how these proteins function and the cellular processes in which they participate.

A predicted chorein motif is present at the N-terminus of SHIP164 (also called UHRF1BP1L) and in its paralogue UHRF1BP1 (also called C6orf107), and fold prediction algorithms indicate high confidence that downstrem portions form an extended chorein domain $\beta$-sheet ${ }^{18,19}$ (Figure 1A). SHIP164 was first identified as an interactor of the Habc domain of Syntaxin 6 (Stx6) and shown to be a component of a multimolecular assembly including subunits of GARP ${ }^{20}$. GARP is a tethering complex which along with the structurally similar EARP cooperates with Stx6 in the fusion of endocytic vesicles with acceptor membranes in endosomes (EARP) and the Golgi complex (GARP) ${ }^{21-23}$. Moreover, over-expressed SHIP164-Stx6 complex was shown to colocalize with the cation-independent mannose-6-phosphate receptor (MPR) and to perturb the traffic of this receptor ${ }^{20}$. More recently, SHIP164 was identified as a top hit in a cellular-based screen for Rab5 effectors, further supporting a role of SHIP164 in the early endocytic pathway ${ }^{24}$. The possibility that SHIP164 may represent a lipid transport protein suggests that its characterization may reveal novel aspects of the biology of the endosomal system. Additional interest in this protein comes from its identification as a Parkinson's disease (PD) candidate gene from a large- 
scale whole exome sequencing (WES) study ${ }^{25}$. To date, Nothing is known about the cell biology of UHRF1BP1.

The goal of this study was to test the hypothesis that SHIP164 may be a lipid transport protein and to gain new information into its localization and physiological function. Here we provide direct evidence for a structural similarity of SHIP164 to ATG2 and the N-terminal half of VPS13 and for the property of SHIP164 to harbor and transport lipids. We show that SHIP64 localizes to clusters of small vesicles in the endocytic pathway and demonstrate its importance in retrograde traffic to the Golgi complex by both over-expression and loss-of-function studies. We also provide evidence for a link between SHIP164 and ATG9A, raising the possibility that SHIP164, like ATG2, may mediate lipid transport in partnership with ATG9A. Finally, our findings predict similar properties for UHRF1BP1.

\section{RESULTS}

\section{Molecular properties of SHIP164 support a lipid transport function}

As a first step in assessing whether SHIP164 might function as a lipid transporter in the VPS13family, we assayed whether it can solubilize and transport lipids between membranes, and, if so, which ones. We expressed full-length, N-terminally FLAG-tagged human SHIP164 (3xFLAGSHIP164) in Expi293 cells and purified it using anti-FLAG affinity resin, amid extensive washing to remove non-specifically bound lipids, then analyzed the sample for co-purified molecules by shotgun mass spectrometry lipidomics (Figure 1B). A large assortment of lipids, primarily phospholipids, co-purified with SHIP164. There was no significant enrichment of a particular phospholipid relative to the content of the whole cell, however.

The full-length construct was prone to aggregation, whereas constructs lacking a long predicted unstructured segment (residues 901-1099) were soluble and were used in subsequent in vitro studies. Further supporting that SHIP164 binds phospholipids, 3XFLAG-SHIP164 $4901-1099$ binds nitrobenzoxadiazole (NBD)-labeled PE, co-migrating with this lipid on a native gel (Figure 1C). From comparing the fluorescence that co-migrated with SHIP164 versus a well characterized lipid transport module from the protein E-Syt2, we estimate that each SHIP164 molecule can accommodate multiple lipids ( $\sim 8)$, as might be expected if SHIP164 has an extended lipid binding groove like VPS13 or ATG2 ${ }^{6,7}$.

We took advantage of the ability of SHIP164 to bind NBD-PE in designing an in vitro FRET-based assay to monitor lipid transfer between membranes ${ }^{6}$. In this assay, SHIP164 is tethered (Figure 1D) between donor liposomes containing both rhodamine (Rh)- and NBD-labeled PE (61\% DOPC, $30 \%$ PE, 2\% NBD-PE, 2\% Rh-PE, 5\% Ni-NTA) and acceptor liposomes (65\% DOPC, 30\% PE, 5\% $\mathrm{PI}(4,5) \mathrm{P}_{2}$ ), initially lacking these fluorescent lipids. FRET between $\mathrm{Rh}$ and NBD reduces NBD fluorescence initially. Transfer to acceptor liposomes and consequent dilution of the fluorescently tagged lipids would reduce FRET and lead to increased NBD fluorescence. Consistent with a role in lipid transfer, addition of SHIP164, but not of a an "empty" tether lacking a lipid transport module, led to increased fluorescence (Figure 1E). Addition of SHIP164 to donor liposomes only, in the absence of acceptor liposomes, led to a fast, smaller fluorescence increase due to the ability of SHIP164 to extract lipids from the liposomes (Fig. 1E, red arrow), causing some dilution (similar to observations for ATG2 and VPS13 $3^{6,7}$ ). SHIP164 mediated fusion between donor and acceptor liposomes would also lead to increased fluorescence. To discriminate between lipid transfer (which occurs only between lipids in the outer leaflet of liposomes in the absence of scramblases) and liposome fusion, we incubated donor and acceptor liposomes with and without SHIP164, as before, then added dithionite to reduce NBD-labeled lipids exposed in the outer 
144

145

146

147

148

149

150

151

152

153

154

155

156

157

158

159

160

161

162

163

164

165

166

167

168

169

170

171

172

173

174

175

176

177

178

179

180

181

182

183

184

185

186

187

188

189

190

191

192

193

194

leaflet. If SHIP164 had induced liposome fusion, the residual fluorescence after addition of SHIP164 would be higher than in its absence, as lipids in the internal leaflet would have been diluted $^{26}$. In contrast, we found that the residual fluorescence after addition of dithionite was the same with and without addition of SHIP164 reflecting the fluorescence of lipids in the internal leaflet of donor liposomes that did not undergo dilution in the absence of membrane fusion (Figure 1F). These experiments support that SHIP164 can solubilize lipids and transfer them between membranes.

We next examined SHIP164 by electron microscopy. 2D class averages of negatively stained 3XFLAG-SHIP164 ${ }_{\triangle 901-1099}$ revealed a $200 \AA$ long $\operatorname{rod}$ (Figure 1G, Supplemental Figure 1A). Comparison of SHIP164 with a MBP-SHIP164 fusion indicates that this rod represents a tail-totail dimer, as there are two densities corresponding to MBP, one at each end. The MBP-tag locates the SHIP164 N-terminus at the rod end. Whether this dimerization is physiologically relevant is unclear; for example, ATG2 similarily dimerizes in vitro, at high concentration, and in the absence of binding partners, but is thought to be monomeric in vivo ${ }^{7}$. Further characterization of 3 XFLAGSHIP164_901-1099 using single particle cryo-electron microscopy techniques yielded a reconstruction at an estimated resolution of $\sim 8.3 \AA$ (Supplemental Figure 1B\&C). As suggested by fold prediction algorithms (ref. ${ }^{18,19}$ )(see Figure 1Ac-d), a cavity runs along the entire length of the rod, as in VPS13 and ATG2 (Figure 1 H\&I). The algorithms also predict that this cavity is lined entirely with hydrophobic residues (Figure 1Ac-d). Thus, the cavity can accommodate the multiple lipids bound by SHIP164, and we propose that it could be a conduit for lipids to transit between membranes.

Collectively, these findings are consistent with the hypothesis that SHIP164 is a lipid transport protein. We next investigated its site of action within cells.

\section{Localization of exogenous SHIP164 points to a role on endocytic organelles}

Antibodies directed against SHIP164 did not yield a consistently reliable signal when tested by immunofluorescence. Thus, we examined the localization of exogenously tagged human SHIP164. In agreement with the study by Otto et $\mathrm{al}^{20}$, SHIP164 tagged at the N-terminus (GFP-SHIP164) had a diffuse cytosolic localization when expressed in mammalian cell lines (e.g. HeLa, COS-7, RPE1) (Supplemental Figure 2A). As studies of VPS13 had shown that tags appended to the $\mathrm{N}$-terminus (i.e the N-terminus of the chorein motif) interfere with its physiological function ${ }^{6,27}$, we engineered tags at the C-terminus of SHIP164 (SHIP164-Halo) or at an internal site within the predicted disordered region (after amino acid residue 915; SHIP164^ ${ }^{\wedge}$ Scarlet-I) (Figure 2A) (ref. ${ }^{6,27}$ ). When either of these tagged SHIP164 constructs was expressed alone, punctate structures of varying size were observed throughout the cytoplasm, with the larger and brighter spots being localized in the central region of the cell, in proximity of the Golgi complex area (Figure 2A). Similar results were observed with other tags (Halo, GFP, mRFP, etc.) at either position. Conversely, even a small N-terminal tag appended to SHIP164^ ${ }^{\wedge}$ Scarlet-I (3xFLAGSHIP $164^{\wedge} \mathrm{mScarlet}-\mathrm{I}$ ) abolished the presence of cytoplasmic foci (Figure $\mathbf{2 B}$ ).

The scattered distribution of SHIP $164^{\wedge} \mathrm{mScarlet}-\mathrm{I}$ foci throughout the cytosol combined with the results of Otto et $\mathrm{al}^{20}$ suggesting a role of SHIP164 in the endocytic pathway, prompted us to examine the colocalization of SHIP164 relative to endosome markers. Many, but not all SHIP164 puncta, localized in proximity of spots or vacuoles positive for GFP-2xHrs ${ }^{\mathrm{FYVE}}$, a $\mathrm{PI} 3 \mathrm{P}$ binding probe $^{28}$ (Figure 2C). Moreover, SHIP164^ $\mathrm{mScarlet}-\mathrm{I}$ spots were observed in close proximity to other co-expressed markers of endosome subcompartments, such as APPL1 (a very early, PI3Pnegative endosomal station), WDFY2 (an endosomal station downstream of APPL1), and EEA1 ${ }^{29}$ (Figure 2D). SHIP164, however, did not localize on the organelles positive for these probes, but 
195

196

197

198

199

200

201

202

203

204

205

206

207

208

209

210

211

212

213

214

215

216

217

218

219

220

221

222

223

224

225

226

227

228

229

230

231

232

233

234

235

236

237

238

239

240

241

242

243

244

245

on foci juxtaposed to them (Figure 2C-E). This was even more clear by observing macropinosomes (both naturally occurring or induced by expressing constitutively active $\operatorname{Ras}^{\mathrm{G} 12 \mathrm{~V}}$ ), given the large size of these vesicles ${ }^{29}$ (Supplemental Figure 2B). As shown by livecell imaging, SHIP164 foci not only were variable in size as well as in fluorescence intensity, but were also highly dynamic structures. They changed shape, often underwent fission, or coalesced into larger spots although they tended to remain tethered to endosomes and micropinosomes (Figure 2F; Supplemental Movie 1). In some cases, they were localized at sites where the endosomes appeared to be close to the ER (Figure 2E), but were not restricted to the space between these two organelles.

A more precise colocalization of exogenous SHIP164 was observed with Rab5 (BFP-Rab5b), confirming previous results ${ }^{20,24}$ (Figure 2D). In this case a pool of SHIP164 colocalized with Rab5 along the entire profile of vacuoles and, conversely, Rab5 robustly colocalized with the bright SHIP164 foci closely apposed to large vacuoles (Figure 2D). This very strong colocalization supports the hypothesis that SHIP164 is a Rab5 effector. However, expression of a dominant negative Rab5 mutant (GFP-Rab5 $\mathrm{a}^{\mathrm{S}_{34} \mathrm{~N}}$ ) did not abolish bright SHIP164 (SHIP164-Halo) foci suggesting that Rab5 is not necessary for their formation (Supplemental Figure 2C).

Notably, exogenous SHIP164 puncta colocalized with endogenous cation-independent mannose6-phosphate receptor (MPR) (as detected by immunofluorescence) and its expression (leading to higher than normal levels of SHIP164) also resulted in an alteration of the localization of the MPR, which accumulated in large foci where the two proteins colocalized (Figure 2G). These accumulations occurred throughout the cell but were especially large in proximity of the Golgi complex, where the normal Trans-Golgi Network (TGN)-like appearance of MPR was replaced by these large accumulations located at some distance from GM130, a Golgi complex marker30 (see Figure 2G for COS-7 cells and Supplemental Figure 2D for HeLa cells). A similar redistribution of MPR and also of the Golgi/endosome protein sortilin ${ }^{31}$ was observed in RPE1 (retinal pigment epithelial) cells transfected with a polycistronic expression plasmid encoding untagged SHIP164 and a soluble RFP to confirm transfection, ruling out non-specific effects of the engineered fluorescent tag of exogenous SHIP164 (Figure H\&I; Supplemental Figure 2E\&F). Such changes were not observed with TGN46, another protein enriched in the TGN that cycles to and from the plasma membrane and endosomes ${ }^{21,32,33}$ (Supplemental Figure 2G\&H). This difference is in line with the known traffic of MPR and sortilin versus TGN46 in different vesicular carriers 33,34 (see also below).

\section{Foci of exogenous SHIP164 reflect accumulations of small vesicles}

To gain further insight into the precise nature of foci of over-expressed SHIP164, we performed correlative light-electron microscopy (CLEM) of COS-7 cells co-expressing the early endosome marker GFP-WDFY2 and SHIP164^mScarlet-I (Figure 3A). Both conventional EM and FIBSEM were performed. We again employed $\operatorname{Ras}^{\mathrm{G} 12 \mathrm{~V}}$ to induce the formation of macropinosomes 35 to facilitate the alignment of fluorescence and EM images. This analysis revealed that spots of SHIP164 fluorescence reflected accumulations of 100's of tightly packed approximately 50-60 nm vesicles juxtaposed to endosomal membranes positive for GFP-WDFY2 (Figure 3A). An approximately 70nm thick matrix appeared to anchor these clusters to the WDFY2-positive vacuoles and the space occupied by this matrix was nearly devoid of vesicles (Figure 3A\&C). ER tubules were present in proximity of these clusters and often penetrated them, but there did not seem to be sites of preferential accumulation of vesicles (Figure $3 \mathbf{B}$ ). The appearance of these vesicle accumulations and their dynamic nature revealed by live imaging (see above) was reminiscent of other vesicle clusters, such as synaptic vesicles clusters in nerve terminals, recently shown to be organized according to principles of liquid-liquid phase separation ${ }^{36-38}$. As such 
"phases" often involve low affinity interaction of disordered protein regions 39 , we considered the possibility that the "disordered region" of SHIP164 (see Figure 1Ac) may be responsible for their formation. However, a truncated form of SHIP164 (SHIP1641-873-mRFP) that lacks the disordered region also induced the formation of large fluorescence puncta closely juxtaposed to endosomes (Supplemental Figure 3). Thus, the mechanism responsible for the clustering of SHIP164 positive vesicles remains unclear. Also unclear is how such clusters are anchored to the large vacuoles.

As these vesicle accumulations, which to our knowledge were never observed in WT cells, suggested an abnormal effect of over-expressed SHIP164, we next tagged SHIP164 at the endogenous locus to assess its localization when expressed at the endogenous level.

\section{Endogenous SHIP164 localizes to small clusters of vesicles near the cell edge}

We tagged SHIP164 at the endogenous locus in HeLa cells. Specifically, we engineered a $\mathrm{mNeonGreen}(\mathrm{mNG})$ tag in the disordered region after amino acid residue 1092 via the ORANGE genomic editing method ${ }^{40}$ (Figure 4A). Two clones were isolated where expression of endogenous SHIP164^ $\mathrm{mNG}$ (eSHIP164^ $\mathrm{mNG}$ ) was confirmed by the presence of a band running at the appropriate molecular weight and recognized by western blotting with both anti-SHIP164 and anti-mNeonGreen antibodies (Figure4B). Correct insertion of the tag was validated by DNA sequencing of the targeted gene region (Figure $4 \mathbf{C}$ ).

Like exogenous SHIP164, eSHIP164^mNG had a punctate appearance. However, eSHIP $164^{\wedge} \mathrm{mNG}$ puncta were very much smaller and, in contrast to foci of over-expressed SHIP164 (Figure 2A), were primarily localized at the cell edge (Figure 4D). On the other hand, when SHIP164^mScarlet-I was expressed in these endogenously tagged cells, exogenous mScarlet-I and endogenous mNeonGreen fluorescence precisely overlapped in large foci, including the ones localized in deep regions of the cell (Supplemental Figure 4A). This demonstrates that endogenous and exogenous SHIP164 completely intermix-as expected from correct gene targeting-confirming that large foci are the result of SHIP164 over-expression.

To determine whether puncta of $\mathrm{eSHIP} 164^{\wedge} \mathrm{mNG}$ represent MPR positive vesicles, we generated a double knock-in (DKI) HeLa cell line where both SHIP164 and MPR were tagged at their endogenous loci (eSHIP164^mNG and eMPR-mScarlet-I). Most, but not all, eSHIP164^ ${ }^{\wedge} \mathrm{mG}$ positive puncta colocalized and moved together with puncta of eMPR-mScarlet-I fluorescence (Figure 4E; Supplemental Movie 2). Conversely, many eMPR-mScarlet-I puncta at the edge of the cell colocalized and moved together with puncta of $\mathrm{eSHIP} 164^{\wedge} \mathrm{mNG}$ (Figure 4E), while MPR vesicles located deeper into the cell were negative for SHIP1644,42. Fluorescent puncta positive for the two proteins were distinct from vesicles positive for newly internalized labeled EGF (EGF-647) revealing that endogenous SHIP164 localizes to a specific endocytic subpopulation (Supplemental Figure 4B). Interestingly, an intrinsic membrane protein of unknown function, that is listed as a SHIP164 interactor in BioGRID (https://thebiogrid.org), FAM174a, strikingly colocalized with exogenous SHIP164 accumulations, although FAM174a was also present in the Golgi complex and other compartments of the secretory/endocytic pathways (Supplemental Figure 4C\&D).

290

To gain further insight into the nature of endogenous SHIP164 puncta, we again employed CLEM in $\mathrm{eSHIP} 164^{\wedge} \mathrm{mNG}$ HeLa cells also expressing a marker of mitochondria (mito-BFP) to aid in fluorescence and EM image alignment (Figure 4F). Given the small size of the fluorescent structures, FIB-SEM rather than TEM was used in spite of the lower resolution afforded by FIB- 
analysis revealed that, similar to the large fluorescence puncta of exogenously expressed SHIP164, spots of eSHIP164^ $\mathrm{mNG}$ fluorescence reflected tightly packed clusters of small vesicles and short tubules (Figure 4F\&G). However, these clusters were much smaller (10's instead of 100's of vesicular structures). As revealed by 3 D reconstruction of FIB-SEM volumes (Figure 4G) and by fluorescence of cells also expressing the ER marker RFP-Sec61 (Figure 4H), ER tubules were localized in close proximity of these clusters but vesicles were preferentially associated with themselves rather than with the ER.

Collectively, these findings indicate that SHIP164, when expressed at endogenous levels, is selectively localized on small MPR-positive vesicles near the cell periphery. They further imply that SHIP164 dissociates from such vesicles as they travel to deeper cellular regions and that the presence of exogenous SHIP164 on the very large vesicle clusters in central cell regions near the Golgi complex reflect an over-expression defect. To better understand SHIP164's dynamics in the endocytic pathway we investigated its interactions.

\section{Interaction of SHIP164 with proteins implicated in the targeting of endocytic cargoes to the Golgi complex.}

We confirmed the previously reported colocalization of exogenous SHIP164 with over-expressed Stx6 ${ }^{20}$ (Figure 5A). SHIP164 and Stx6 colocalized on spots scattered throughout the cytoplasm and in the Golgi complex area irrespective of the presence or absence of N-terminal tags, i.e. tags that impair the localization of SHIP164 to vesicles enriched foci when expressed alone (Supplemental Figure 2A). This indicates that binding to Stx6 does not play a major role in the localizations of SHIP164 described above.

The location of the Stx6 binding site within the SHIP164 protein was not known. A short hydrophobic motif $\left(\mathrm{L}_{37} \mathrm{XxYY}_{41}\right)$ responsible for binding to the Habc domain of Stx6 was previously identified in the N-terminal region of $\mathrm{VPS}_{51} 1^{23}$. A similar motif $\left(\mathrm{L}_{759} \mathrm{xxYY} \mathrm{Y}_{763}\right)$ is present in a predicted disordered loop of SHIP164 within the extended chorein domain (Figure 5E; Figure 1Ac) and mutations of both tyrosine resides (Y772A, Y773A) abolished the recruitment of GFPSHIP164 (GFP-SHIP164 ${ }^{\mathrm{Y} 772 \mathrm{~A}}$, Y773A; i.e. N-terminally tagged SHIP164 that when expressed by itself is cytosolic) to mRFP-Stx6 (Supplemental Figure 5A). However, the same mutations, when introduced into C-terminally tagged SHIP164 (SHIP164 ${ }^{\mathrm{Y} 772 \mathrm{~A}}, \mathrm{Y}_{773 \mathrm{~A}}-\mathrm{mRFP}$ ) did not affect the localization of the protein into bright foci in cells not transfected with Stx6, further indicating that Stx6 does not account for these localizations (Supplemental Figure 5B).

To identify additional SHIP164 interacting partners that may impact its localization and/or function, we performed pull-down experiments from detergent solubilized mouse brain lysates onto purified SHIP164 (3xFLAG-SHIP164) bound to anti-FLAG resin. Shotgun mass spectrometry of the affinity-purified material showed a significant specific enrichment (relative to control) of the light chains 1 and 2 (DYNLL1/2; also known as LC8) of cytoplasmic dynein, the minus-end directed microtubule motor 43 (Figure 5B). DYNLL1/2 act as dynein complex adaptors which mediate a wide variety of protein-protein interactions through a short linear binding motif44 $\left(\mathrm{V}_{-5}\left[\mathrm{~S} / \mathrm{N} / \mathrm{T}_{-4}\left[\mathrm{~K} / \mathrm{R}_{-3} \mathrm{X}_{-2} \mathrm{~T}_{-1} \mathrm{Q}_{0} \mathrm{~T}_{+1}\right)\right.\right.$. Accordingly, a motif that fits this consensus is present in SHIP164 near its C-terminus $\left(\mathrm{V}_{1395}\right.$ TQATQT $\left._{1401}\right)$ and LC8 is another protein listed among putative SHIP164 interactors in BioGRID (Figure 5E). Moreover, when an MBP-tagged fragment of SHIP164 containing this region (MBP-SHIP1641312-1464) and untagged LC8 were coexpressed in bacteria from a polycistronic plasmid, LC8 co-purified with MBP-SHIP164 ${ }_{1312-1464}$ on amylose-resin and co-fractionated with MBP-SHIP164 1312-1464 $_{4}$ when the eluate of the resin was fractionated on a size-exclusion column indicating a direct interaction (Figure 5C). 
Interestingly, another potential SHIP164 interactor listed in BioGRID, Rab45 (RASEF), is linked to dynein function. Rab45 and its better-characterized paralog CRACR2a are dynein/dynactin activators that connect endocytic cargoes to minus-end microtubule transport 45,46 . In agreement with the possibility that SHIP164 may be an effector of Rab45, over-expression of Rab45 dramatically concentrated both transfected SHIP164^mScarlet-I and endogenously tagged SHIP164 (eSHIP164^ ${ }^{\wedge N G)}$ to perinuclear spots (i.e. the position occupied by the centrosome), depleting them from the periphery (Figure 5D; Supplemental Figure $5 \mathbf{C}$ ). At this perinuclear location, SHIP164 and Rab45 precisely colocalized (Figure 5D; Supplemental Figure 5C). Over-expression of Rab45 also clustered endogenous MPR tagged at the C-terminus with a mNeonGreen tag (eMPR-mNeonGreen), but only in cells over-expressing SHIP64, i.e. in cells where the majority of MPR-positive vesicles (not only the peripheral vesicles) are positive for SHIP164 (Supplemental Figure 5D). A dominant-inactive Rab45 (S555N) mutant had a cytosolic localization did not induce SHIP164 accumulation in this area suggesting that the nucleotide bound state of Rab45 regulates recruitment (Supplemental Figure 5E).

Taken together, our interaction studies point to an association of SHIP164 with vesicles that traffic from the cell periphery to the centrosomal/Golgi complex region, although endogenous SHIP164 appears to be shed by vesicles as they move to central regions of the cells unless Rab45 is overexpressed. One would therefore expect a role of SHIP164 in some aspect of retrograde membrane traffic. To validate this hypothesis, we performed loss-of-function studies.

\section{Defects in retrograde membrane traffic to the TGN in SHIP164 knockout cells}

To assess the impact of the absence of SHIP164 on cell physiology we chose RPE1 cells as a model system due to their reliable genetic editing and flat morphology optimal for organelle imaging. Using CRISPR/Cas9 methodology, two independent SHIP164 knockout (KO) clones were generated where indels led to a frameshift of the reading frame that resulted in premature stop codons as shown by sequencing (Supplemental Figure 6A). In both clones, identical indels were observed on both alleles (but different between the two clones) and absence of the SHIP164 protein was confirmed by western blotting (Figure 6A). No obvious changes were observed in cell shape, in mitochondria, ER, or Golgi morphology as assessed by the cis-Golgi marker (GM130) (see below). Two differences, however, were noted.

One was a difference in the size of endosomes labeled by EEA1 (visualized by immunostaining), and GFP-2xHrs ${ }^{\mathrm{FYVE}}$ (visualized by live-cell imaging) as the largest $\left(>1 \mu \mathrm{m}^{2}\right)$ vesicles positive for these markers in WT cells were mostly absent in KO cells (Figures 6B-C, ${ }^{* *}, \mathrm{p}<0.01$ ).

The other difference was a change in the steady state localization of MPR and other proteins that recycle between the cell periphery (plasma membrane and endosomes) and the TGN. Specifically, upon immunostaining of SHIP164 KO cells for the MPR, an increase in the pool of MPR localized in vesicles scattered throughout the cytoplasm relative to the pool localized in the Golgi complex area was observed ${ }^{42}$, (Figure 6D, $\left.{ }^{* *}, \mathrm{p}<0.01\right)$. The localizations by immunofluorescence of TGN46 and of Sortilin showed a similar difference relative to controls (Figure 6E \& Supplemental Figure B, ${ }^{* *}, p<0.01$ ), although the vesicles positive for TGN46 were different from those positive for MPR and sortilin (Supplemental Figure 6C). As a control, the ratio of clathrin heavy chain (CHC) immunoreactivity sparse throughout the cytoplasm relative to immunoreactivity in the Golgi complex was also measured and such ratio was not statistically different between SHIP164 KO cells and parental control cells (Figure 6F).

398

To validate the dependence of these phenotypes from the lack of SHIP164, we attempted to rescue them by expressing exogenous SHIP164 in the KO cells. To this aim we used the polycistronic 
construct described above encoding both untagged SHIP164, in order to avoid any artifact due to the tag, and soluble RFP, to identify transfected cells. In both KO clones, transfection of this construct (likely resulting in levels of SHIP164 higher than in WT cells), but not of a construct encoding only the RFP reporter, resulted in the rescue of the vesicles-to-Golgi ratio of TGN46 immunoreactivity (Figure 6G; ${ }^{*}, \mathrm{p}<0.05 ;{ }^{* *}, \mathrm{p}<0.01$ ). However, in the case of MPR and sortilin, expression of the SHIP164 construct did not restore their WT localization, but resulted in their robust accumulation into large foci as shown above upon SHIP164 over-expression in wild type cells (Supplemental Figure 6D). This result is most likely explained by the disrupting effect of SHIP164 over-expression, which, as shown above, does not impact TGN46 localization (Supplemental Figure 2G\&H). Likewise, SHIP164 over-expression did not seem to rescue the presence of the large EEA1 positive endosomes present in WT cells as it induced large focal EEA1 accumultions, but these did not have the typical vacuolar apperance. (Supplemental Figure 6E). Also in this case this result may be to due a dominant negative effect as similar EEA1 positive clusters rather than the typical vacuolar structures were observed in WT cells over-expressing SHIP164 (Supplemental Figure 6E). However, we confirmed the impact of SHIP164 deficiency on the presence of large EEA1 endosomes by SHIP164 siRNA-dependent knockdown in RPE-1 cells, thus ruling out off-target effects of CRISPR/Cas9 editing (Supplemental Figure 6F\&G; $\left.{ }^{* *}, \mathrm{p}<0.01\right)$.

We conclude that loss of SHIP164 function may globally impact membrane traffic between the cell periphery and the Golgi complex, while over-expression of SHIP164 disrupts selectively the retrograde traffic of a subset of the vesicles with which SHIP164 is associated.

\section{Presence of ATG9A in clusters of SHIP164-positive vesicles}

The structural similarity of SHIP164 to proteins thought to mediate bulk lipid transportparticularly ATG2-suggests a similar function of SHIP164,7,11,47. A plausible scenario is that SHIP164 may allow the regulation of bilayer lipids (abundance and possibly also type of lipids) on organelles of the endocytic pathway by mediating transient contacts with these organelles and either the ER or other membranes to transport lipids 4,9 . The lack of the large endosomes in SHIP164 KO cells would be consistent with a role of SHIP164 in bulk transfer of lipids. So far, however, we have not found direct evidence for a role of SHIP164 as a tether between two membranes. Moreover, as stated above, the endosomal size phenotype could not be clearly rescued by the expression of exogenous SHIP164 in SHIP164 KO cells (Supplemental Figure 6E), thus preventing us from directly testing this hypothesis using SHIP164 proteins that cannot transport lipids, in addition to a propensity to aggregate in living cells of putative lipid-transport dead mutants that we generated.

ATG2 was found to function in cooperation with the scramblase ATG9, as lipids are delivered by ATG2 to the cytosolic leaflet of the receiving membrane and thus lipid scrambling is needed to allow equilibration of lipid concentration on both bilayer leaflets ${ }^{10,48-51}$. In WT cells, ATG9 (ATG9A) is concentrated in the Golgi complex area and also present as scattered dots throughout the cytoplasm (Figure 7A). Interestingly, we found that ATG9A-GFP is highly concentrated on the SHIP164 positive foci resulting from SHIP164 over-expression (Figure $7 \mathbf{B}$ ). Moreover, while no major redistribution of ATG9A-GFP is observed in cells over-expressing Rab45 (RFP-Rab45), co-expression of SHIP164-Halo with RFP-Rab45 resulted in a striking co-enrichment and colocalization of all three proteins in the centrosomal area proving that ATG9A is localized on SHIP164-positive vesicles (Figure 7C). We also explored whether autophagy was affected in SHIP164 KO cells, but we did not find any effect on LC3 abundance upon starvation. While the 
activity of SHIP164, it is consistent with such an activity and raises the interesting possibility that ATG9A may have more general functions in cell physiology than a selective role in autophagy ${ }^{52}$.

\section{UHRF1BP1, a SHIP164 paralogue, is also localized in the endocytic pathway}

UHRF1BP1 shares substantial primary sequence similarity (42\% identity) and domain organization with SHIP $164^{20}$. Accordingly, phenotypes produced by expression of exogeneous UHRF1BP1 (UHRF1BP1-Halo) revealed similarities to those produced by the expression of exogenous SHIP164. As in the case of SHIP164, UHRF1BP1-Halo localized to foci of varying size and fluorescence intensity with the larger foci being concentrated in the central region of the cell (Figure 7D). These foci were positive for exogenous ATG9A (ATG9A-GFP) (Figure $7 \mathbf{E}$ ). However, in contrast to SHIP164 foci, which were primarily associated with early endosomes, UHRF1BP1 foci were predominantly associated with LAMP1-GFP-positive organelles, in agreement with previous work suggesting that UHRF1BP1 is a Rab7 effector, rather then a Rab5 effector $^{24}$ (Supplemental Figure 7). We conclude that SHIP164 and UHRF1BP1 likely function in a similar manner but at different stations of the endocytic pathway

\section{DISCUSSION}

Our study identifies SHIP164 as a bona fide member of the chorein motif protein family with a role in membrane traffic. The EM-analyses of SHIP164 show that as in VPS13 and ATG2, the two well established members of this family, the N-terminal chorein motif of SHIP164 caps an extended rod that harbors a cavity running along its length ${ }^{6-8,47}$. Fold prediction algorithms (Alphafold, trRosetta) indicate that SHIP164 features an extended B-sheet that resembles a taco shell, whose concave elongated surface is lined with hydrophobic residues, and so constitutes a groove that can solubilize multiple lipids ${ }^{18,19}$. In vitro lipid binding and transfer assays further support that SHIP164 might function as a lipid transfer protein. The SHIP164 paralogue $\mathrm{UHRF} 1 \mathrm{BP} 1$ is predicted to have a similar structure.

Our analysis of the subcellular localization of SHIP164 reveals an association with endocytic organelles, extending previous observations ${ }^{20,24}$. This is supported by several pieces of evidence: 1) Endogenous SHIP164 is predominantly localized on a population of small peripheral vesicles that assemble in small clusters and contain in their membranes endosomal cargo proteins, such as $\mathrm{MPR}^{42}$. 2) Over-expressed SHIP164 drastically enlarges the size of these clusters, which become, in many cases, tightly associated with vacuoles positive for markers of early endosomal subcompartments, such as Rab5, APPL1, WDFY2, PI3P, and EEA1 and are found also in deep regions of the cell. 3) The interactors of SHIP164 that we have identified or validated are endocytic factors or proteins that mediate retrograde organelle traffic from the cell periphery to the centrosomal/Golgi complex area. One of them is Rab5, an early endosomal Rab53. Another one is Stx6, a component of SNARE complexes that mediates the fusion of vesicles with recycling endosomes and with the Golgi complex and whose action is facilitated by the GARP and EARP tethering complexes ${ }^{54-56}$. Interestingly, binding of SHIP164 to the Habc domain of Stx6 is mediated by the same motif used by the GARP and EARP subunit VPS51, also a Stx6 interactor $^{21,23}$. While this finding implies a competitive binding to Stx6, it also suggests an interplay of SHIP164 with GARP, further linking SHIP164 to retrograde traffic. A third interactor is the light chain of dynein (DYNLL1/2), the microtubule motor that mediates retrograde traffic ${ }^{57}$. The fourth is Rab45, an unconventional Rab that anchors endocytic vesicles to dynein, creating an additional link to dynein and retrograde traffic ${ }^{45,46}$. Notably, however, SHIP164, when expressed at endogenous levels is predominantly associated with peripheral vesicles, suggesting a regulated interaction with vesicles that is lost and replaced by other interactors as they travel to deeper destinations in the cell. 
A role of SHIP164 in retrograde traffic is further supported by SHIP164 loss of function and gainof-function studies. In SHIP164 KO cells, a larger pool of proteins that shuttle between the cell periphery and the Golgi complex (MPR, sortilin and TGN46) is localized on vesicles scattered throughout the cytoplasm relative to their major pool localized in the Golgi complex area suggesting a defect in transport/docking or fusion with the Golgi complex. Similar observations have been made in cells deficient in GARP function ${ }^{21,58,59}$. Conversely, SHIP164 over-expression (gain-of-function) results in large vesicle clusters positive for MPR and sortilin, but not for TGN46, indicating that loss-of-function and gain-of-function effects are not precise opposites. A potential scenario is that the accumulation of sortilin and MPR vesicles results from a block in their progression to the next traffic station produced by excess SHIP164. Such dominant negative effect could be the result of sequestration of, or competition with, critical factor(s) (for example GARP) by over-expressed SHIP164 or by alteration of membrane lipid homeostasis.

A key question is how the structure and molecular properties of SHIP164, which predict a lipid transport function at intracellular membrane contact sites, similar to the proposed function of VPS13 and ATG2, relates to the observed localization and loss-of-function phenotypes of SHIP164. We consider the hypothesis that SHIP164, as proposed for VPS13 and ATG2, may function in the transport of lipids from one membrane where the chorein domain may extract lipids - for example the ER - to other membranes ${ }^{9}$ and more specifically to the small vesicles enriched with endogenous SHIP164. This transport may deliver specific lipids or simply be responsible for membrane expansion. However, the localization of SHIP164 that we have observed is not at contacts of two types of membranous organelles, as predicted by this model. While some SHIP164 foci detectable by fluorescence appear to be localized at the interface of the ER and endosomes, such foci are represented by vesicle clusters and not by SHIP164 tethers between the ER and endosomes. Moreover, until now we have not identified the binding of SHIP164 to any ER protein. SHIP164 does not have an FFAT or FFAT-like motif that, as in the case of VPS13 ${ }^{6,60}$, could account for binding to the ER protein $\mathrm{VAP}^{61,62}$. In spite of these considerations, binding of SHIP164 to the ER cannot be excluded. Binding to the ER of SHIP164 tagged at the endogenous locus is difficult to analyze given the small size of SHIP164 associated vesicles. SHIP164 over-expression may overwhelm a binding site on the ER, unless such binding site was also over-expressed. One should also consider that an interaction with the ER of SHIP164-positive transport vesicles may be regulated and only transient.

Of special interest in the context of protein-mediated lipid transport is the strong colocalization of SHIP64 with ATG9A, as ATG9A is a functional partner of ATG2 in the expansion of the autophagic membrane ${ }^{48-50,63}$. ATG9A, a protein scramblase, is thought to allow equilibration between the two bilayer leaflets, as phospholipids are delivered to the cytosolic leaflet of the autophagic membrane by ATG248-50. While ATG9A was discovered as a core component of the autophagy machinery, it is plausible that it may function in other contexts, as also recently reported ${ }^{52}$, more so in cooperation with a protein that shares strong similarities with ATG2, such as SHIP164. Interestingly, studies of ATG9A have consistently localized it to small vesicles often organized in clusters, similar to the SHIP164 vesicles described here ${ }^{16,64}$. Thus, the overlapping localization of SHIP164 and ATG9A is consistent with a role of SHIP164 in lipid transport. The absence of large endosomes in SHIP164 KO cells would be supportive of a role of SHIP164 in lipid transfer to expand the membranes of endocytic organelles, but since this phenotype could not be clearly rescued (possibly due to dominant negative effects of SHIP164 overexpression), its significance remains uncertain. Future studies will be needed to provide further mechanistic insight into these findings. We note that mechanisms to control bulk lipid transport to the membrane of an endocytic organelle independent of membrane fusion may help fine tune the 
protein/lipid ratio of such membrane and may therefore play an important role in controlling its maturation as it travels to deeper positions in the cell.

Finally, in view of the link between the function of SHIP164 and GARP suggested by our study and a previous study ${ }^{20}$, it is of interest that defects in retrograde traffic from the cell periphery to the Golgi complex produced by SHIP164 loss-of-function have similarities to those observed upon loss of function of the GARP complex ${ }^{20,58}$. GARP has also been linked to lipid metabolism. In zebrafish, loss of the GARP subunit fat-free (Ffr) (later identified as the paralog to mammalian VPS51) results in a striking defect of the absorption into the body of dietary lipids ${ }^{65}$. Defects in GARP in mice or humans, either at the cellular or organismal level, result in abnormal sphingolipid metabolism (with an abnormal accumulation of long chain bases) and neurodegenerative conditions ${ }^{59,66,67}$. SHIP164 was reported be a Parkinson's disease candidate gene $^{25}$ and loss-of-function mutations in VPS13C, another chorein motif lipid transport protein implicated in the endocytic/lysosome pathway is responsible for familial forms of Parkinson's disease $^{68}$. It is therefore possible that SHIP164 may be part of a network of proteins that play an important role in neuronal health by controlling lipid transport and metabolism at the interface with membrane traffic. 


\section{REFERENCES}

1. Alva, V. \& Lupas, A. N. The TULIP superfamily of eukaryotic lipid-binding proteins as a mediator of lipid sensing and transport. Biochimica et Biophysica Acta (BBA) - Molecular and Cell Biology of Lipids 1861, 913-923 (2016).

2. Prinz, W. A., Toulmay, A. \& Balla, T. The functional universe of membrane contact sites. Nature Reviews Molecular Cell Biology 21, 7-24 (2020).

3. Saheki, Y. \& Camilli, P. D. Endoplasmic Reticulum-Plasma Membrane Contact Sites. Annual review of biochemistry 86, 659-684 (2017).

4. Reinisch, K. M. \& Prinz, W. A. Mechanisms of nonvesicular lipid transport. Journal of Cell Biology 220, (2021).

5. Wong, L. H., Gatta, A. T. \& Levine, T. P. Lipid transfer proteins: the lipid commute via shuttles, bridges and tubes. Nature Reviews Molecular Cell Biology 2o, 85-101 (2019).

6. Kumar, N., Leonzino, M., Hancock-Cerutti, W., Horenkamp, F. A., Li, P. Q., Lees, J. A., Wheeler, H., Reinisch, K. M. \& De Camilli, P. VPS13A and VPS13C are lipid transport proteins differentially localized at ER contact sites. The Journal of cell biology (2018).

7. Valverde, D. P., Yu, S., Boggavarapu, V., Kumar, N., Lees, J. A., Walz, T., Reinisch, K. M. \& Melia, T. J. ATG2 transports lipids to promote autophagosome biogenesis. The Journal of cell biology 14, jcb.201811139 (2019).

8. Li, P., Lees, J. A., Lusk, C. P. \& Reinisch, K. M. Cryo-EM reconstruction of a VPS13 fragment reveals a long groove to channel lipids between membranes. The Journal of cell biology 219, (2020).

9. Leonzino, M., Reinisch, K. M. \& De Camilli, P. Insights into VPS13 properties and function reveal a new mechanism of eukaryotic lipid transport. Biochim Biophys Acta Mol Cell Biol Lipids 1866, 159003 (2021).

10. Noda, N. N. Atg2 and Atg9: Intermembrane and interleaflet lipid transporters driving autophagy. Biochimica et Biophysica Acta (BBA) - Molecular and Cell Biology of Lipids 1866, 158956 (2021).

11. Osawa, T., Kotani, T., Kawaoka, T., Hirata, E., Suzuki, K., Nakatogawa, H., Ohsumi, Y. \& Noda, N. N. Atg2 mediates direct lipid transfer between membranes for autophagosome formation. Nat Struct Mol Biol 26, 281-288 (2019).

12. Ueno, S., Maruki, Y., Nakamura, M., Tomemori, Y., Kamae, K., Tanabe, H., Yamashita, Y., Matsuda, S., Kaneko, S. \& Sano, A. The gene encoding a newly discovered protein, chorein, is mutated in chorea-acanthocytosis. Nat Genet 28, 121-122 (2001).

13. Rampoldi, L., Dobson-Stone, C., Rubio, J. P., Danek, A., Chalmers, R. M., Wood, N. W., Verellen, C., Ferrer, X., Malandrini, A., Fabrizi, G. M., Brown, R., Vance, J., Pericak-Vance, M., Rudolf, G., Carrè, S., Alonso, E., Manfredi, M., Németh, A. H. \& Monaco, A. P. A conserved sorting-associated protein is mutant in chorea-acanthocytosis. Nat Genet 28, 119120 (2001).

14. Park, J.-S., Okumura, Y., Tachikawa, H. \& Neiman, A. M. SPO71 Encodes a Developmental Stage-Specific Partner for Vps13 in Saccharomyces cerevisiae. Eukaryotic Cell 12, 1530-1537 (2013).

15. Da Costa, R., Bordessoules, M., Guilleman, M., Carmignac, V., Lhussiez, V., Courot, H., Bataille, A., Chlémaire, A., Bruno, C., Fauque, P., Thauvin, C., Faivre, L. \& Duplomb, L. $\mathrm{Vps} 13 \mathrm{~b}$ is required for acrosome biogenesis through functions in Golgi dynamic and membrane trafficking. Cell. Mol. Life Sci. 77, 511-529 (2020).

16. Mari, M., Griffith, J., Rieter, E., Krishnappa, L., Klionsky, D. J. \& Reggiori, F. An Atg9containing compartment that functions in the early steps of autophagosome biogenesis. Journal of Cell Biology 190, 1005-1022 (2010).

17. Chang, C., Jensen, L. E. \& Hurley, J. H. Autophagosome biogenesis comes out of the black box. Nat Cell Biol 23, 450-456 (2021). 
618

619

620

621

622

623

624

625

626

627

628

629

630

631

632

633

634

635

636

637

638

639

640

641

642

643

644

645

646

647

648

649

650

651

652

653

654

655

656

657

658

659

660

661

662

663

664

665

666

667

668

18. Jumper, J., Evans, R., Pritzel, A., Green, T., Figurnov, M., Ronneberger, O., Tunyasuvunakool, K., Bates, R., Žídek, A., Potapenko, A., Bridgland, A., Meyer, C., Kohl, S. A. A., Ballard, A. J., Cowie, A., Romera-Paredes, B., Nikolov, S., Jain, R., Adler, J., Back, T., Petersen, S., Reiman, D., Clancy, E., Zielinski, M., Steinegger, M., Pacholska, M., Berghammer, T., Bodenstein, S., Silver, D., Vinyals, O., Senior, A. W., Kavukcuoglu, K., Kohli, P. \& Hassabis, D. Highly accurate protein structure prediction with AlphaFold. Nature 596, 583-589 (2021).

19. Yang, J., Anishchenko, I., Park, H., Peng, Z., Ovchinnikov, S. \& Baker, D. Improved protein structure prediction using predicted interresidue orientations. PNAS 117, 1496-1503 (2020).

20. Otto, G. P., Razi, M., Morvan, J., Stenner, F. \& Tooze, S. A. A novel syntaxin 6interacting protein, SHIP164, regulates syntaxin 6-dependent sorting from early endosomes. Traffic 11, 688-705 (2010).

21. Pérez-Victoria, F. J. \& Bonifacino, J. S. Dual roles of the mammalian GARP complex in tethering and SNARE complex assembly at the trans-golgi network. Molecular and cellular biology 29, 5251-5263 (2009).

22. Schindler, C., Chen, Y., Pu, J., Guo, X. \& Bonifacino, J. S. EARP is a multisubunit tethering complex involved in endocytic recycling. Nature cell biology 17, 639-650 (2015).

23. Abascal-Palacios, G., Schindler, C., Rojas, A. L., Bonifacino, J. S. \& Hierro, A. Structural basis for the interaction of the Golgi-Associated Retrograde Protein Complex with the tSNARE Syntaxin 6. Structure 21, 1698-1706 (2013).

24. Gillingham, A. K., Bertram, J., Begum, F. \& Munro, S. In vivo identification of GTPase interactors by mitochondrial relocalization and proximity biotinylation. eLife $\mathbf{8}$, e45916 (2019).

25. Jansen, I. E., Ye, H., Heetveld, S., Lechler, M. C., Michels, H., Seinstra, R. I., Lubbe, S. J., Drouet, V., Lesage, S., Majounie, E., Gibbs, J. R., Nalls, M. A., Ryten, M., Botia, J. A., Vandrovcova, J., Simon-Sanchez, J., Castillo-Lizardo, M., Rizzu, P., Blauwendraat, C., Chouhan, A. K., Li, Y., Yogi, P., Amin, N., Duijn, C. M. van, (IPGDC), I. P. D. G. C., Morris, H. R., Brice, A., Singleton, A. B., David, D. C., Nollen, E. A., Jain, S., Shulman, J. M. \& Heutink, P. Discovery and functional prioritization of Parkinson's disease candidate genes from largescale whole exome sequencing. Genome biology 18, 22 (2017).

26. Meers, P., Ali, S., Erukulla, R. \& Janoff, A. S. Novel inner monolayer fusion assays reveal differential monolayer mixing associated with cation-dependent membrane fusion.

Biochimica et Biophysica Acta (BBA) - Biomembranes 1467, 227-243 (2000).

27. Park, J.-S., Thorsness, M. K., Policastro, R., McGoldrick, L. L., Hollingsworth, N. M., Thorsness, P. E. \& Neiman, A. M. Yeast Vps13 promotes mitochondrial function and is localized at membrane contact sites. $M B O C$ 27, 2435-2449 (2016).

28. Stenmark, H., Aasland, R. \& Driscoll, P. C. The phosphatidylinositol 3-phosphatebinding FYVE finger. FEBS Letters 513, 77-84 (2002).

29. Zoncu, R., Perera, R. M., Balkin, D. M., Pirruccello, M., Toomre, D. \& De Camilli, P. A Phosphoinositide Switch Controls the Maturation and Signaling Properties of APPL Endosomes. Cell 136, 1110-1121 (2009).

30. Nakamura, N., Rabouille, C., Watson, R., Nilsson, T., Hui, N., Slusarewicz, P., Kreis, T. E. \& Warren, G. Characterization of a cis-Golgi matrix protein, GM130. Journal of Cell Biology 131, 1715-1726 (1995).

31. Lefrancois, S., Zeng, J., Hassan, A. J., Canuel, M., Morales, C. R. The lysosomal trafficking of sphingolipid activator proteins (SAPs) is mediated by sortilin. The EMBO Journal 22, 6430-6437 (2003).

32. Luzio, J. P., Brake, B., Banting, G., Howell, K. E., Braghetta, P. \& Stanley, K. K. Identification, sequencing and expression of an integral membrane protein of the trans-Golgi network (TGN38). Biochem $J$ 270, 97-102 (1990). 
669

670

671

672

673

674

675

676

677

678

679

680

681

682

683

684

685

686

687

688

689

690

691

692

693

694

695

696

697

698

699

700

701

702

703

704

705

706

707

708

709

710

711

712

713

714

715

716

717
33. Wakana, Y., van Galen, J., Meissner, F., Scarpa, M., Polishchuk, R. S., Mann, M. \& Malhotra, V. A new class of carriers that transport selective cargo from the trans Golgi network to the cell surface. The EMBO Journal 31, 3976-3990 (2012).

34. Petersen, C. M., Nielsen, M. S., Nykjær, A., Jacobsen, L., Tommerup, N., Rasmussen, H. H., Røigaard, H., Gliemann, J., Madsen, P. \& Moestrup, S. K. Molecular Identification of a Novel Candidate Sorting Receptor Purified from Human Brain by Receptor-associated Protein Affinity Chromatography. J. Biol. Chem. 272, 3599-3605 (1997).

35. Porat-Shliom, N., Kloog, Y. \& Donaldson, J. G. A Unique Platform for H-Ras Signaling Involving Clathrin-independent Endocytosis. $M B o C$ 19, 765-775 (2008).

36. Milovanovic, D., Wu, Y., Bian, X. \& De Camilli, P. A liquid phase of synapsin and lipid vesicles. Science 361, 604-607 (2018).

37. Milovanovic, D. \& Camilli, P. D. Synaptic Vesicle Clusters at Synapses: A Distinct Liquid Phase? Neuron 93, 995-1002 (2017).

38. Park, D., Wu, Y., Lee, S.-E., Kim, G., Jeong, S., Milovanovic, D., Camilli, P. D. \& Chang, S. Cooperative function of synaptophysin and synapsin in the generation of synaptic vesiclelike clusters in non-neuronal cells. Nature Communications 12, 263 (2021).

39. Wheeler, R. J. \& Hyman, A. A. Controlling compartmentalization by non-membranebound organelles. Philosophical Transactions of the Royal Society B: Biological Sciences 373, 20170193 (2018).

40. Willems, J., Jong, A. P. H. de, Scheefhals, N., Mertens, E., Catsburg, L. A. E., Poorthuis, R. B., Winter, F. de, Verhaagen, J., Meye, F. J. \& MacGillavry, H. D. ORANGE: A

CRISPR/Cas9-based genome editing toolbox for epitope tagging of endogenous proteins in neurons. PLOS Biology 18, e3000665 (2020).

41. Waguri, S., Dewitte, F., Le Borgne, R., Rouillé, Y., Uchiyama, Y., Dubremetz, J.-F. \& Hoflack, B. Visualization of TGN to Endosome Trafficking through Fluorescently Labeled MPR and AP-1 in Living Cells. MBoC 14, 142-155 (2003).

42. Lin, S. X., Mallet, W. G., Huang, A. Y. \& Maxfield, F. R. Endocytosed CationIndependent Mannose 6-Phosphate Receptor Traffics via the Endocytic Recycling Compartment en Route to the trans-Golgi Network and a Subpopulation of Late Endosomes. MBoC 15, 721-733 (2003).

43. Carter, A. P., Diamant, A. G. \& Urnavicius, L. How dynein and dynactin transport cargos: a structural perspective. Current Opinion in Structural Biology 37, 62-70 (2016).

44. Rapali, P., Radnai, L., Süveges, D., Harmat, V., Tölgyesi, F., Wahlgren, W. Y., Katona, G., Nyitray, L. \& Pál, G. Directed Evolution Reveals the Binding Motif Preference of the LC8/DYNLL Hub Protein and Predicts Large Numbers of Novel Binders in the Human Proteome. PLOS ONE 6, e18818 (2011).

45. Wang, Y., Huynh, W., Skokan, T. D., Lu, W., Weiss, A. \& Vale, R. D. CRACR2a is a calcium-activated dynein adaptor protein that regulates endocytic traffic. Journal of Cell Biology 218, 1619-1633 (2019).

46. Shintani, M., Tada, M., Kobayashi, T., Kajiho, H., Kontani, K. \& Katada, T.

Characterization of Rab45/RASEF containing EF-hand domain and a coiled-coil motif as a self-associating GTPase. Biochemical and Biophysical Research Communications 357, 661667 (2007).

47. Maeda, S., Otomo, C. \& Otomo, T. The autophagic membrane tether ATG2A transfers lipids between membranes. eLife 8, e45777 (2019).

48. Guardia, C. M., Tan, X.-F., Lian, T., Rana, M. S., Zhou, W., Christenson, E. T., Lowry, A. J., Faraldo-Gómez, J. D., Bonifacino, J. S., Jiang, J. \& Banerjee, A. Structure of Human ATG9A, the Only Transmembrane Protein of the Core Autophagy Machinery. Cell Reports 31, (2020). 
49. Ghanbarpour, A., Valverde, D. P., Melia, T. J. \& Reinisch, K. M. A model for a partnership of lipid transfer proteins and scramblases in membrane expansion and organelle biogenesis. PNAS 118, (2021).

50. Matoba, K., Kotani, T., Tsutsumi, A., Tsuji, T., Mori, T., Noshiro, D., Sugita, Y., Nomura, N., Iwata, S., Ohsumi, Y., Fujimoto, T., Nakatogawa, H., Kikkawa, M. \& Noda, N. N. Atg9 is a lipid scramblase that mediates autophagosomal membrane expansion. Nat Struct Mol Biol 27, 1185-1193 (2020).

51. Reinisch, K. M., Chen, X.-W. \& Melia, T. J. "VTT"-Domain Proteins VMP1 and TMEM41B Function in Lipid Homeostasis Globally and Locally as ER Scramblases. Contact 4, 251525642110244 (2021).

52. Claude-Taupin, A., Jia, J., Bhujabal, Z., Garfa-Traoré, M., Kumar, S., da Silva, G. P. D., Javed, R., Gu, Y., Allers, L., Peters, R., Wang, F., da Costa, L. J., Pallikkuth, S., Lidke, K. A., Mauthe, M., Verlhac, P., Uchiyama, Y., Salemi, M., Phinney, B., Tooze, S. A., Mari, M. C., Johansen, T., Reggiori, F. \& Deretic, V. ATG9A protects the plasma membrane from programmed and incidental permeabilization. Nat Cell Biol 1-13 (2021).

53. Wandinger-Ness, A. \& Zerial, M. Rab Proteins and the Compartmentalization of the Endosomal System. Cold Spring Harbor Perspectives in Biology 6, a022616-a022616 (2014).

54. Simonsen, A., Gaullier, J. M., D’Arrigo, A. \& Stenmark, H. The Rab5 effector EEA1 interacts directly with syntaxin-6. The Journal of biological chemistry 274, 28857-28860 (1999).

55. Bock, J. B., Lin, R. C. \& Scheller, R. H. A new syntaxin family member implicated in targeting of intracellular transport vesicles. The Journal of biological chemistry 271, 1796117965 (1996).

56. Ganley, I. G., Espinosa, E. \& Pfeffer, S. R. A syntaxin 10-SNARE complex distinguishes two distinct transport routes from endosomes to the trans-Golgi in human cells. The Journal of cell biology 180, 159-172 (2008).

57. Rapali, P., Szenes, Á., Radnai, L., Bakos, A., Pál, G. \& Nyitray, L. DYNLL/LC8: a light chain subunit of the dynein motor complex and beyond. The FEBS Journal 278, 2980-2996 (2011).

58. Pérez-Victoria, F. J., Mardones, G. A. \& Bonifacino, J. S. Requirement of the Human GARP Complex for Mannose 6-phosphate-receptor-dependent Sorting of Cathepsin D to Lysosomes. Molecular biology of the cell 19, 2350-2362 (2008).

59. Gershlick, D. C., Ishida, M., Jones, J. R., Bellomo, A., Bonifacino, J. S. \& Everman, D. B. A neurodevelopmental disorder caused by mutations in the VPS51 subunit of the GARP and EARP complexes. Human Molecular Genetics 28, 1548-1560 (2019).

6o. Guillén-Samander, A., Leonzino, M., Hanna, M. G., IV, Tang, N., Shen, H. \& De Camilli, P. VPS13D bridges the ER to mitochondria and peroxisomes via Miro. Journal of Cell Biology 220, (2021).

61. Murphy, S. E. \& Levine, T. P. VAP, a Versatile Access Point for the Endoplasmic Reticulum: Review and analysis of FFAT-like motifs in the VAPome. Biochimica et Biophysica Acta (BBA) - Molecular and Cell Biology of Lipids 1861, 952-961 (2016).

62. Cabukusta, B., Berlin, I., van Elsland, D. M., Forkink, I., Spits, M., de Jong, A. W. M., Akkermans, J. J. L. L., Wijdeven, R. H. M., Janssen, G. M. C., van Veelen, P. A. \& Neefjes, J. Human VAPome Analysis Reveals MOSPD1 and MOSPD3 as Membrane Contact Site Proteins Interacting with FFAT-Related FFNT Motifs. Cell Reports 33, 108475 (2020). 63. Gómez-Sánchez, R., Rose, J., Guimarães, R., Mari, M., Papinski, D., Rieter, E., Geerts, W. J., Hardenberg, R., Kraft, C., Ungermann, C. \& Reggiori, F. Atg9 establishes Atg2dependent contact sites between the endoplasmic reticulum and phagophores. The Journal of cell biology jcb.201710116 (2018). 
64. Davies, A. K., Itzhak, D. N., Edgar, J. R., Archuleta, T. L., Hirst, J., Jackson, L. P., Robinson, M. S. \& Borner, G. H. H. AP-4 vesicles contribute to spatial control of autophagy via RUSC-dependent peripheral delivery of ATG9A. Nature Communications 9, 3958 (2018).

65. Pérez-Victoria, F. J., Schindler, C., Magadán, J. G., Mardones, G. A., Delevoye, C., Romao, M., Raposo, G. \& Bonifacino, J. S. Ang2/Fat-Free Is a Conserved Subunit of the Golgi-associated Retrograde Protein Complex. MBoC 21, 3386-3395 (2010).

66. Fröhlich, F., Petit, C., Kory, N., Christiano, R., Hannibal-Bach, H.-K., Graham, M., Liu, X., Ejsing, C. S., Farese, R. V. \& Walther, T. C. The GARP complex is required for cellular sphingolipid homeostasis. eLife 4, (2015).

67. Khakurel, A., Kudlyk, T., Bonifacino, J. S. \& Lupashin, V. V. The Golgi-associated retrograde protein (GARP) complex plays an essential role in the maintenance of the Golgi glycosylation machinery. $M B O C$ mbc.E21-04-0169 (2021).

68. Lesage, S., Drouet, V., Majounie, E., Deramecourt, V., Jacoupy, M., Nicolas, A., CormierDequaire, F., Hassoun, S. M., Pujol, C., Ciura, S., Erpapazoglou, Z., Usenko, T., Maurage, C.A., Sahbatou, M., Liebau, S., Ding, J., Bilgic, B., Emre, M., Erginel-Unaltuna, N., Guven, G., Tison, F., Tranchant, C., Vidailhet, M., Corvol, J.-C., Krack, P., Leutenegger, A.-L., Nalls, M. A., Hernandez, D. G., Heutink, P., Gibbs, J. R., Hardy, J., Wood, N. W., Gasser, T., Durr, A., Deleuze, J.-F., Tazir, M., Destée, A., Lohmann, E., Kabashi, E., Singleton, A., Corti, O., Brice, A., (PDG), F. P. D. G. S. \& (IPDGC), I. P. D. G. C. Loss of VPS13C Function in AutosomalRecessive Parkinsonism Causes Mitochondrial Dysfunction and Increases PINK1/ParkinDependent Mitophagy. American journal of human genetics 98, 500-513 (2016).

69. Schauder, C. M., Wu, X., Saheki, Y., Narayanaswamy, P., Torta, F., Wenk, M. R., Camilli, P. D. \& Reinisch, K. M. Structure of a lipid-bound extended synaptotagmin indicates a role in lipid transfer. Nature 510, 552-555 (2014).

70. Bian, X., Saheki, Y. \& Camilli, P. D. Ca2+releases E-Syt1 autoinhibition to couple ERplasma membrane tethering with lipid transport. The EMBO journal 37, 219-234 (2018). 71. Zivanov, J., Nakane, T. \& Scheres, S. H. W. Estimation of high-order aberrations and anisotropic magnification from cryo-EM data sets in RELION-3.1. IUCrJ 7, 253-267 (2020).

72. Zheng, S. Q., Palovcak, E., Armache, J.-P., Verba, K. A., Cheng, Y. \& Agard, D. A. MotionCor2: anisotropic correction of beam-induced motion for improved cryo-electron microscopy. Nat Methods 14, 331-332 (2017).

73. Rohou, A. \& Grigorieff, N. CTFFIND4: Fast and accurate defocus estimation from electron micrographs. Journal of Structural Biology 192, 216-221 (2015). 
803

804

805

806

807

808

809

810

811

812

813

814

815

816

817

818

819

820

821

822

823

824

825

826

827

828

829

830

831

832

833

834

835

836

837

838

839

840

841

842

843

844

845

846

847

848

849

850

851

852

853

\section{FIGURE LEGENDS}

\section{Figure 1. In vitro characterization of SHIP164.}

(A) The fold prediction algorithm Alphafold indicates that SHIP164 harbors an extended B-sheet folded to resemble a taco-shell, as in VPS13 ${ }^{8}$. From left to right: (a) Ribbons representation for the taco-shell "core", predicted with high confidence (b) the extended $\beta$-sheet is shown in two orientations as surface representation, with carbons shown white, oxygens red, nitrogens blue, and sulfurs yellow. The concave surface of the taco-shell is predicted to be entirely hydrophobic, providing a binding site for lipid fatty acid moieties. (c) additional secondary structure that may associate with the "core" is shown; segments discussed in text are indicated.

(B) SHIP164 co-purifies with phospholipids according to their abundance in cells as assessed by shotgun lipidomics.

(C) SHIP164 co-migrates with NBD-PE in a native gel. Comparison of NBD-fluorescence that comigrates with SHIP164 versus with the well-characterized lipid transport module from E-Syt2 suggests that each SHIP164 molecule accomodates multiple ( 8) phospholipids.

(D) Schematic drawing explaining the FRET-based lipid transfer and the dithionite-based control for the absence of liposome fusion.

(E) Assay consistent with transfer of fluorescent lipids from donor to acceptor liposomes by SHIP164 but not by a tether construct lacking a lipid transfer module. An increase in fluorescence observed with donor liposomes only (red arrow) is due to lipid extraction by SHIP164. A larger increase is observed when lipids are subsequently transferred to the acceptor liposomes.

(F) Dithionite addition excludes that SHIP164 facilitates membrane fusion.

(G) 2D class averages from negatively stained SHIP164 and MBP-SHIP164, showing tail-to-tail dimerization. MBPs (arrows) are at the ends of the elongated dimer.

(H) 2D class averages for the cryo-EM reconstruction show a channel running along the length of SHIP164.

(I) Cryo-EM map of SHIP164 at a resolution of $\sim 8.3 \AA$, showing a long central cavity with or without the Alphafold model (see panel A-a) superimposed onto it. The docking is approximate because the resolution of the reconstruction is low and because a high confidence model for SHIP164, beyond the $\beta$-sheet taco shell core, is not available.

Experiments in panels E-F were performed in triplicate; SD's are indicated.

Figure 2. Localization of exogenous SHIP164 points to a role on endocytic organelles.

(A) Live fluorescence (inverted grays) image of a COS-7 cell expressing exogenous SHIP $164^{\wedge} \mathrm{mScarlet}-\mathrm{I}$. Scale bar, 20nm. High magnification of the indicated regions is shown at right. Scale bars, $5 \mu \mathrm{m}$.

(B) Live fluorescence (inverted grays) image of a COS-7 cell expressing exogenous 3xFlagSHIP164^mScarlet-I. Scale bar, 20 $\mu$ m.

(C) Live image of the cytoplasm of a COS-7 cell expressing exogenous SHIP164^mScarlet-I (magenta) and the endosomal marker GFP-2xHrs ${ }^{\mathrm{FYVE}}$ (green). Arrows indicate SHIP164 accumulation juxtaposed to endosomal membrane. Scale bar, $5 \mu \mathrm{m}$.

(D) High magnification live fluorescence images of COS-7 cell expressing exogenous SHIP164^mScarlet-I (magenta) and the organelle marker indicated at the top (green). The individual channels are shown as inverted grays. Scar bar, $2 \mu \mathrm{m}$.

(E) Live image of the cytoplasm of a COS-7 cell expressing exogenous SHIP164-Halo, the endosome marker EEA1-RFP, and the ER marker GFP-Sec61. Scale bar, $2 \mu \mathrm{m}$. The individual channels are shown as inverted grays. Scar bar, $1 \mu \mathrm{m}$.

(F) Time-series of live fluorescence images of exogenous SHIP164-mRFP (magenta) and EEA1GFP (green). Arrowheads point to a SHIP164 accumulation as it undergoes fission between two EEA1 positive organelles. Time, seconds. Scale bar, $1 \mu \mathrm{m}$. 
854

855

856

857

858

859

860

861

862

863

864

865

866

867

868

869

870

871

872

873

874

875

876

877

878

879

880

881

882

883

884

885

886

887

888

889

890

891

892

893

894

895

896

897

898

899

900

901

902

903

904

(G) Fluorescence images of a COS-7 cell expressing exogenous SHIP164^ ${ }^{\wedge}$ Scarlet-I (magenta) and immunolabeled with antibodies against MPR (green) and GM130 (red). Scale bar, 20 $\mu$ m. The individual channels are shown as inverted grays in the higher magnification of the Golgi complex region shown at right. Arrowheads indicate colocalization of exogenous SHIP164 and endogenous MPR. Scale bar, $5 \mu \mathrm{m}$.

(H-I) Fluorescence images of RPE-1 cells demonstrating normal Golgi complex localization of MPR in a cell expressing RFP alone $(\mathrm{H})$ and its abnormal localization in a cell expressing both RFP and SHIP164 (H). Cells were immunolabeled with antibodies against MPR (green) and GM130 (magenta). Both the merge image and the single channels are shown. Arrowheads indicate ectopic accumulations of MPR in cells over-expressing SHIP164. Scale bar, $5 \mu \mathrm{m}$.

Figure 3. Correlative light electron microscopy (CLEM) reveals that foci of exogenous SHIP164 reflect large accumulations of small vesicles.

(A) SHIP164^ mScarlet-positive structures juxtaposed to large GFP-WDFY2-positive endosome compartments in a COS-7 cell also expressing untagged Ras ${ }^{\mathrm{G} 12 \mathrm{~V}}$ to induce micropinosomes. The two EM images (scale bar, 200nm) correspond to the regions framed by two rectangles in the merge fluorescence image (scale bar, $1 \mu \mathrm{m}$ ). SHIP164 fluorescence reflects clusters of small vesicles separated from the endosomes by a band occupied by a dense matrix (arrows).

(B and C) High power view of endosomes of COS-7 cells expressing exogenous SHIP164^mScarlet-I (magenta), GFP-WDFY2 (green), and untagged Ras ${ }^{\mathrm{G} 12 \mathrm{~V}}$. Merge fluorescence images are shown at left and FIB-SEM based reconstructions are shown at right. Scale bar, $1 \mu \mathrm{m}$.

Figure 4. Localization of Endogenous SHIP164 on small clusters of vesicular structures.

(A) Cartoon of wild-type (top) and edited SHIP164^ $\mathrm{mNG}$ (bottom).

(B) Western blot of control and edited cell clones for SHIP164, mNG, and GAPDH as a loading control. The different motility of SHIP164 in control and edited clone indicates the incorporation of $\mathrm{mNG}$ in the edited SHIP164.

(C) Cartoon of endogenously edited locus of SHIP $164^{\wedge} \mathrm{mNG}$ in HeLa cell. Red, DNA scar as a result of HITI; blue, small Gly-Ser linkers; green, mNG sequence (shortened for brevity by forward slashes).

(D) Fluorescence image of endogenous SHIP164^mNG (inverted greys) in an edited HeLa knockin cell. Arrowheads indicate concentration of endogenous SHIP164 at the cell edge, shown at a higher magnification in the inset. Scale bar, $10 \mu \mathrm{m}$ (main field) and $2 \mu \mathrm{m}$ (inset).

(E) Single channel (inverted grays) fluorescence images of endogenous SHIP $164^{\wedge} \mathrm{mNG}$ and endogenous MPR-mScarlet-I in a HeLa double-knock-in cell demonstrating partial colocalization of the two proteins at the cell edge and the selective concentration of MPR in perinuclear area. Scale bar, $10 \mu \mathrm{m}$. High magnification of the boxed regions is shown at right where arrowheads indicate overlapping fluorescence. Scale bar, $2 \mu \mathrm{m}$.

(F) Left to right: Fixed fluorescence image of endogenously tagged SHIP164^ ${ }^{\wedge} \mathrm{NG}$ (magenta) HeLa cell also expressing mito-BFP (green) for alignment in CLEM analysis. Scale bar, $5 \mu$ m. Single plane of area outlined in yellow. Fluorescence overlay with FIB-SEM image: numbered boxes mark region of interest of eSHIP $164^{\wedge} \mathrm{mNG}$ fluorescence to be aligned with EM image. Scale bar of magnification area, $1 \mu \mathrm{m}$. Magnification of cluster of vesicles aligned with $\mathrm{eSHIP} 164^{\wedge} \mathrm{mNG}$ fluorescence marked by numbered boxes. Scale bar of EM area, 100nm.

(G) Reconstruction of cluster 1 from panel F above. SHIP164 associated endosome structures, magenta; ER tubules, yellow.

(H) Fluorescence image of endogenously tagged SHIP $164^{\wedge} \mathrm{mNG}$ in a HeLa knock-in cell also expressing the ER marker RFP-Sec61 (green) demonstrating some SHIP164 foci are in proximity of ER tubules. Scale bar, $1 \mu \mathrm{m}$. 
Figure 5. Interaction of SHIP164 with proteins implicated in retrograde traffic to the Golgi complex.

907

908

909

910

911

912

913

914

915

916

917

918

919

920

921

922

923

924

925

926

927

928

929

930

931

932

933

934

935

936

937

938

939

940

941

942

943

944

945

946

947

948

949

950

951

952

953

954

955

(A) Live fluorescence image of a COS-7 cell demonstrating partial colocalization of exogenous SHIP164^mScarlet-I (magenta) and mNeonGreen-Stx6 (green) in the Golgi complex area. Scale bar, $10 \mu \mathrm{m}$. High magnification of the indicated regions is shown at right and the individual channels are shown as inverted grays. Arrowheads indicate overlapping fluorescence. Scale bar, $2 \mu \mathrm{m}$.

(B) Mass spectrometry-based identification of material affinity-purified onto immobilized SHIP164 or onto a control protein from mouse brain extract. The selective enrichment of DYNLL1/2 peptides on the SHIP164 bait is shown.

(C) A mixture of MBP-SHIP164 ${ }_{1312-1464}$ and DYNLL1/2 was subjected to size exclusion chromatography. Coomassie blue staining of SDS-PAGE of the eluted fractions reveals comigration of the two proteins.

(D) Live fluorescence images (inverted grays) of COS-7 cells expressing either GFP-Rab45 (left) or SHIP164^mScarlet-I (right), or both proteins together (only SHIP164 is shown) as indicated. Scale bar, $10 \mu \mathrm{m}$. Note the massive recruitment of SHIP164 to the centrosomal region in the presence of Rab45. High magnification of the indicated regions is shown at right and the individual channels are shown as inverted grays. Scale bar, $2 \mu \mathrm{m}$.

(E) Cartoon of wild-type SHIP164 highlighting (blue) newly identified Stx6 $\left(\mathrm{L}_{759} \mathrm{xxYY}_{763}\right)$ and DYNLL1/2 $\left(\mathrm{V}_{1395}\right.$ TQATQT $\left._{1401}\right)$ interaction motifs (see also Fig. 1Aa).

Figure 6. Defects in retrograde membrane traffic to the TGN in SHIP164 knockout cells.

(A) Western blot of control and edited RPE1 cell clones for SHIP164 and for GAPDH as a loading control.

(B) Left: fluorescence images of a parental control (left) and SHIP164 KO cells (right) immunolabeled with antibodies against EEA1 (green) and GM130 (magenta). Scale bar, 20 $\mu$ m.

Right: Quantification of large EEA1 endosomes $\left(>1 \mu \mathrm{m}^{2}\right)$ per cell in control and SHIP164 KO cell clones. Middle line, median; +, mean; bars, 10-90 percentiles. Data represents three biological replicates. ${ }^{* *}, \mathrm{p}<0.01$.

(C) Live fluorescence (inverted grays) image of parental control (top) and SHIP164 KO (bottom) cells expressing the endosomal marker GFP-2xHrs ${ }^{\mathrm{FYVE}}$. Scale bar, $20 \mu \mathrm{m}$.

(D) Left: fluorescence images of parental control (left) and SHIP164 KO cells (right) immunolabeled with antibodies against MPR (green) and GM130 (magenta). Scale bar, $5 \mu \mathrm{m}$.

Right: Quantification of scattered cytoplasmic spots-to-Golgi complex ratio of MPR signal per cell in control and SHIP164 KO cell clones. Middle line, mean; bars, SD. ${ }^{* *}, \mathrm{p}<0.01$.

(E) Left: fluorescence images of parental control (left) and SHIP164 KO cells (right) immunolabeled with antibodies against TGN46 (green) and GM130 (magenta). Scale bar, $5 \mu$ m.

Right: Quantification of scattered cytoplasmic spots-to-Golgi complex ratio of TGN46 signal per cell in control and SHIP164 KO cell clones. Middle line, mean; bars, SD. ${ }^{* *}, \mathrm{p}<0.01$.

(F) Left: fluorescence images of parental control (left) and SHIP164 KO cells (right) immunolabeled with antibodies against CHC (green) and GM130 (magenta). Scale bar, $5 \mu \mathrm{m}$.

Right: Quantification of scattered cytoplasmic spots-to-Golgi complex ratio of CHC signal per cell in control and SHIP164 KO cell clones. Middle line, mean; bars, SD. ${ }^{* *}, \mathrm{p}<0.01$.

(G) Left: fluorescence images of SHIP164 KO cells expressing RFP alone (left) or both RFP and SHIP164 (right) immunolabeled with antibodies against TGN46 (green) and GM130 (magenta). Scale bar, $5 \mu \mathrm{m}$. Right: Quantification of scattered cytoplasmic spots-to-Golgi complex ratio of TGN46 signal per cell in SHIP164 KO cell clones expressing RFP alone (solid circles) or both RFP and SHIP164 (open circles). Middle line, mean; bars, SD. ${ }^{* *}, \mathrm{p}<0.01 ;{ }^{*}, \mathrm{p}<0.5$.

Data of panels D-F reflect three biological replicates and of panel $\mathrm{G}$ two biological replicates. 
Figure 7. Selective properties of SHIP164 vesicle clusters.

958

959

960

961

962

963

964

965

966

967

968

969

970

971

972

973

974

975

976

977

978

979

980

981

982

983

984

985

986

987

988

989

990

(A) Live fluorescence (inverted grays) image of a COS-7 cell expressing exogenous ATG9A-GFP. Scale bar, 10nm.

(B) Live fluorescence (inverted greys) image of a COS-7 cell demonstrating the clustering of exogenous ATG9A-GFP (left) fluorescence in the Golgi complex area from SHIP164^mScarlet-I expression (right). Scale bar, $10 \mu \mathrm{m}$. High magnification of the indicated regions is shown at right and the individual channels are shown as inverted grays. Arrowheads indicate overlapping fluorescence. Scale bar, $1 \mu \mathrm{m}$.

(C) Impact of the expresion of SHIP164 on the localization of ATG9A in cells also overexpressing Rab45. Cells were transfected with both Rab45 and ATG9A without (left) and with (right) the additional expression of SHIP164. Note that in the presence of SHIP164, Rab45 and ATG9A colocalize in a perinuclear spot. Left, live fluorescence image of a COS-7 cell demonstrating no change to the localization of exogenous ATG9A-GFP (green) upon expression of RFP-Rab45 (magenta) and Right, fluorescence image of a COS-7 cell demonstrating colocalization of exogenous ATG9A-GFP and RFP-Rab45 upon the expression of SHIP164-Halo (not shown) in the centrosomal region. Scale bar, $10 \mu \mathrm{m}$. High magnification of the indicated regions is shown at right and the individual channels are shown as inverted grays. Arrowheads indicate overlapping fluorescence. Scale bar, $2 \mu \mathrm{m}$.

(D) Live fluorescence (inverted grays) image of a COS-7 cell expressing exogenous UHRF1BP1Halo. Scale bar, 20nm. High magnification of the indicated regions is shown at right. Scale bar, $5 \mu \mathrm{m}$.

(E) Live fluorescence image of a COS-7 cell demonstrating partial colocalization of exogenous

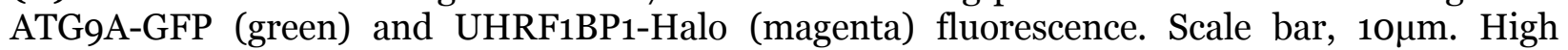
magnification of the indicated regions is shown at right and the individual channels are shown as inverted grays. Scale bar, $2 \mu \mathrm{m}$.

\section{Supplemental Figure 1.}

In vitro characterization of SHIP164. (A)(a) Following batch purification using anti-FLAG M2 resin, 3XFLAG-SHIP164 $4901-1099$ was further purified by size exclusion chromatography on a Superdex-200 column. The gel filtration profile is shown (black), along with that for molecular weight standards (light blue). (b) Sample purity was examined by SDS-PAGE. (c) Representative negative stain electron micrograph of 3XFLAG-SHIP164 ${ }_{4901-1099}(5 \mathrm{O} \mathrm{nM})$ using FEI Tecnai 12 microscope at $120 \mathrm{kV}$ at a nominal magnification of $52,000 \times$. Staining was with $2 \%$ uranyl acetate on carbon-coated copper grids that were glow-discharged for $30 \mathrm{~s}$ at $22 \mathrm{~mA}$. Green circles represent particles manually picked with a 300 Å mask diameter in RELION-3.1.

991 (B) Cryo-EM workflow. Micrographs, including the representative one shown, were collected 992 using Titan Krios G2 transmission electron microscope (Thermo Fisher Scientific) at $300 \mathrm{kV}$ 993 equipped with a K3 summit direct detection camera (Gatan). Green circles represent particles manually picked for initial reference-free 2D classification prior to autopicking.

(C) The processing workflow yielded a reconstruction with an estimated resolution of $8.3 \AA$ according to the Fourier shell correlation $(\mathrm{FSC})=0.143$ criterion.

\section{Supplemental Figure 2.}

1000

(A) Live fluorescence images of a HeLa cell expressing exogenous GFP-SHIP164 (green) and

1001 soluble RFP-Stx6 1-234 (top) or full-length RFP-Stx6 (bottom; magenta). Individual channels are shown in inverted grays on the left. Scale bar, $10 \mu \mathrm{m}$.

1002 (B) High power views of micropinosomes of a COS-7 cell expressing exogenous

1003

1004 SHIP164^mScarlet-I (magenta) and the early endosomal marker GFP-WDFY2 (green). Untagged

1005 $\operatorname{Ras}^{\mathrm{G} 12 \mathrm{~V}}$ was also expressed to induce macropinosome formation. The individual channels are shown as inverted grays. Scar bar, $1 \mu \mathrm{m}$. 
1006

1007

1008

1009

1010

1011

1012

1013

1014

1015

1016

1017

1018

1019

1020

1021

1022

1023

1024

1025

1026

1027

1028

1029

1030

1031

1032

1033

1034

1035

1036

1037

1038

1039

1040

1041

1042

1043

1044

1045

1046

1047

1048

1049

1050

1051

1052

1053

1054

1055

(C) Live fluorescence image of a COS-7 cell expressing SHIP164-Halo (magenta) and the dominant negative GFP-Rab5 S34N mutant. Scale bar, 20 4 m.

(D) Fluorescence images of wild-type HeLa cells immunolabeled with antibodies against MPR (green) and GM130 (red) and without (top) or with transfection of exogenous SHIP164^mScarletI (magenta; bottom) demonstrating abnormal localization of MPR in the cell expressing SHIP164. The individual channels are shown as inverted grays. Arrowheads indicate colocalization of exogenous SHIP164 and endogenous MPR. Scale bar, $5 \mu \mathrm{m}$.

( $E$ and F) Fluorescence images of RPE-1 cells demonstrating normal Golgi complex localization of sortilin in a cell expressing RFP alone (E) and its abnormal localization in a cell expressing both RFP and SHIP164 (F). Cells were immunolabeled with antibodies against sortilin (green) and GM130 (magenta). Both the merge image and the single channels are shown. Arrowheads indicate ectopic accumulations of sortilin in cells over-expressing SHIP164. Scale bar, $5 \mu \mathrm{m}$.

( $G$ and H) Fluorescence images of RPE-1 cells demonstrating normal Golgi complex localization of TGN46 in a cell expressing RFP alone $(\mathrm{G})$ and its unaffected localization in a cell expressing both RFP and SHIP164 (H). Cells were immunolabeled with antibodies against TGN46 (green) and GM130 (magenta). Both the merge image and the single channels are shown. Scale bar, $5 \mu \mathrm{m}$.

\section{Supplemental Figure 3 .}

High magnification live fluorescence images of COS-7 cell expressing exogenous SHIP164 1-873mRFP (magenta) and either the endosome marker WDFY2 or the ER protein Sec61b (green). The individual channels are shown as inverted grays. Scar bar, $2 \mu \mathrm{m}$.

\section{Supplemental Figure 4 .}

(A) Merge fluorescence image of endogenous SHIP164^mNG (green) and exogenous SHIP $164^{\wedge}$ mScarlet-I (magenta) in an edited HeLa knock-in cell to demonstrate overlap of the two fluorescence signals. Scale bar, $10 \mu \mathrm{m}$. High magnification of the indicated region is shown at right where the individual channels are shown as inverted grays. Scale bar, $2 \mu \mathrm{m}$.

(B) Merge fluorescence image of endogenous MPR-mScarlet-I and endogenous SHIP164^mNG in a HeLa double-knock-in cell demonstrating partial colocalization of the two fusion proteins at the cell edge but not with pulsed EGF-647 (blue) foci. Scale bar, 10 $\mu \mathrm{m}$. High magnification of the indicated region is shown at right and the individual channels are shown as inverted grays. Open arrowheads indicate overlapping fluorescence and blue arrowheads an EGF-647-positive endocytic structure. Scale bar, $2 \mu \mathrm{m}$.

(C) Live fluorescence image of a COS-7 cell expressing FAM174a-mRFP (inverted grays) and GFP-WDFY2 (not shown). Scale bar, $20 \mu \mathrm{m}$. High magnification of the indicated regions is shown at right and the individual channels are shown as inverted grays. Arrowheads indicate overlapping fluorescence. Scale bar, $2 \mu \mathrm{m}$.

(D) Live fluorescence image of a COS-7 cell demonstrating partial colocalization of exogenous SHIP164-GFP (green) FAM174a-mRFP (magenta) fluorescence in the cytoplasm. Scale bar, $10 \mu \mathrm{m}$. High magnification of the indicated regions is shown at right and the individual channels are shown as inverted grays. Arrowheads indicate overlapping fluorescence. Scale bar, $2 \mu \mathrm{m}$.

\section{Supplemental Figure 5 .}

(A) Live fluorescence images of a HeLa cell expressing exogenous GFP-SHIP164 Y772A, Y773A (magenta) and RFP-Stx6 (green) showing loss of Stx6 binding by this SHIP164 mutant. Individual channels are shown in inverted grays on the left. Scale bar, $10 \mu \mathrm{m}$.

(B) High magnification live fluorescence images COS-7 cell expressing exogenous SHIP164 Y772A, Y773A-mRFP and endosome marker EEA1 or the ER marker Sec61b showing that this SHIP164 mutant still accumulates at hot spots. The individual channels are shown as inverted grays. Scar bar, $2 \mu \mathrm{m}$. 
1056

1057

1058

1059

1060

1061

1062

1063

1064

1065

1066

1067

1068

1069

1070

1071

1072

1073

1074

1075

1076

1077

1078

1079

1080

1081

1082

1083

1084

1085

1086

1087

1088

1089

1090

1091

1092

1093

1094

1095

1096

1097

1098

1099

1100

1101

1102

1103

1104

(C) Live fluorescence images (inverted grays) of wild-type HeLa cell expressing RFP-Rab45, $r$ endogenous SHIP164^mNG in a HeLa knock-in cell, or HeLa knock-in cell expressing RFP$\mathrm{Rab} 45$, as indicated. Scale bar, $10 \mu \mathrm{m}$. Note the massive recruitment of endogenous SHIP164 to the centrosomal region in the presence of Rab45. High magnification of the indicated regions is shown at right and the individual channels are shown as inverted grays. Scale bar, $2 \mu \mathrm{m}$.

(D) Impact of the expresion of exogenous SHIP164 on the localization of endogenous MPR-mNG in cells also overexpressing Rab45. HeLa eMPR-mNG knock-in cells were transfected with Rab45 without (left) and with (right) the additional expression of SHIP164. Note that in the presence of SHIP164, Rab45 and MPR colocalize in a perinuclear spot. Left, live fluorescence image of a HeLa knock-in cell demonstrating no change to the localization of endogenous MPR-mNG (green) upon expression of RFP-Rab45 (magenta) and Right, fluorescence image of a HeLa knock-in cell demonstrating colocalization of endogenous MPR-mNG and RFP-Rab45 upon the expression of

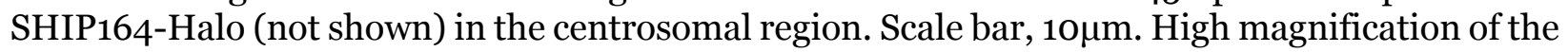
indicated regions is shown at right and the individual channels are shown as inverted grays. Arrowheads indicate overlapping fluorescence. Scale bar, $2 \mu \mathrm{m}$.

(E) Live fluorescence image of a COS-7 cell expressing SHIP164^mScarlet-I (magenta) and the dominant negative GFP-Rab45 S555N mutant (green) showing that this Rab45 mutant does not recruit SHIP164. Individual channel shown in inverted gray. Scale bar, $20 \mu \mathrm{m}$.

\section{Supplemental Figure 6.}

(A) Sequencing results confirming editing of SHIP164 locus in RPE1 cells. PAM sequence (green) was directed to exon 2 and each clone was found to have a mutation starting four nucleotides upstream. \# Indicates nucleotide is the same between parental control and clone 2.

(B) Left: Fluorescence images of a parental control (left) and SHIP164 KO cells (right) immunolabeled with antibodies against sortilin (green) and GM130 (magenta). Scale bar, $5 \mu \mathrm{m}$. Right: Quantification of the scattered cytoplasmic spots-to-Golgi complex ratio of Sortilin signal per cell (circles) in control and SHIP164 KO cell clones. Middle line, mean; bars, SD. Data represents three biological replicates. ${ }^{* *}, \mathrm{p}<0.01$.

(C) Fluorescence images of a SHIP164 KO cell immunolabeled with antibodies against TGN46 (green) and MPR (magenta) demonstrating distinct post-Golgi vesicle populations. Scale bar, $5 \mu \mathrm{m}$. High magnifications of the indicated regions are shown as insets and the individual channels are shown as inverted grays. Arrowheads indicate divergent fluorescence. Scale, $2 \mu \mathrm{m}$.

(D) Fluorescence images of a SHIP164 KO cells expressing both RFP and SHIP164 (not shown) immunolabeled with antibodies against the indicated proteins (green) and GM130 (magenta). Scale bar, $5 \mu \mathrm{m}$.

(E) Fluorescence images of parental control or SHIP164 KO cells expressing either RFP alone (not shown) or RFP and exogenous untagged SHIP164 (not shown) immunolabeled with antibodies against the EEA1 (green) demonstrating that overexpression of SHIP164, even in KO cells, reuslts in EEA1 accumulations not typically found in wild-type cells where SHIP164 is not over-expressed (far left). Scale bar, $10 \mu \mathrm{m}$.

(F) Western blot of RPE1 cells for SHIP164 and for GAPDH as a loading control, either treated with control or SHIP164 specific siRNAs.

(G) Left: Fluorescence images of a wild-type cells treated with control (left) or SHIP164 specific siRNAs (right) immunolabeled with antibodies against EEA1 (green). Scale bar, 20 $\mu$ m. Right, Quantification of large EEA1 endosomes $\left(>1 \mu \mathrm{m}^{2}\right)$ per cell in control and SHIP164 knock-down cell. Middle line, median; +, mean; bars, 10-90 percentiles. Data represents three biological replicates. ${ }^{* *}, \mathrm{p}<0.01$.

\section{Supplemental Figure 7 .}


1105 High magnification live fluorescence image COS-7 cell expressing exogenous UHRF1BP1-Halo 1106 (magenta) and the lysosomal marker LAMP1-GFP (green). The individual channels are shown as 1107 inverted grays. Scar bar, $2 \mu \mathrm{m}$.

\section{Supplemental movie 1}

High magnification of live fluorescence time series of COS-7 cell expressing exogenous SHIP164mRFP (magenta) and the endosomal marker EEA1-GFP (green) demonstrating the dynamics of SHIP164 accumulations. Frames captured every 2s. Scale bar, $1 \mu \mathrm{m}$.

\section{Supplemental movie 2}

Zoom of live fluorescence time series of a double-knock-in HeLa cell demonstrating the colocalization of fluorescencnt signal from endogenous MPR-mScarlet-I (magenta; left) and endogenous SHIP $164^{\wedge} \mathrm{mNG}$ (green; right) puncta at the cell periphery. Arrowheads indicate puncta positive for both mScarlet-I and mNG fluorescence. Frames captured every $2 \mathrm{~s}$. Scale bar, $10 \mu \mathrm{m}$. 


\section{MATERIALS AND METHODS}

\section{Antibodies and Reagents}

The list of antibodies, their working dilution, and the supplier for this study can be found in Table S1. All Halo-tag ligands used (JF549 and JF646) were a kind gift from Luke Lavis (Janelia Research Campus). All SHIP164 (UHRF1BP1L) ORFs used in this study utilized a human codon optimized sequence designed and purchased from Genscript (sequence available upon request). The following constructs were kind gifts: BFP-Rab5b and mito-BFP from G. Voeltz (University of Colorado-Boulder, CO; Addgene plasmids \#49147, \#49151, respectively); Sec61b-GFP and RFP from T. Rapoport (Harvard University, Cambridge, MA); GFP-2xHrs ${ }^{\mathrm{FYVE}}$ from Harald Stenmark (University of Oslo, Norway; Addgene plasmids \#140047). Other plasmids encoding EEA1, WDFY2, APPL1, 2xFYVE were previously generated in the De Camilli lab. All other ORFs used are listed in Table S2.

All EM reagents were purchased from Electron Microscopy Sciences (Hatfield, PA).

Lipids were purchased from Avanti Polar Lipids: DOPC (850357), liver PE (840026), DGS-NTA (Ni; 790404), brain PI(4,5)P2 (840046), Rh-PE (810150), and NBD-PE (810145).

\section{Generation of Plasmids}

Codon optimized human SHIP164 generated by Genscript was amplified using PCR from the pUC57 plasmid and ligated into various mammalian and bacterial expression plasmids. Most constructs were generated with regular cloning protocols or through site-directed mutagenesis. The desired ORFs were amplified by PCR and inserted into plasmids through enzyme digestions and ligation. Some amplified ORFs were ligated using HiFi assembly (NEB). Details of primer sets, enzymes, techniques, and plasmids used for each construct can be found in Table S2.

For internal tagging of SHIP164, the codon optimized human sequence was first amplified by PCR and cloned into p3xFLAG between the EcoRI/KpnI restriction sites using HiFi assembly. From there, the ORF of mScarlet-I was amplified by PCR and ligated into the EcoRV site at residue 915 of SHIP164 using HiFi assembly. To generate the amino-terminal free version, SHIP164^mScarlet-I was amplified by PCR and ligated into pcDNA3.1 His-A between the HindIII/XhoI sites removing the His 6 tag. Unless stated otherwise, all mutations in this study were generated using site directed mutagenesis. All ORFs were sequenced in their entirety after cloning and before use in any and all experiments.

For the MBP-SHIP164 fusion construct used in the in vitro analysis, sequences coding for residues 27-392 of E. coli maltose binding protein (MBP) and two additional alanines were fused to the N-terminus of SHIP164 ${ }_{\triangle 901-1099}$ using Gibson Assembly and site-directed mutatgenesis.

The tethered SHIP164 construct used to perform the in vitro lipid transfer assay was generated using Gibson Assembly as previously described ${ }^{6}$, and consists of SHIP164 ${ }_{\Delta 901-1099}$ followed by the unstructured region of human Esyt2(residues 649-689), then the pleckstrin homology domain of rat PLC $\Delta$ (residues 11-140), the unstructured region of Eyst2(residues 690-739), and a hexahistidine tag at the $\mathrm{C}$-terminus.

\section{Protein Expression and Purification}

For lipid transfer and cryo-EM studies, $3 \times$ FLAG-SHIP164 $4901-1099$ constructs were transfected into Expi293F cells (Thermo Fisher Scientific) according to manufacturer instructions. Protein expression was enhanced by the addition of nonessential amino acids (Gibco) and valproic acid (3.5 mM final concentration) $16 \mathrm{~h}$ after transfection. Cells were harvested by centrifugation $65 \mathrm{~h}$ 
after transfection and either flash-frozen for storage or used immediately for protein purification. Cells were lysed by 3 freeze-thaw cycles in buffer (50 mM HEPES pH 8.0, $500 \mathrm{mM} \mathrm{NaCl}, 1 \mathrm{mM}$ TCEP, $5 \%$ glycerol) containing $1 \times$ complete EDTA-free protease inhibitor cocktail (Roche). Insoluble debris was removed by centrifugation at $15000 \mathrm{rpm}$ for $30 \mathrm{~min}$, and clarified lysate was mixed with anti-FLAG M2 resin (Sigma) for $3 \mathrm{~h}$ while rotating at $4^{\circ} \mathrm{C}$. Resin was then washed with $3 \times 10$ bed volumes of buffer and subsequently incubated for $18 \mathrm{~h}$ at $4^{\circ} \mathrm{C}$ in buffer supplemented with $1 \mathrm{mM}$ ATP and $2 \mathrm{mM} \mathrm{MgCl}_{2}$. Resin was washed again with 3 bed volumes of buffer and then eluted in $5 \times 0.5$ bed volumes of buffer containing $0.25 \mathrm{mg} / \mathrm{mL} 3 \times$ FLAG peptide (APExBio). The protein was further purified by gel filtration (Superdex 200 10/300 GL, GE Healthcare) and concentrated to approximately $1.5 \mu \mathrm{M}$ (Amicon). E-Syt2 was expressed and purified as previously described 69 .

The MBP-SHIP1641312-1464/DYNLL1 complex was recombinantly expressed in BL21 DE3 competent cells for purification and size exclusion chromatography analysis using the polycistronic pET Duet expression plasmid, details of which can be found in Table S2. BL21 cells transformed with the dual expression plasmid were grown at $37^{\circ} \mathrm{C}$ in super broth (SB) media (1L) until reaching an $\mathrm{OD}_{600}$ between 2 and 3, after which the temperature was turned down to $18^{\circ} \mathrm{C}$ and cells were induced with $0.25 \mathrm{mM}$ IPTG for 16 hours with continuous shaking. Cells were pelleted in a floor centrifuge at $4000 \mathrm{~g}$ for 15 minutes and then resuspended in lysis buffer $(25 \mathrm{mM}$ Tris $\mathrm{pH} 7.5,200 \mathrm{mM} \mathrm{NaCl}, 0.1 \%$ Tween-20) and frozen at $-80^{\circ} \mathrm{C}$ until ready for purification. For purification, the pellet was thawed in a water bath and then sonicated until the desired lysis using a macro sonicator tip (VirTris VirSonic). Membrane and un-sonicated material were pelleted in a floor ultra-centrifuge at 24,000g for 20 minutes and the supernatant was collected and incubated with $250 u \mathrm{~L}$ of amylose resin for 1 hour rotating at $4^{\circ} \mathrm{C}$. The resin was then washed three times with $40 x$ bed volumes of ice-cold wash buffer (25mM Tris $\mathrm{pH} 7.5,200 \mathrm{mM} \mathrm{NaCl}$, 1mM BME). Two elutions were performed from the resin using $2 x$ bed volume of elution buffer (25mM Tris $\mathrm{pH} 7.5$, $150 \mathrm{mM} \mathrm{NaCl}, 10 \mathrm{mM}$ maltose, $1 \mathrm{mM}$ BME). The eluate was collected and run over a Superdex S2O0 column using a GE AKTA pure system, and individual fractions (1mL) were collected for analysis by SDS-PAGE and Coomassie staining.

\section{Lipidomics Analysis of SHIP164 by Mass Spectrometry}

Full length human 3xFLAG-SHIP164 was expressed and purified as described above with the following modifications. Following immunoprecipitation, FLAG resin bound SHIP164 was washed with 3x100 bed volumes of sonication buffer containing $1 \mathrm{mM}$ BME and protease inhibitor cocktail for 20 minutes. After elution, the protein was buffer exchanged into 50mM mass

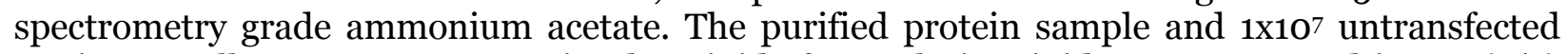
Expi293F cells was sent to Avanti Polar Lipids for analysis. Lipids were extracted in 2:1 (v/v) methanol:chloroform. The chloroform layer was dried, and lipids were reconstituted with internal standards for PC, PE, PI, PS, PA, PG, SM, TAG, DAG, and CE for quantification. As described by the company, the sample was injected into a reverse phase $\mathrm{C} 8$ column with a gradient elution profile for the resolution required of each lipid class and detected by an AB Sciex 5500 tandem mass spectrometer. The molecular species of lipids was quantified based on internal standards and summed by lipid class.

\section{Native gel lipid binding assay.}

Purified E-Syt2 and SHIP164 ${ }_{\Delta 901-1099}$ at indicated concentrations were mixed with methanoldissolved NBD-PE (0.2 mM final concentration) in $20-\mu \mathrm{L}$ total reaction volumes and incubated for $2 \mathrm{~h}$ on ice. Samples were loaded on 4-20\% Mini-PROTEAN TGX Precast Gels and run for $3 \mathrm{~h}$ at 200 V. NBD fluorescence was visualized using an ImageQuant LAS400o (GE Healthcare), and

1221 gels were stained with Coomassie Brilliant Blue R (Sigma Aldrich) to visualize total protein. A 
1222

1223

1224

1225

1226

1227

1228

1229

1230

1231

1232

1233

1234

1235

1236

1237

1238

1239

1240

1241

1242

1243

1244

1245

1246

1247

1248

1249

1250

1251

1252

1253

1254

1255

1256

1257

1258

1259

1260

1261

1262

1263

1264

1265

1266

1267

1268

1269

1270

standard curve was generated using the fluorescence values of E-Syt2 and the quantity of lipid bound to SHIP164 was analyzed using ImageJ (National Institutes of Health).

\section{FRET-based lipid transfer assay.}

Liposomes were prepared as previously described ${ }^{6}$. Briefly, lipids in chloroform were mixed in the indicated ratios and dried to thin films, then resuspended in buffer containing $50 \mathrm{mM}$ HEPES, $\mathrm{pH}$ 8.0, $500 \mathrm{nM} \mathrm{NaCl}, 1 \mathrm{mM}$ TCEP, and $5 \%$ glycerol to $1 \mathrm{mM}$ total lipid concentration. Rehydrated lipids were then incubated at $37^{\circ} \mathrm{C}$ for $1 \mathrm{~h}$ before being subjected to 10 freeze-thaw cycles. Crude liposomes were freshly extruded through a polycarbonate filter with $100-\mathrm{nm}$ pore size prior to transfer assays.

Lipid transfer experiments were set up in 100- $\mu \mathrm{L}$ reaction volumes containing $0.125 \mu \mathrm{M}$ protein, $25 \mu \mathrm{M}$ donor liposomes (61\% DOPC, 30\% liver PE, 2\% NBD-PE, $2 \%$ rhodamine-PE, and 5\% DGS$\mathrm{NTA}[\mathrm{Ni}]$ ) and $25 \mu \mathrm{M}$ acceptor liposomes $\left(65 \%\right.$ DOPC, $30 \%$ liver PE, and $5 \% \mathrm{PI}(4,5) \mathrm{P}_{2}$. Donor and acceptor liposomes were included in the reaction for 5 minutes prior to the addition of protein to establish a fluorescence baseline. The lipid transfer reaction was monitored via NBD fluorescence intensity detected every $1 \mathrm{~min}$ at $538 \mathrm{~nm}$ upon excitation at 46onm. Lipid transfer assay was performed for $1 \mathrm{~h}$ at $30^{\circ} \mathrm{C}$ in a 96-well plate (Nunc) using a Synergy H1 Plate Reader (BioTek).

A tether-only construct consisting of an N-terminal hexahistidine-tagged plexstrin homology domain from rat PLC $\Delta$ (11-140) was expressed and purified as previously described70. The lipid transfer assay using this construct was performed using the same protein:lipid ratio.

A dithionite assay, to rule out the possibility that the NBD fluorescence increase was due to SHIP164-mediated liposome fusion, was performed in the same way as the transfer assay, except for the final addition of $5 \mu \mathrm{L}$ freshly prepared dithionite buffer [100 $\mathrm{mM}$ dithionite (Sigma Aldrich) in $50 \mathrm{mM}$ Tris, $\mathrm{pH}$ 10] after fluorescence increase observed during the transfer assay had reached its maximum. NBD emission was then monitored for an additional $30 \mathrm{~min}$.

\section{Cryo-EM sample preparation, data collection, and image processing}

Purified SHIP164 $4901-1099$ was supplemented with $0.05 \%$ n-Octyl- $\beta$-D-glucoside immediately before cryo-EM samples were prepared. Quantifoil R1.2/1.3 300 mesh copper grids were glow discharged for $30 \mathrm{~s}$ at $22 \mathrm{~mA}$, then $4 \mu \mathrm{L}$ of sample was applied. The grids were blotted with a single blotting paper for $5.5 \mathrm{~s}$ at a blot force of -2 in $90 \%$ humidity at $4^{\circ} \mathrm{C}$ before being plunge-frozen in liquid ethane using an FEI Vitrobot Mark IV (Thermo Fisher Scientific).

Data collection was performed on a Titan Krios G2 transmission electron microscope (Thermo Fisher Scientific) at $300 \mathrm{kV}$ with a $\mathrm{K}_{3}$ summit direct detection camera (Gatan). SerialEM was used to collect 5,381 movies at a nominal magnification of $81,000 \times$ in super-resolution mode with a magnified pixel size of $1.068 \AA \AA$ on the specimen level (counting mode). Movies were dosefractionated into 43 frames of 0.08 seconds each at a dose rate of 16.9 electrons/ $\AA^{2}$ per s for a total dose of $51 \mathrm{e}^{-} / \AA^{2}$. The defocus range for the sample was between 1.4 and $2.4 \mu \mathrm{m}$.

Image processing was carried out using RELION-3.171. The 5,381 micrographs were motioncorrected and dose-weighted in MotionCor $2^{72}$ with a binning factor of 2 and divided into $5 \times 5$ patches. The contrast transfer function was calculated with CTFFIND-4.173. Reference-free 2D classification of 1,044 manually picked particles was done, and the three best classes that showed well-defined particles were used as references for autopicking that yielded a dataset of 3.36 million particles. Multiple rounds of $2 \mathrm{D}$ classification were carried out to remove ice contamination and bad particles. The subset of the most homogeneous 254,169 particles was used 
to generate a 3D initial model using stochastic gradient descent with $\mathrm{C} 1$ symmetry as implemented in RELION, and 3 D classification further isolated 86,720 particles. This 3 D class underwent autorefinement and post-processing for a final reconstruction at a resolution of $8.3 \AA$ according to the Fourier shell correlation $(\mathrm{FSC})=0.143$ criterion .

\section{Correlative Light and Electron Microscopy}

For TEM CLEM, COS-7 cells were plated on $35 \mathrm{~mm}$ MatTek dish (P35G-1.5-14-CGRD) and transfected as described above with SHIP164^ mScarlet-I, GFP-WDFY2, mito-BFP, and Ras ${ }^{\mathrm{G} 12 \mathrm{~V}}$. Cells were pre-fixed in 4\% PFA in Live Cell Imaging Buffer (see above) then washed before fluorescence light microscopy imaging. Regions of interest were selected and their coordinates on the dish were identified using phase contrast. Cells were further fixed with $2.5 \%$ glutaraldehyde in $0.1 \mathrm{M}$ sodium cacodylate buffer, postfixed in $2 \% \mathrm{OsO}_{4}$ and $1.5 \% \mathrm{~K}_{4} \mathrm{Fe}(\mathrm{CN})_{6}$ (Sigma-Aldrich) in $0.1 \mathrm{M}$ sodium cacodylate buffer, en bloc stained with $2 \%$ aqueous uranyl acetate, dehydrated, and embedded in Embed 812. Cells of interest were relocated based on the pre-recorded coordinates. Ultrathin sections $(50-60 \mathrm{~nm})$ were observed in a Talos L $120 \mathrm{C}$ TEM microscope at $80 \mathrm{kV}$, images were taken with Velox software and a $4 \mathrm{k} \times 4 \mathrm{~K}$ Ceta CMOS Camera (Thermo Fisher Scientific). For FIBSEM CLEM, mito-BFP was expressed in endogenously tagged eSHIP164^mNG HeLa cells processed as above except the dehydration was implemented at the low temperatures gradually decreased from $\mathrm{o}^{\circ} \mathrm{C}$ to $-5 \mathrm{O}^{\circ} \mathrm{C}$. Epon blocks were glued onto the SEM sample mounting aluminum and platinum en bloc coating on the sample surface was carried out with the sputter coater (Ted Pella, Inc., Redding, California). Sample were FIBSEM imaged in a Crossbeam 550 FIBSEM workstation operating under SmartSEM (Carl Zeiss Microscopy GmbH, Oberkochen, Germany) and Atlas engine 5 (Fibics incorporated, Ottawa, Canada). The imaging resolution was set at 5 $\mathrm{nm} /$ pixel in the $\mathrm{X}, \mathrm{Y}$ axis with milling being performed at $2.5 \mathrm{~nm} / \mathrm{step}$ along the $\mathrm{Z}$ axis (binned down by 2 to $5 \mathrm{~nm}$ when images were exported) to achieve an isotropic resolution of $5 \mathrm{~nm}$ voxel. Images were aligned and exported with Atlas 5 (Fibics incorporated, Ottawa, Canada), further processed and analyzed with DragonFly Pro software [Object Research Systems (ORS) Inc., Montreal, Canada]. Except noted all reagents were from EMS (Electron Microscopy Sciences), Hatfield, PA.

\section{Cell culture and Transfections}

hTERT-RPE1 cells were a kind gift of A. Audhya (University of Wisconsin, Madison, WI). HeLa and COS-7 cells were obtained from ATCC. All mammalian cells were maintained at $37^{\circ} \mathrm{C}$ in humidified atmosphere at $5 \% \mathrm{CO}_{2}$ unless noted otherwise. HeLa and COS-7 cells were grown in DMEM and RPE1 cells in DMEM/F12 medium (Thermo Fisher Scientific) supplemented with $10 \% \mathrm{FBS}, 100 \mathrm{U} / \mathrm{mL}$ penicillin, 100mg/mL streptomycin, and $2 \mathrm{mM}$ glutamax (Thermo Fisher Scientific). Expi293F were grown to manufacturers specification in Expi293 expression medium with constant shaking. All cell lines were routinely tested and always resulted free from mycoplasma contamination.

Transient transfections were carried out on cells that were seeded at last 8 hours prior. All transfections of plasmids used FugeneHD (Promega) to manufacturers specifications for 16-24 hours in complete media without antibiotics. Expi293 transfections were carried out to manufacturers specifications and reagents. siRNAs (IDT) for knowck-down experiments against SHIP164 (design ID: hs.Ri.UHRF1BP1L.13.2) were transfected using Lipofectamine RNAiMAX (ThermoFisher) for 48 hours before fixation for immunocytochemistry experiments or collected for immunoblotting (see below)

\section{Immunoblotting and Imaging Procedure}

All cell samples analyzed by immunoblotting (RPE1 and HeLa) were scraped from plates and 
1321

1322

1323

1324

1325

1326

1327

1328

1329

1330

1331

1332

1333

1334

1335

1336

1337

1338

1339

1340

1341

1342

1343

1344

1345

1346

1347

1348

1349

1350

1351

1352

1353

1354

1355

1356

1357

1358

1359

1360

1361

1362

1363

1364

1365

1366

1367

1368

1369

1370

1371

centrifuged again in a 1.7mL Eppendorf tube. The cells pellet was resuspended in Lysis buffer (20mM Tris- $\mathrm{HCl} \mathrm{pH} \mathrm{7.5,150mM} \mathrm{NaCl,} \mathrm{1mM} \mathrm{EDTA)} \mathrm{containing} \mathrm{protease} \mathrm{inhibitor} \mathrm{cocktail}$ (Roche) and lysed using mechanical disruption (Isobiotec Cell Homogenizer). The lysate was clarified by centrifugation (17,000xg for 10 minutes) and then mixed with 3x SDS sample buffer (Cold Spring Harbor) to $1 \mathrm{x}$ concentration and then heated to 95C for 5 minutes. A small portion of lysate was reserved for quantification of protein concentration by Bradford. 15-25ug of protein samples were separated by electrophoresis on a 4-20\% Mini-PROTEAN TGX gel and then subjected to standard western blot transfer and procedures. Blots were imaged using the Odyssey imaging system (Licor) using manufacturers protocols. All primary antibodies used in this study are listed in Table S1.

\section{Live Cell Imaging and Immunofluorescence}

For all live cell microscopy cells were seeded on glass-bottom mat-tek dishes (MATtek corporation) $5500 / \mathrm{cm}^{2}$ in complete media. Transfections were carried out as described above. Spinning-disk confocal imaging was preformed 16-24 post transfection using an Andor Dragon Fly 200 (Oxford Instruments) inverted microscope equipped with a Zyla cMOS 5.5 camera and controlled by Fusion (Oxford Instruments) software. Laser lines used: DAPI, 440nm; GFP, 488; RFP, 561; Cy5, 647. Images were acquired with a PlanApo objective (6ox 1.45-NA). During imaging, cells were maintained in Live Cell Imaging buffer (Life Technologies) in a cage incubator (Okolab) with humidified atmosphere at $37 \mathrm{C}$.

Halo-tag ligands ligands were used at a final concentration of 200nM. Cells were incubated with indicated dye for 45 minutes in complete media, rinsed three times with complete media, and then incubated in complete media for 45 minutes before imaging. Immunofluorescent experiments were performed with cells grown on \#1 glass cover slips. Cells were fixed with $4 \%$ PFA in fixation buffer (400mM sucrose, $125 \mathrm{mM} \mathrm{NaCal}, 5 \mathrm{mM} \mathrm{KCl}, 1 \mathrm{mM} \mathrm{NaH} 2 \mathrm{PO}_{4}, 2 \mathrm{mM} \mathrm{MgCl} 2$, $5 \mathrm{mM}$ glucose, $1 \mathrm{mM}$ EGTA, $5 \mathrm{mM}$ PIPES) for $10 \mathrm{mins}$ at $37^{\circ} \mathrm{C}$, washed $3 \mathrm{x}$ with $\mathrm{TBS}$ (Tris-HCl pH $7.5,150 \mathrm{mM} \mathrm{NaCl}$ ), permeabilized using $1 \mathrm{x}$ PBS containing $0.5 \%$ Triton for $10 \mathrm{~min}$ at RT and then blocked using antibody dilution buffer (50 mM Tris $\mathrm{pH} 7.5,150 \mathrm{mM} \mathrm{NaCl}, 0.1 \%$ Triton, 4\% BSA) for 1 hour at $25^{\circ} \mathrm{C}$. Coverslips were incubated with the indicated primary antibody diluted in the same buffer overnight at $4^{\circ} \mathrm{C}$. Slides were washed with PBS containing $0.1 \%$ Triton to remove excess primary antibody and subsequently incubated with the indicated secondary antibody diluted in antibody dilution buffer for $45 \mathrm{~min}$ at room temperature in the dark prior to mounting.

\section{Generation of CRISPR edited Cell Lines}

SHIP164 RPE1 knockout cells were generated by first identifying a guide RNA (gRNA) directed to exon 2 of SHIP164 using a Cas9 target identification tool (CHOPCHOP). A single stranded oligo (IDT) was synthesized containing the sense sequence and then cloned into PX458 (Addgene \# 48138) and transfected into RPE1 cells. 48 hours post transfection cells were single cell sorted using FACS Aria based on GFP expression into 96-well plates, and individual clones were grown out and subsequently examined by immunoblot analysis. Sanger sequencing was used to confirm the presence of mutations, which led to frameshifts and premature stop codons within the coding sequence of SHIP164. Two validated clones were used in subsequent studies.

Endogenous tagging of in HeLa cells was carried out using the ORANGE system. Briefly, a gRNA targeted close the desired site within the endogenous reading frame of the indicated target protein was identified and subsequently cloned into empty pORANGE using HiFi assembly at the tandem BbsI site. The ORF of the indicated fluorescent protein (mNeonGreen or mScarlet-I) with linker regions to make an in-frame insertion was cloned into the HindIII/XhoI sites of pORANE using standard restriction enzyme cloning. The finalized plasmid was transfected into wild-type HeLa 
1372

1373

1374

1375

1376

1377

1378

1379

1380

1381

1382

1383

1384

1385

1386

1387

1388

1389

1390

1391

1392

1393

1394

1395

1396

1397

1398

1399

1400

1401

1402

1403

1404

1405

1406

1407

1408

1409

1410

1411

1412

1413

1414

1415

1416

1417

1418

1419

cells using the transfection protocol described above. Cells were split once to keep confluency below $80 \%$ and 5 -days post transfection and the cells were imaged using confocal microscopy. After visualizing cells positive for the correct fluorescent protein, cells were serially diluted and plated at 10 cells per well on a glass bottom 96-well plate (Cellvis P96-1-N) and inspected for fluorescence when the wells were sub-confluent. Wells with positive fluorescence were expanded, serially diluted, and plated at one cell per wll on a glass bottom 96-well plate and inspected for fluorescence when the clones were sub-confluent. All gRNAs used in this study are listed in Table S2.

\section{Mouse Brain Lysate Preparation, Affinity Purification, and Protein Identification} Brains were collected from sacrificed wild-type $\mathrm{C}_{57} /$ black mice. For each $1 \mathrm{~g}$ of whole brian material, $10 \mathrm{~mL}$ of buffer (25mM HEPES pH 7.4, 200mM NaCl, $5 \%$ glycerol, protease inhibitors) was added. Mechanical lysis was performed using a glass dounce-homogenizer (15 strokes). Triton X-10o was added to $1 \%$ and material was rotated at $4 \mathrm{C}$ for 30 minutes. Material was centrifuged at $1000 \mathrm{~g}$ to remove cell debris and the collected supernatant was centrifuged at 27000 for 20 minutes. The resulting supernatant was flash frozen and stored at $-80 \mathrm{C}$ until use.

Purified 3xFLAG-SHIP164 or FLAG-tagged control protein was immobilized on anti-FLAG resin as described above. Immobilized SHIP164 and control protein was incubated with mouse brain lysate for $16 \mathrm{hrs}$ gently rotating at $4 \mathrm{C}$. Resin was spun down and the supernatant was removed before $2 \times 10$ bed volume washes using a wash buffer (25mM HEPES pH 7.4, $150 \mathrm{mM} \mathrm{NaCl}, 1 \mathrm{mM}$ BME, protease inhibitors). Protein bound to resin was boiled in the same wash buffer and eluate was transferred to a new Eppendorf tube. Protein in the eluate was precipitated using trichloroacetic acid (TCA) on ice for 16hrs, neutralized using Tris pH 8.5 buffer, and then the precipitate was pelleted in a table top centrifuge. The precipitate was washed twice with ice cold acetone and then dried using a speed-vac. Protein and peptide identification was achieved by shotgun tandem LC-MS/MS analysis. Analysis was performed using Scaffold 5 proteome software to identify promising identifications.

\section{Image processing, Analysis, and Statistics}

Florescence images presented in this study are representative of cells imaged in at least three independent experiments and were processed with ImageJ software. The dimensions of some of the magnification insets or panels were enlarged using the Scale function on ImageJ.

Quantification of vesicle-to-Golgi ratio and peripheral structures: unprocessed images with two channels (GM13o for Golgi in one channel and the protein of interest in the other channel) were made into maximum intensity projections. A mask of the Golgi complex was made using the GM130 signal and then used to subtract the Golgi signal from the signal of the entire cell protein of interest channel resulting in peripheral signal only. Outlines of individual cells were drawn, and the amount of peripheral signal was measured and then divided by the extracted Golgi signal for each cell to obtain the ratio. Where stated that the number of peripheral structures were counted, the subtracted peripheral image was made into a mask to identify structures of the indicated area and subsequently counted per cell.

Statistical analysis was performed with GraphPad Prism 7 software. Groups were compared using a two-tail unpaired Student $t$ test and results were deemed significant when a p value was smaller than 0.05 . 
TABLES

1421

Table S1. List of antibodies used in this study.

1423

\begin{tabular}{|c|c|c|c|c|}
\hline $\begin{array}{l}\text { Protein } \\
\text { (epitope) }\end{array}$ & $\begin{array}{c}\text { Company; } \\
\text { Catalog number }\end{array}$ & $\begin{array}{l}\text { Antibody } \\
\text { species }\end{array}$ & $\begin{array}{l}\text { Working dilution for } \\
\text { immunocytochemistry }\end{array}$ & $\begin{array}{l}\text { Working dilution } \\
\text { for } \\
\text { immunoblotting }\end{array}$ \\
\hline GM130 & $\begin{array}{c}\text { BD Bioscience; } \\
610822\end{array}$ & Mouse & $1: 100$ & $\mathrm{~N} / \mathrm{A}$ \\
\hline GM130 & $\begin{array}{c}\text { Abcam; } \\
\text { ab30637 }\end{array}$ & Rabbit & $1: 300$ & $\mathrm{~N} / \mathrm{A}$ \\
\hline EEA1 & $\begin{array}{c}\text { BD Bioscience; } \\
610457\end{array}$ & Mouse & $1: 100$ & $\mathrm{~N} / \mathrm{A}$ \\
\hline EEA1 & $\begin{array}{c}\text { Thermo } \\
\text { Scientific; PA1- } \\
\text { 063A }\end{array}$ & Rabbit & $1: 400$ & N/A \\
\hline Sortilin & $\begin{array}{c}\text { Abcam; } \\
\text { ab243043 }\end{array}$ & Rabbit & $1: 500$ & N/A \\
\hline MPR (IGF-IIR) & $\begin{array}{l}\text { Santa Cruz } \\
\text { Biotechnology; } \\
\text { sc-53146 }\end{array}$ & Mouse & $1: 100$ & N/A \\
\hline TGN46 & $\begin{array}{l}\text { Abcam; } \\
\text { ab50595 }\end{array}$ & Rabbit & $1: 200$ & $\mathrm{~N} / \mathrm{A}$ \\
\hline TGN46 & $\begin{array}{l}\text { AbD Serotec; } \\
\text { AHP50oGT }\end{array}$ & Sheep & $1: 300$ & N/A \\
\hline mNeonGreen & $\begin{array}{l}\text { ChromoTek; } \\
\text { 32f6-100 }\end{array}$ & Mouse & $1: 500$ & 1:1000 \\
\hline SHIP164 & $\begin{array}{l}\text { Custrom } \\
\text { antibody } \\
\text { produced by } \\
\text { Proteintech }\end{array}$ & Rabbit & $\mathrm{N} / \mathrm{A}$ & $1: 500$ \\
\hline GAPDH & $\begin{array}{c}\text { Proteus; 40- } \\
1246\end{array}$ & Mouse & $\mathrm{N} / \mathrm{A}$ & $1: 1000$ \\
\hline
\end{tabular}

1424

1425

1426

1427
Table S2. List of ORFs and primers used for cloning in this study. See associated excel file. 


\section{ACKNOWLEDGMENTS}

1429 We thank members of the De Camilli and Reinisch lab for critical reading of the manuscript. We also thank Shan Xu and Song Pang (Janelia Research Labs) for help and discussion with FIB-SEM experiments. This work was in supported in part by grants from the NIH (NS36251, DA18343 and DK45735), the Kavli Institute for Neuroscience, and the Parkinson Foundation to PDC, the NIH (R35GM131715) to KMR, the NIH (F32NS108448) to MGH, and the NIH (T32GMoo8283) to PS. This research was also funded in part by Aligning Science Across Parkinson's grant ASAP-000580 through the Michael J. Fox Foundation for Parkinson's Research (MJFF) to PDC and KMR. For Accepted Manuscripts arising from this submission. 


\section{AUTHOR CONTRIBUTIONS}

1440 MGH, PS, KMR, PDC conceptualized the project. PS performed structural analysis and lipid 1441 binding and transport experiments, YW performed CLEM experiments in collaboration with $1442 \mathrm{MGH}$, and MGH performed everything else. MGH, PS, YW, KMR, PDC analyzed data. MGH, PS, 1443 KMR, PDC wrote the original draft of the manuscript, which was then reviewed and edited by all 1444 the authors. 
bioRxiv preprint doi: https://doi.org/10.1101/2021.11.04 467353; this version posted November 12, 2021. The copyright holder for this preprint (which was not certified by peer review) is the author/funder, who has granted bioRxiv a license to display the preprint in perpetuity. It is made available under aCC-BY 4.0 International license.

\section{CONFLICT OF INTEREST}

1447 PDC is a member of the Scientific Advisory Board of Casma Therapeutics. No conflict exists with 1448 this role 
bioRxiv preprint doi: https://doi.org/10.1101/2021.11.04.467353; this version posted November 12, 2021. The copyright holder for this preprint (which was not certified by peer review) is the author/funder, who has granted bioRxiv a license to display the preprint in perpetuity. It is made available under aCC-BY 4.0 International license.

A

a

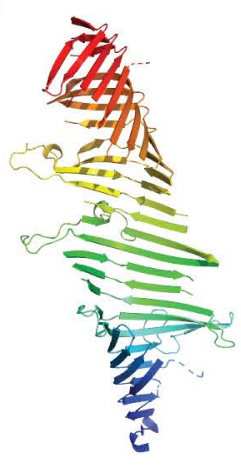

Taco-shaped

B-sheet core

high confidence

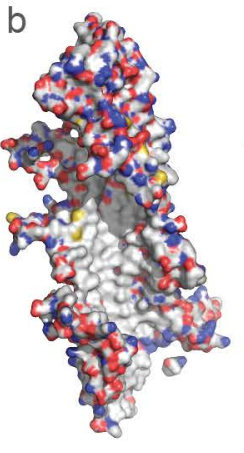

E-Syt2 $(\mu \mathrm{M}) \quad$ SHIP164 ${ }_{\triangle 901-1099}$ + NBD-PE $(2.5 \mu \mathrm{M})$
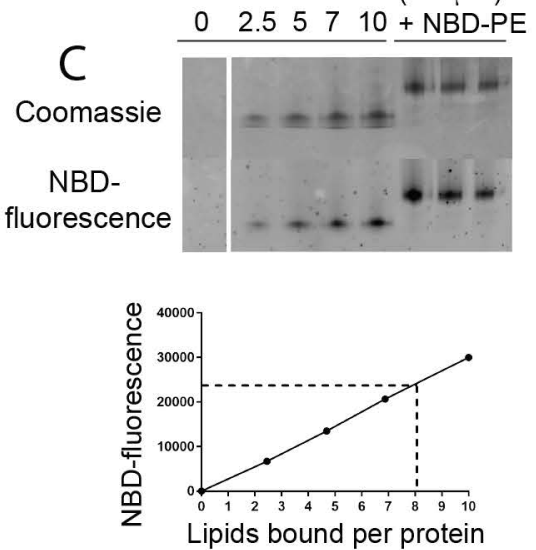

G

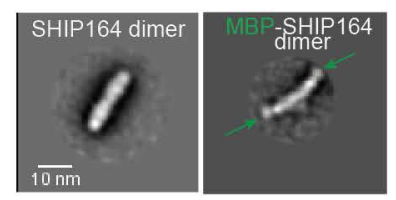

$\mathrm{H}$

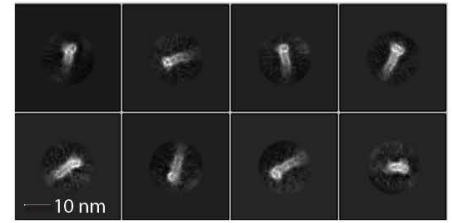

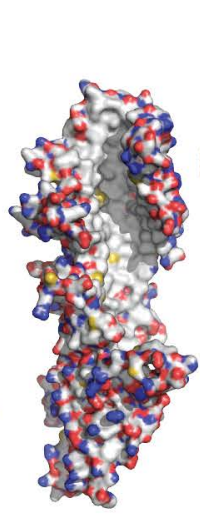

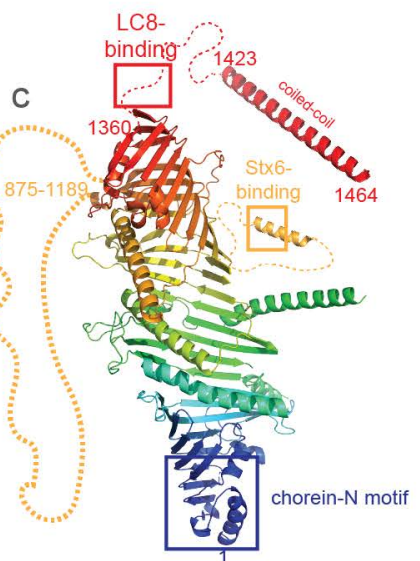

Taco-shaped core \& associated structural elements

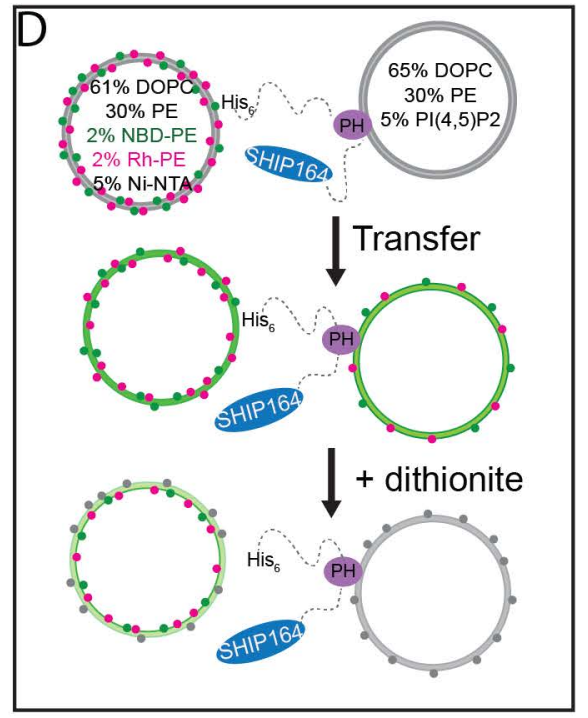

E

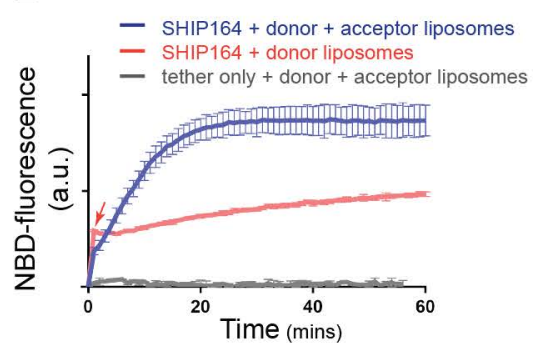

F

Dithionite fusion control

- SHIP164 + donor+ acceptor liposomes

- donor + acceptor liposomes only
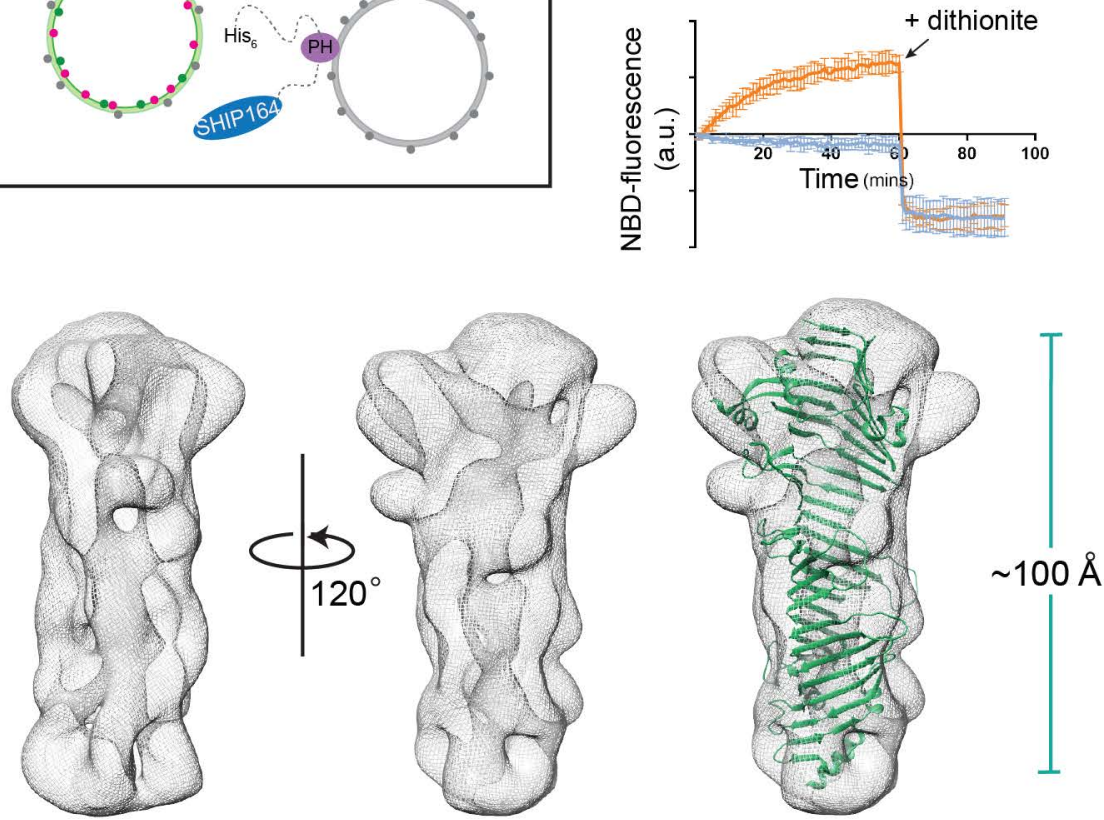
bioRxiv preprint doi: https://doi.org/10.1101/2021.11.04.467353; this version posted November 12, 2021. The copyright holder for this preprint (which was not certified by peer review) is the author/funder, who has granted bioRxiv a license to display the preprint in perpetuity. It is made available under aCC-BY 4.0 International license.

A

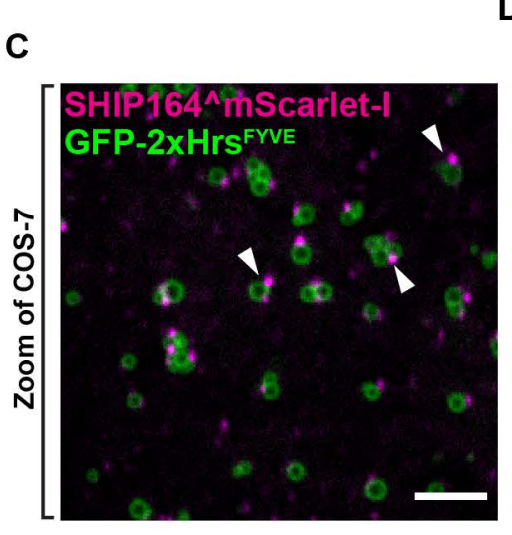

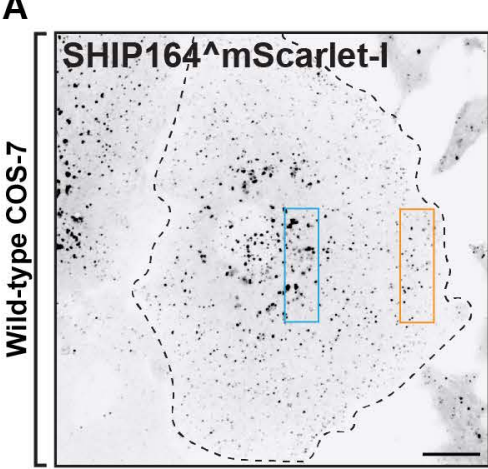

D

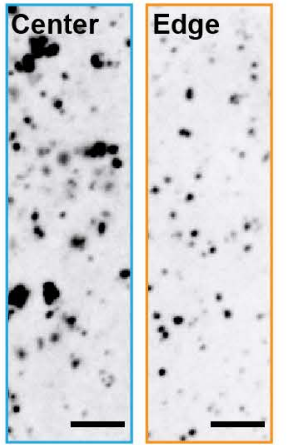

SHIP $164^{\wedge} \mathrm{mScarlet-I}$

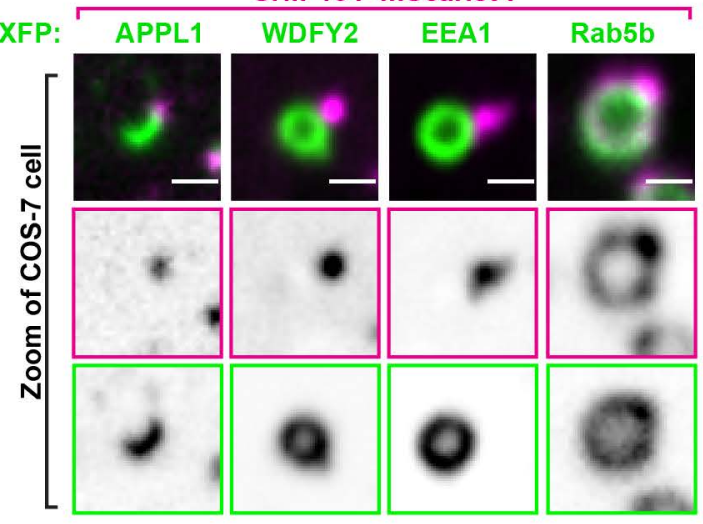

B

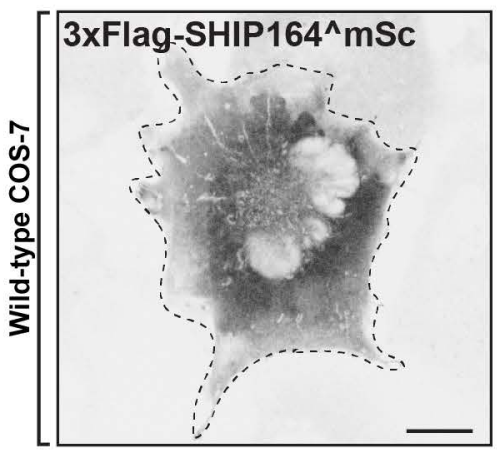

E

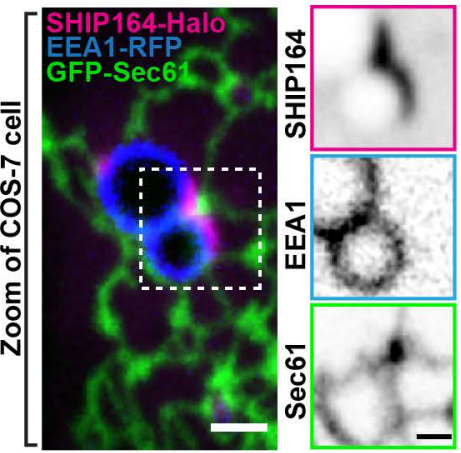

$\mathbf{F}$

SHIP164-mRFP GFP-WDFY2
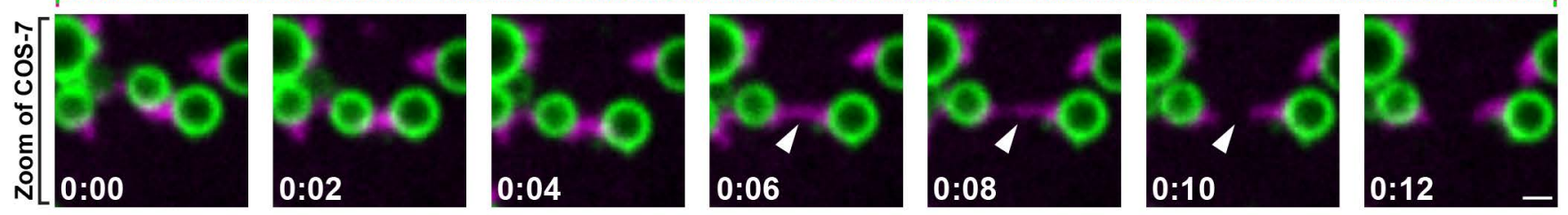

G

Merge of channels
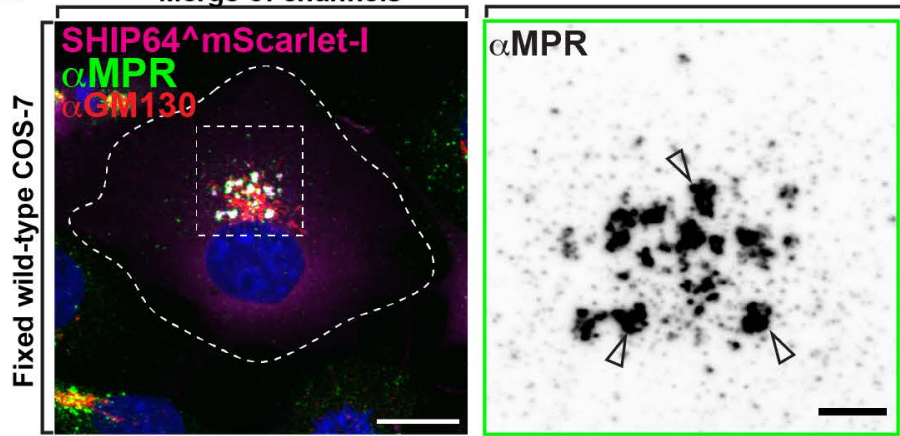

Single channels

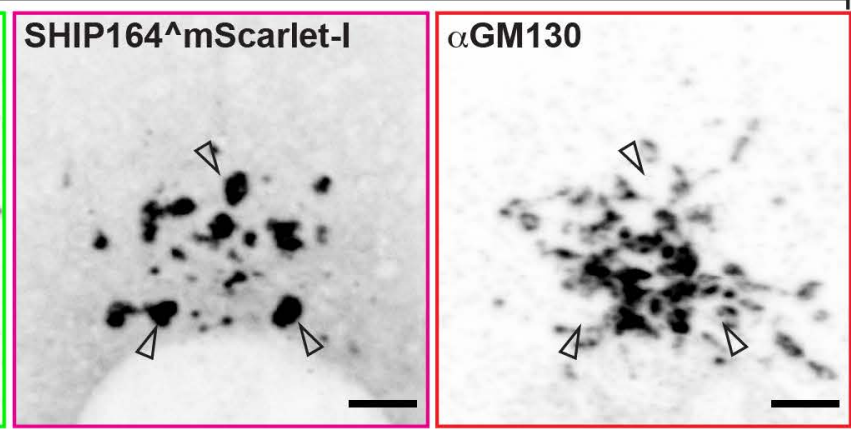

H

RFP alone (Not shown)
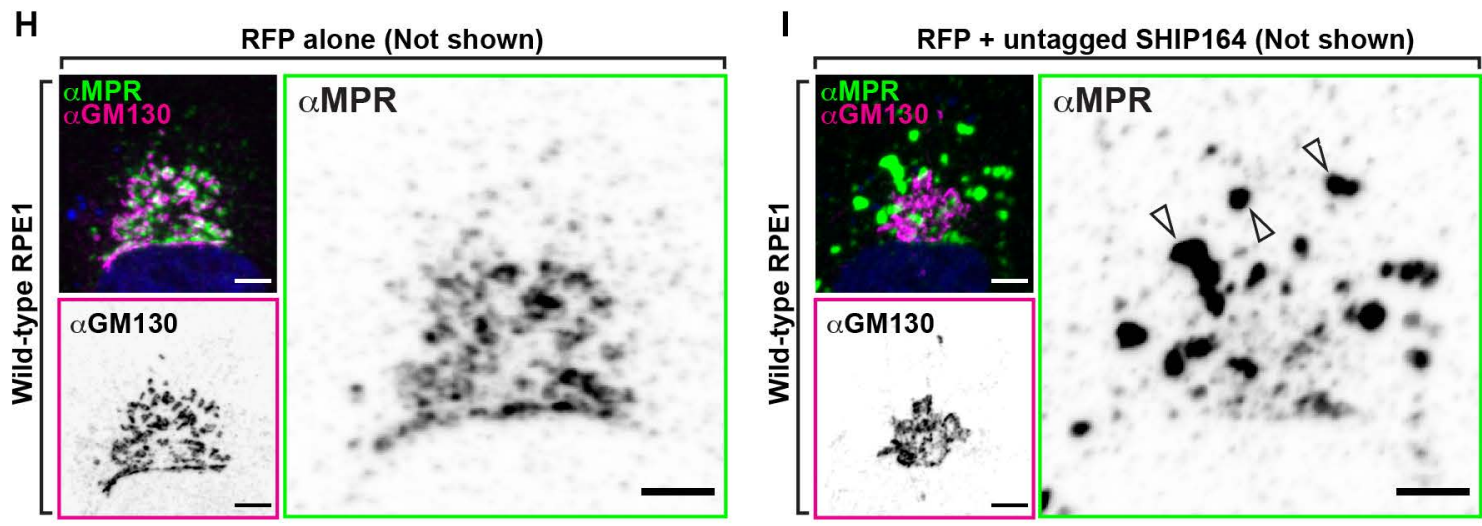

Figure 2 
bioRxiv preprint doi: https://doi.org/10.1101/2021.11.04.467353; this version posted November 12,2021 . The copyright holder for this preprint (which was not certified by peer review) is the author/funder, who has granted bioRxiv a license to display the preprint in perpetuity. It is made available under aCC-BY 4.0 International license.

A

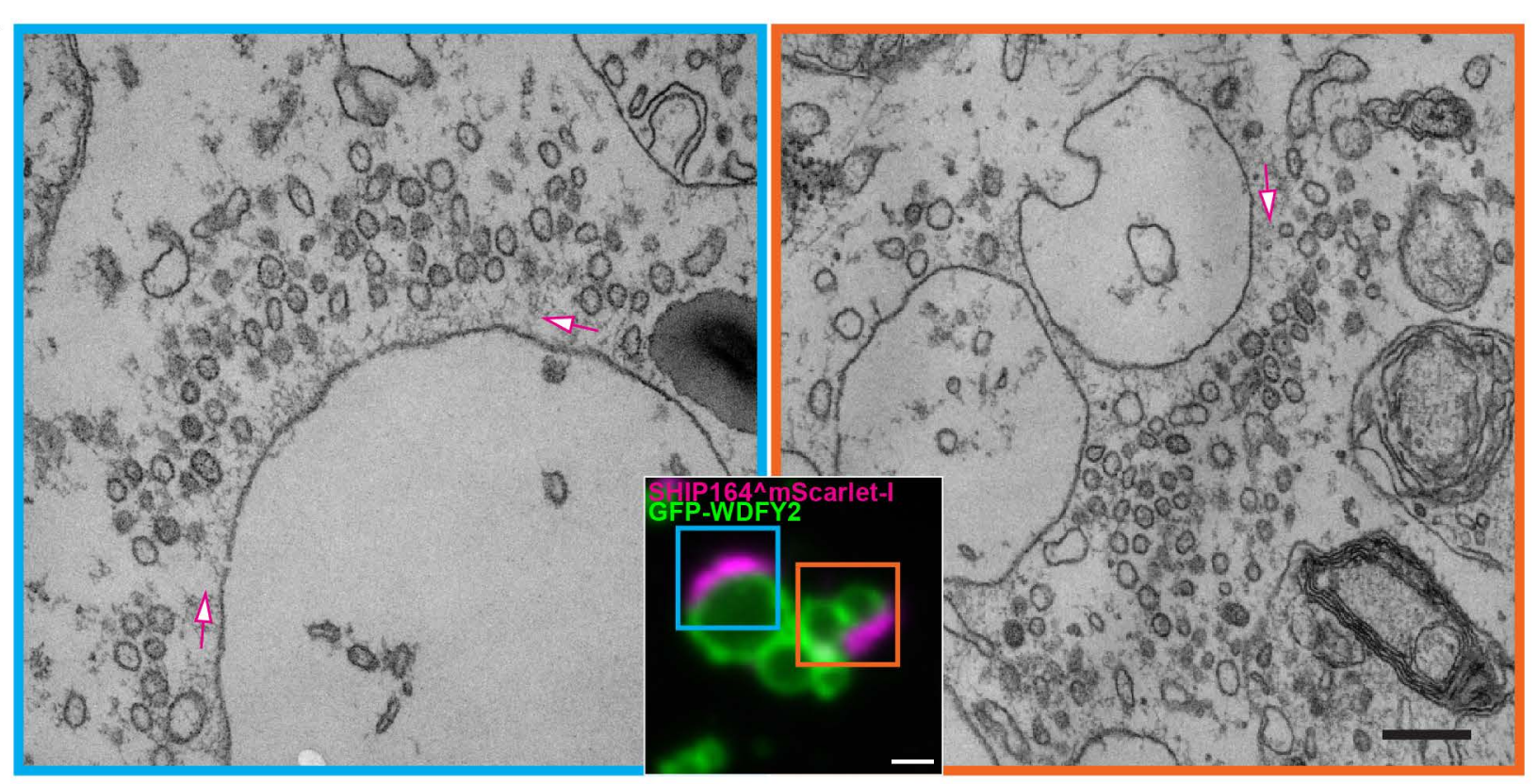

B

GFP-WDFY2

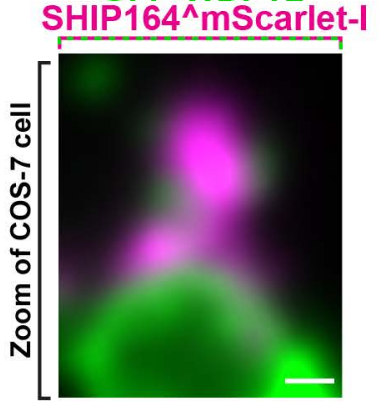

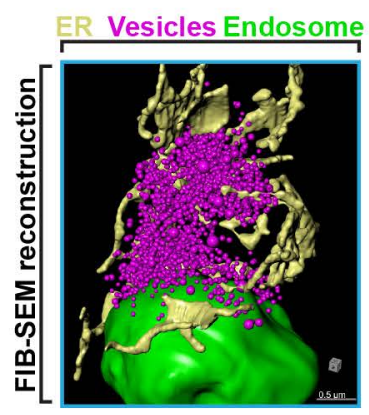

C

GFP-WDFY2
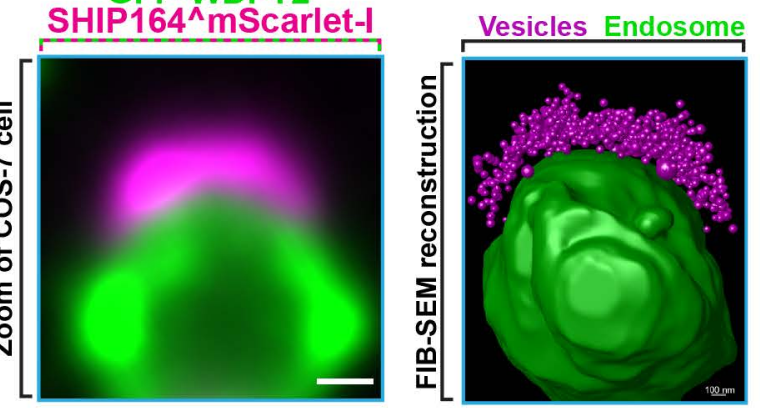

Figure 3 
bioRxiv preprint doi: https://doi.org/10.1101/2021.11.04.467353; this version posted November 12, 2021. The copyright holder for this preprint (which was not certified by peer review) is the author/funder, who has granted bioRxiv a license to display the preprint in perpetuity. It is made available under aCC-BY 4.0 International license.

A

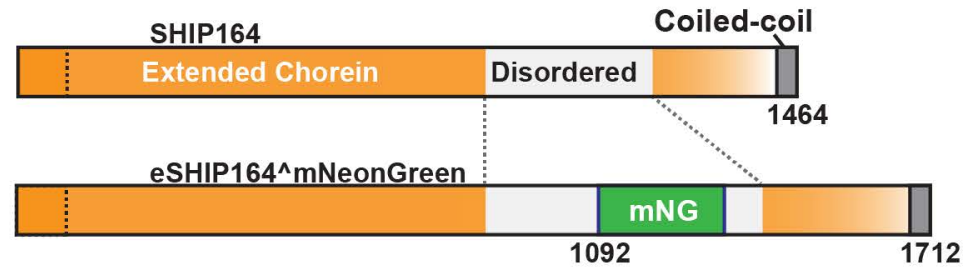

B

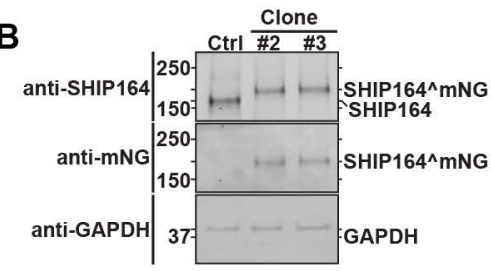

C

SHIP164 Exon 15 5' gRNA Scar _ 5' GS-linker _ mNeonGreen _...mNG continued 3' GS-linker 3' gRNA Scar _ Exon 15 5' GAACGTTGCCCACCCATGGGTGGGCAACGTTCCGGTTCTGGATCGGTTGTGAGCAAGGGCGAG//GACGAGCTGTACAAGGGTTCAGGTAGCACCAGGTACCTGGCTCCTCTCTGT 3' 3 ' CTTGCAACGGGTGGGTACCCACCCGTTECAAGGCCAAGACCTAGCCCACACTCGTTCCCGCTC//CTGCTGGTCATGTTCCCAAGTCCATCGTGGTCCATGGACCGAGGAGAGACA 5'

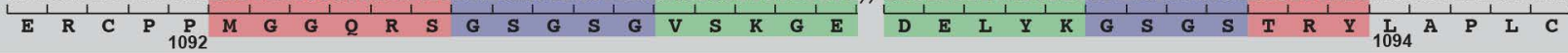

D

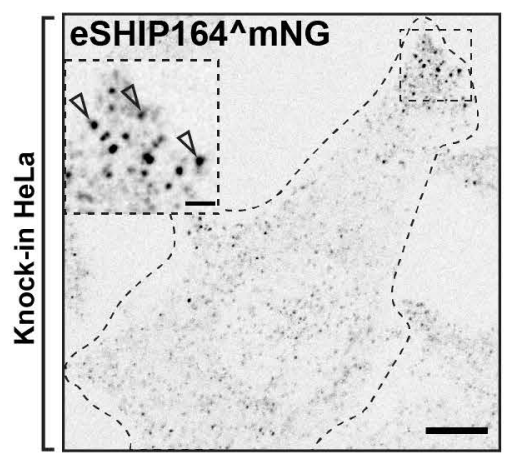

E

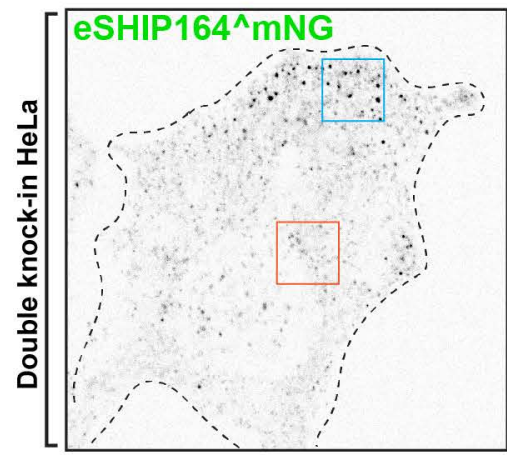

Fluorescencel

F

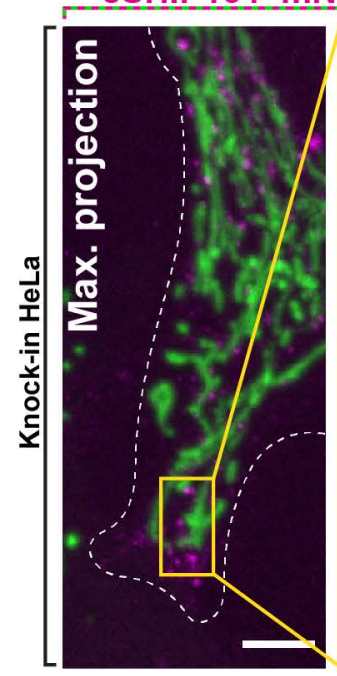

G

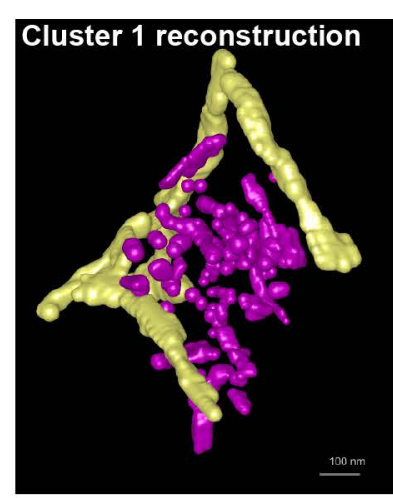

EM Overlay
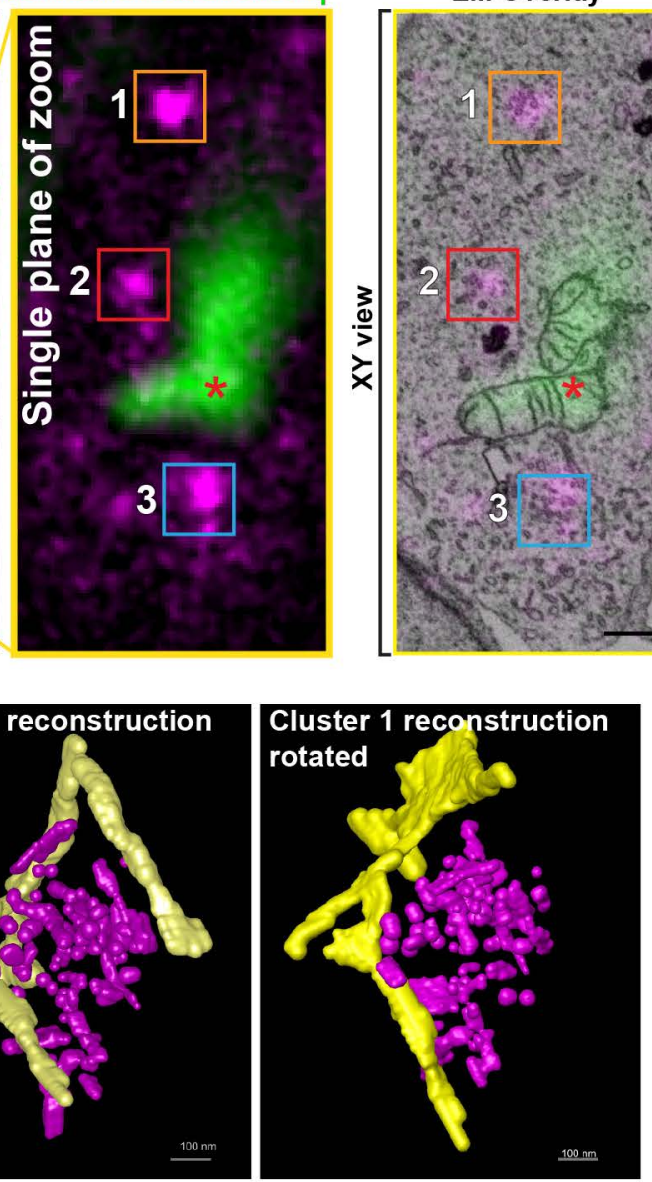

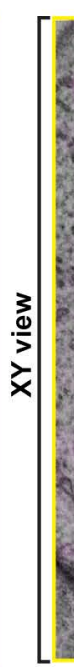

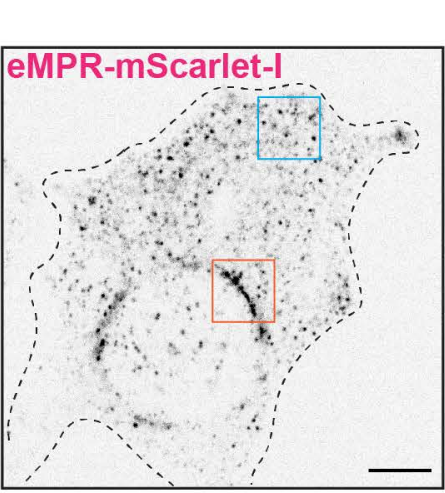

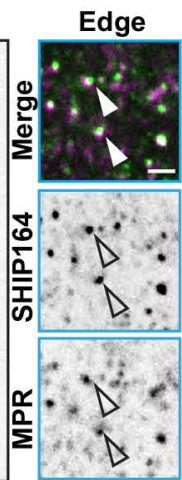

Center

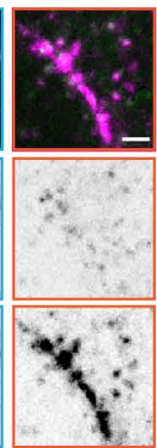

\section{Zoom of $X Y$ view}
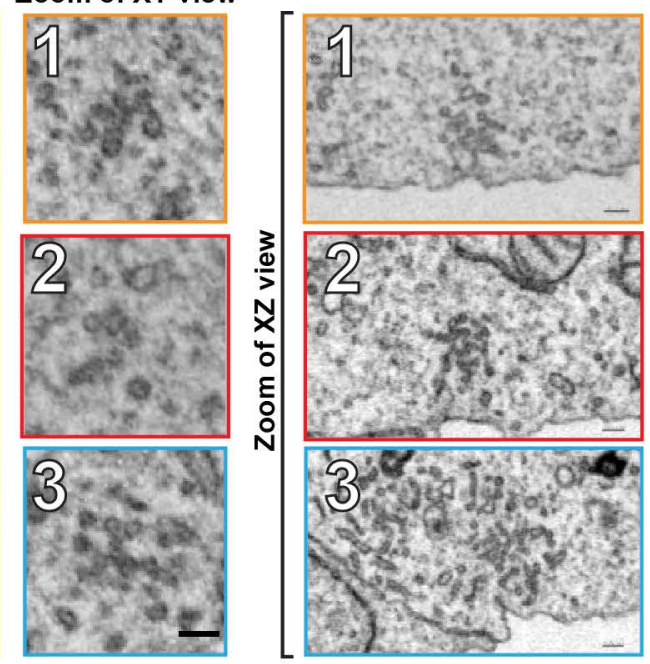

$\mathrm{H}$

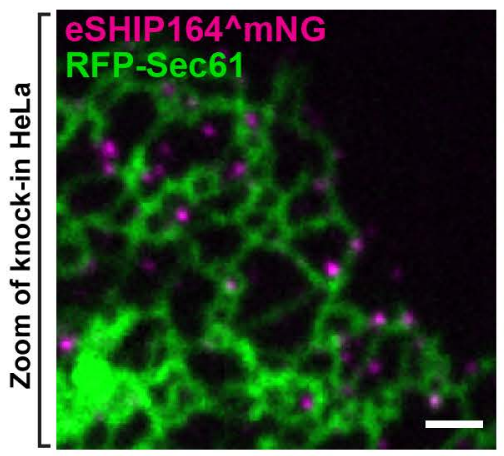


bioRxiv preprint doi: $\mathrm{https}$ //doi.org/10.1101/2021.11.04.467353; this version posted November 12,2021 . The copyright holder for this preprint (which was not certified by peer review) is the author/funder, who has granted bioRxiv a license to display the preprint in perpetuity. It is made available under aCC-BY 4.0 International license.

A

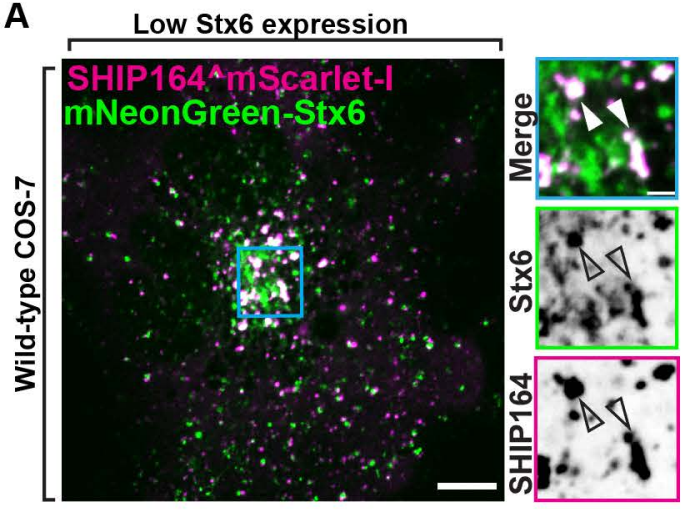

B

\begin{tabular}{|c|c|c|c|}
\hline \multirow{2}{*}{\multicolumn{2}{|c|}{ Bait }} & \multicolumn{2}{|c|}{ Identified Targe } \\
\hline & & \multicolumn{2}{|c|}{ DYNLL1 DYNLL2 } \\
\hline 6 & SHIP164 & 233 & 107 \\
\hline $\begin{array}{l}\text { 离 } \\
\end{array}$ & Control & 4 & 4 \\
\hline & SHIP164 & 111 & 109 \\
\hline $\bar{x}$ & Control & 4 & 3 \\
\hline
\end{tabular}

C

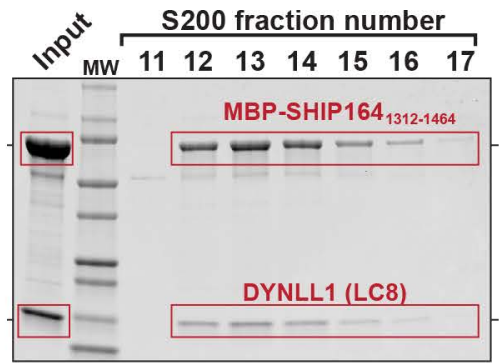

D

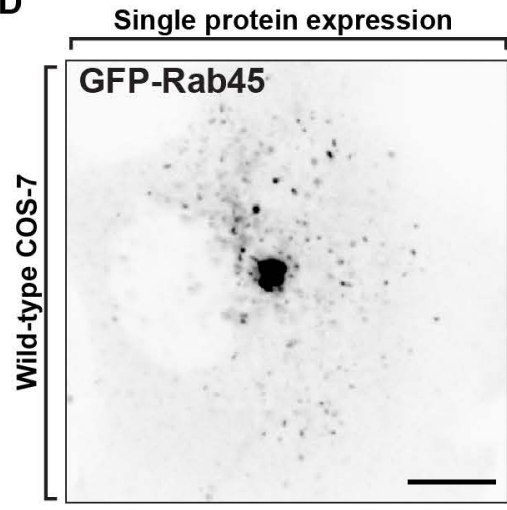

E
Single protein expression

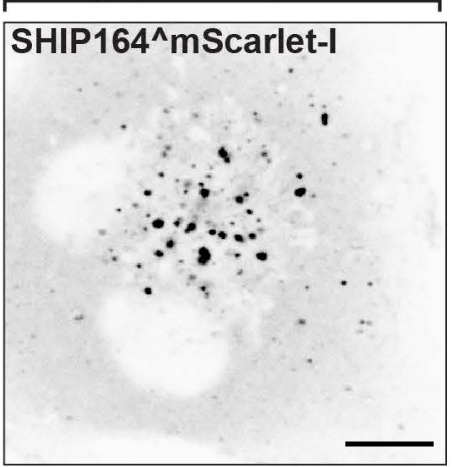

Dual expression

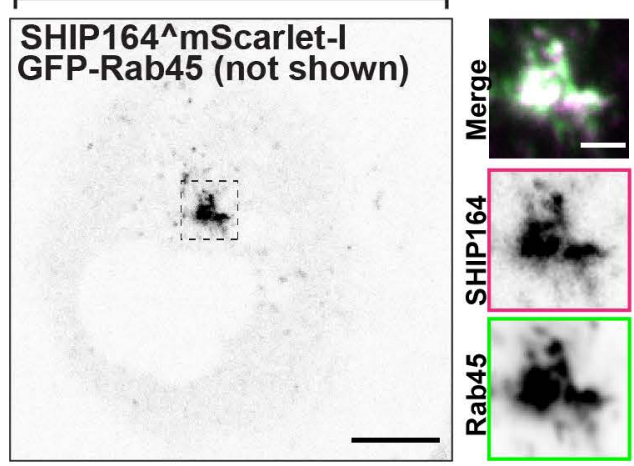

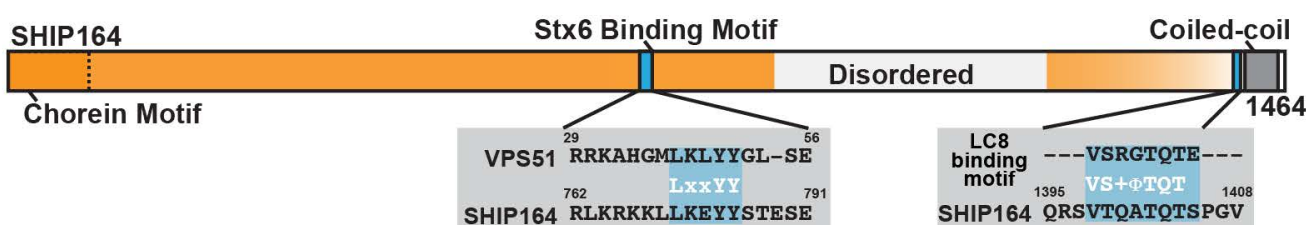


bioRxiv preprint doi: https://doi.org/10.1101/2021.11.04.467353; this version posted November 12, 2021. The copyright holder for this preprint (which was not certified by peer review) is the author/funder, who has granted bioRxiv a license to display the preprint in perpetuity. It is made available under aCC-BY 4.0 International license.

A

B

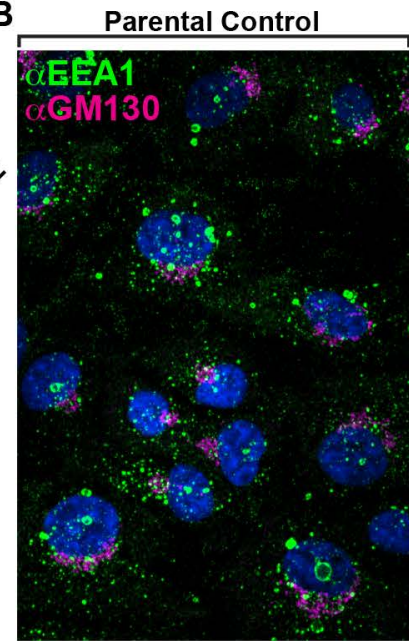

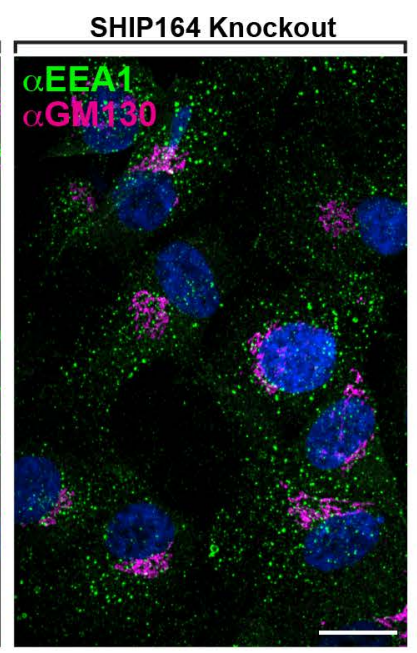

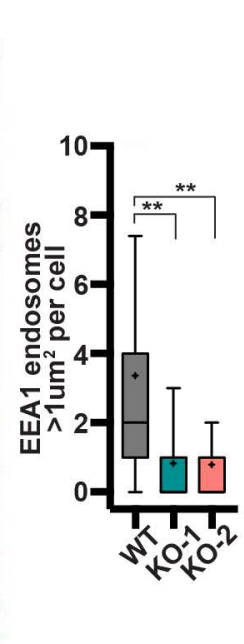

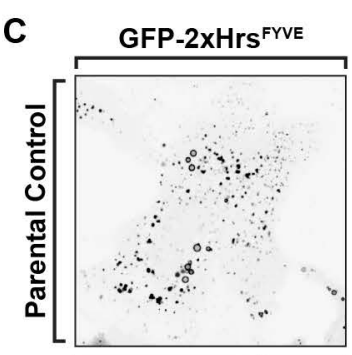

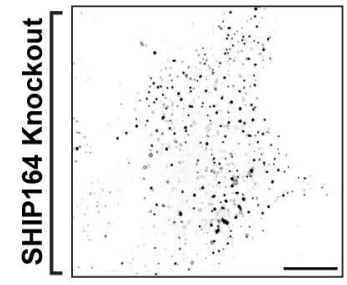

D

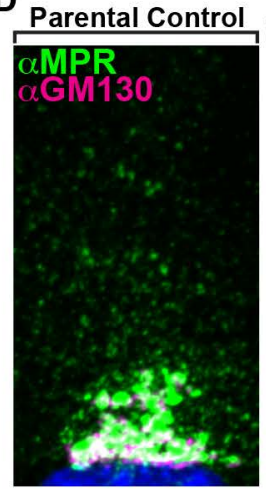

F Parental Control SHIP164 Knockout
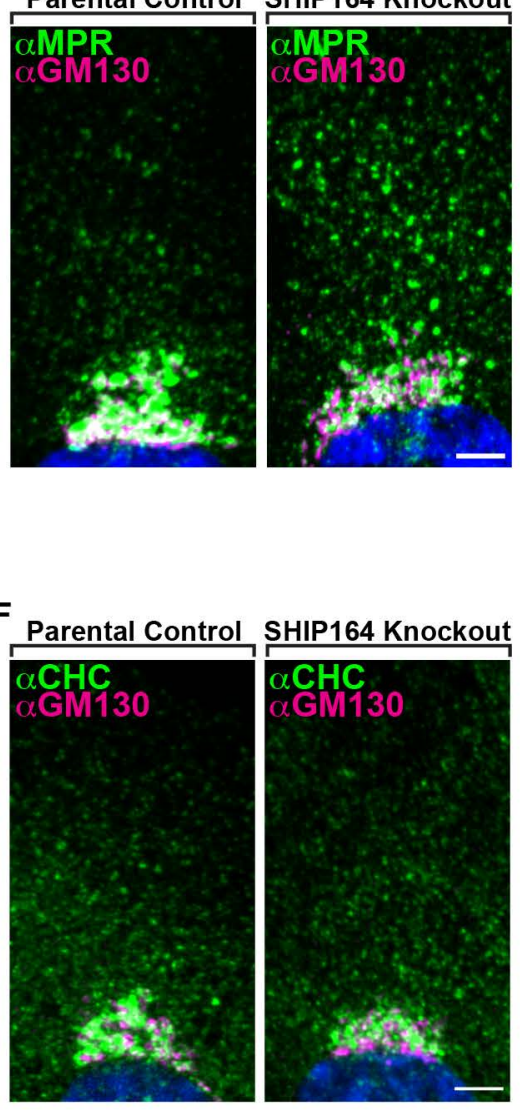

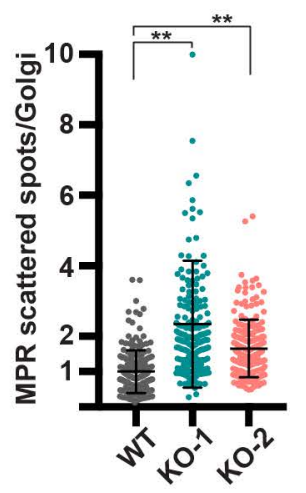

E
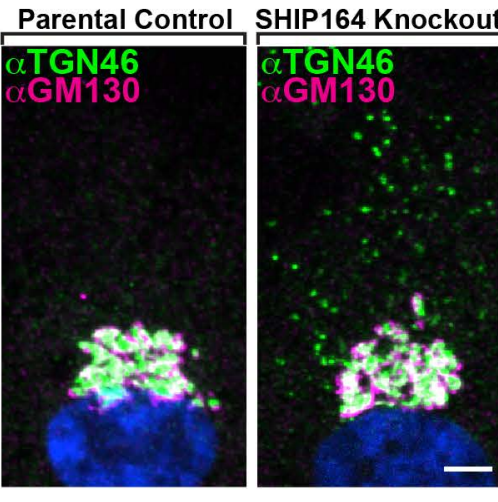

+untagged SHIP164

G +RFP reporter (not shown)

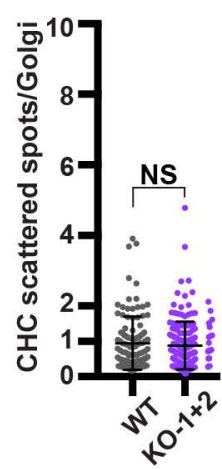

SHIP164 Knockout

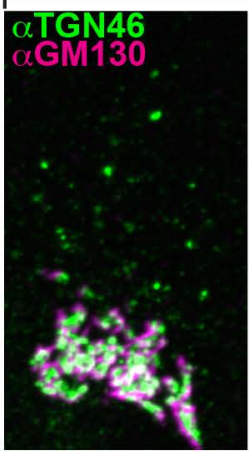

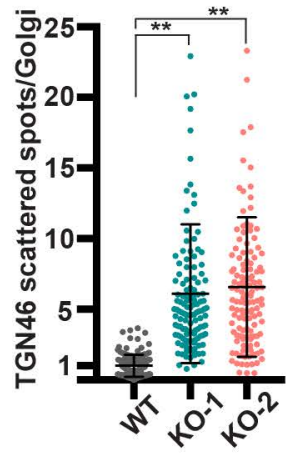

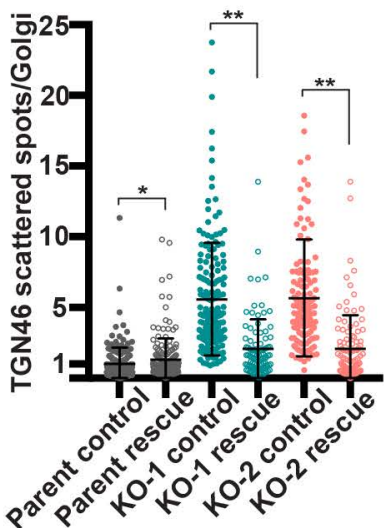


bioRxiv preprint doi: https://doi.org/10.1101/2021.11.04.467353; this version posted November 12, 2021. The copyright holder for this preprint (which was not certified by peer review) is the author/funder, who has granted bioRxiv a license to display the preprint in perpetuity. It is made

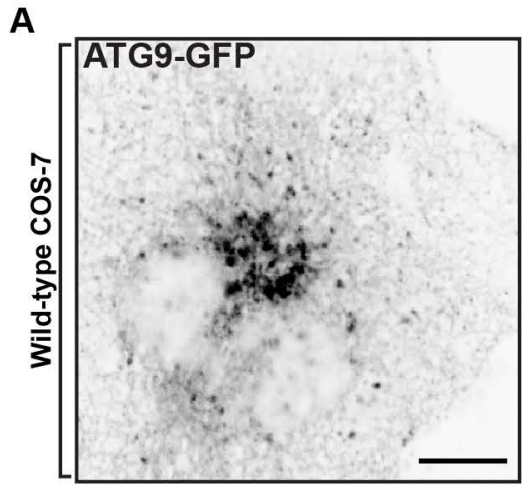

C

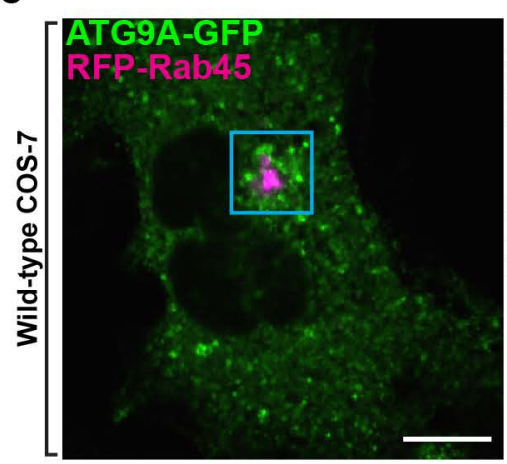

D

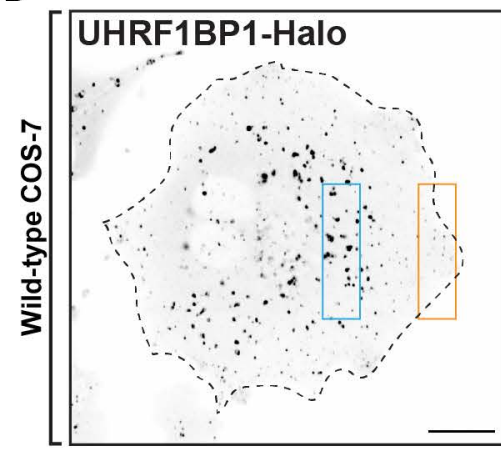

available und
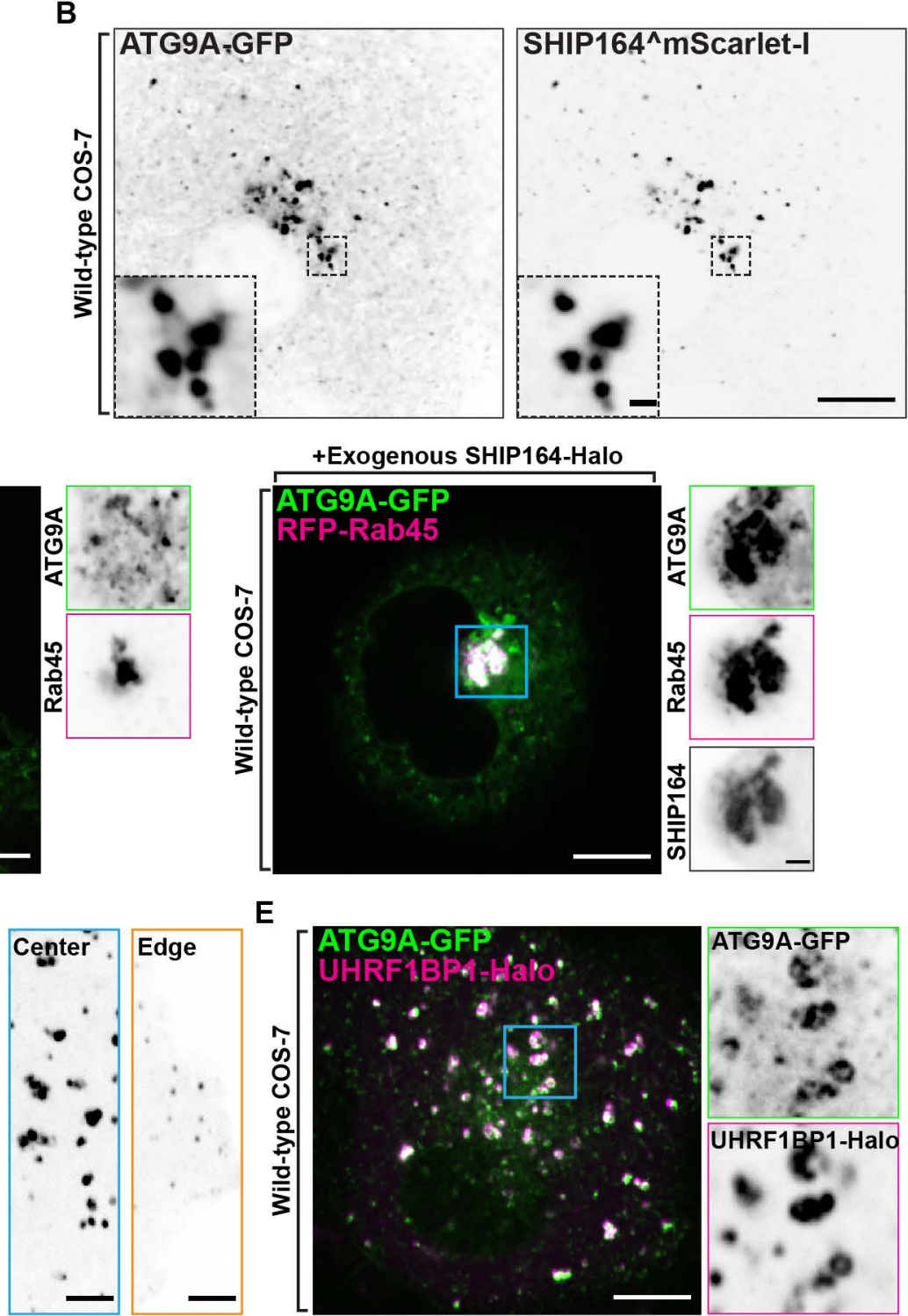

E

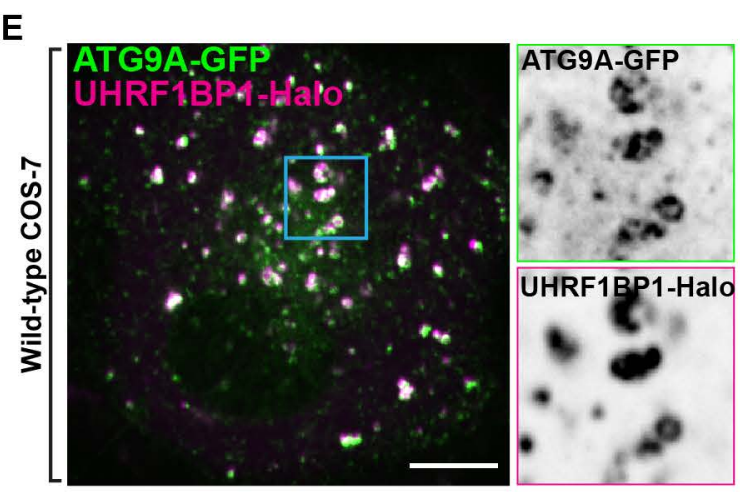

+Exogenous SHIP164-Halo

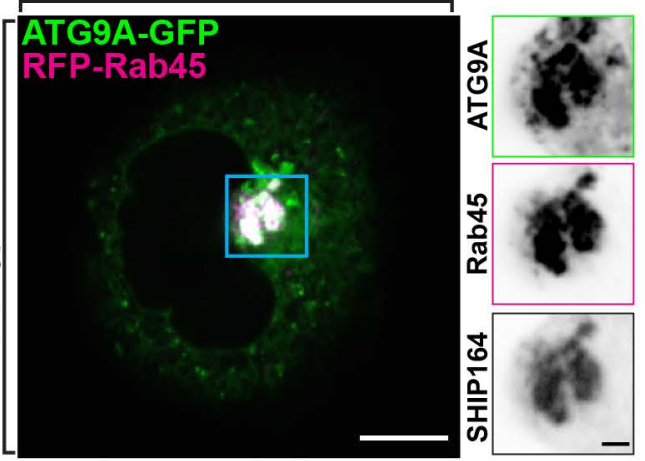


bioRxiv preprint doi: https://doi.org/10.1101/2021.11.04.467353; this version posted November 12, 2021. The copyright holder for this preprint (which was not certified by peer review) is the author/funder, who has granted bioRxiv a license to display the preprint in perpetuity. It is made available under aCC-BY 4.0 International license.

A

(a)

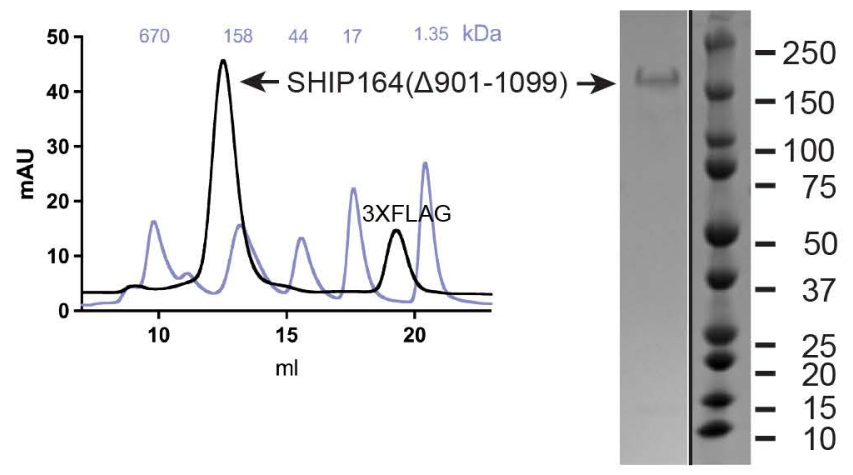

$\mathrm{MW}$

(kDa)

$-250$

150

75

50

25

15

10 (c)

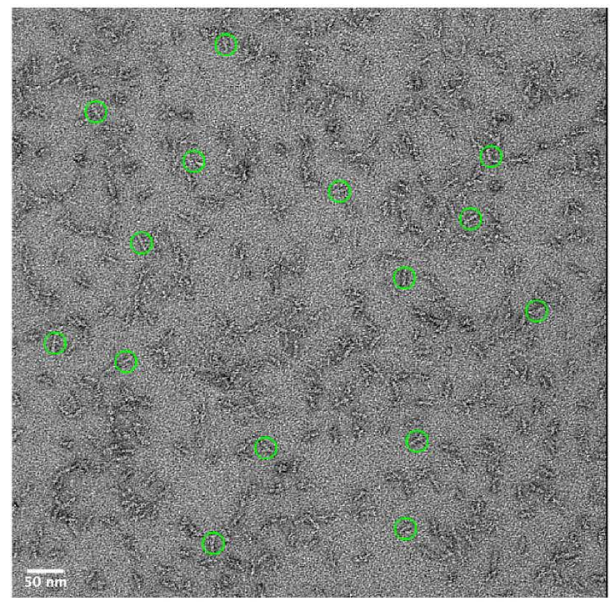

Tecnai T12 negative stain micrograph
B

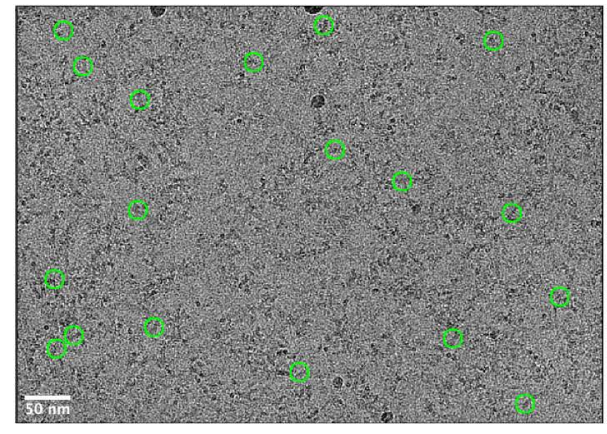

\section{5,381 movies}

MotionCor2

RELION autopick

$3.36 \cdot 10^{6}$ particles

4 rounds of RELION 2D classification
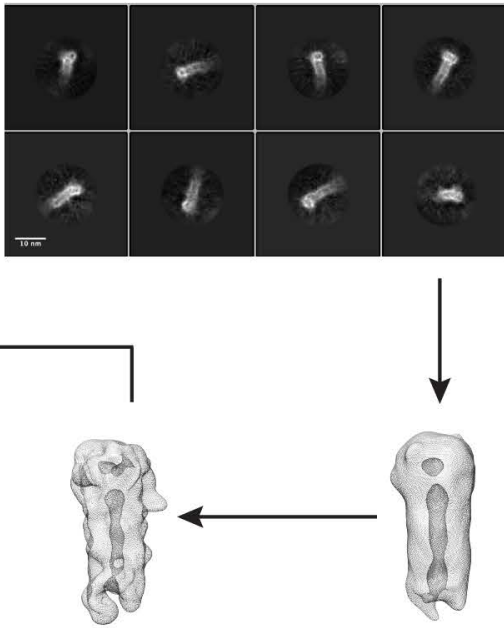
with C1 symmetry
RELION 3D

classification

with 254,169 particles
RELION 3D

initial model

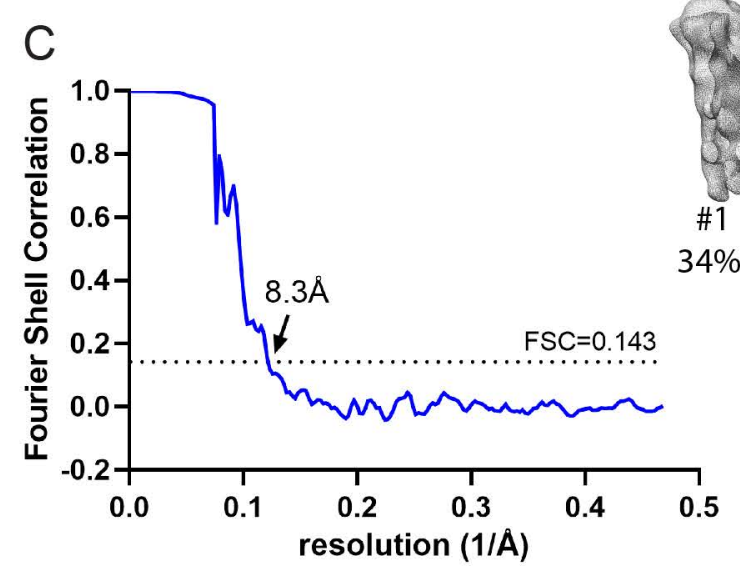

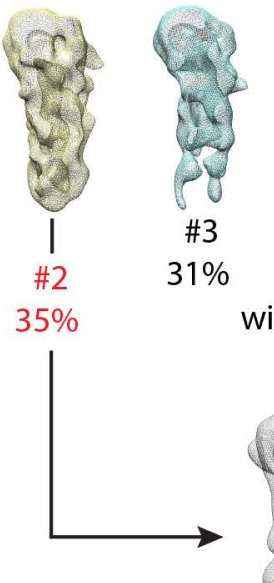

RELION 3D refinement 86,720 particles

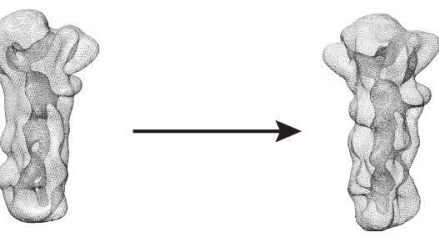

RELION post-process $8.3 \AA$ 
bioRxiv preprint doi: https://doi.org/10.1101/2021.11.04.467353; this version posted November 12, 2021. The copyright holder for this preprint (which was not certified by peer review) is the author/funder, who has granted bioRxiv a license to display the preprint in perpetuity. It is made A
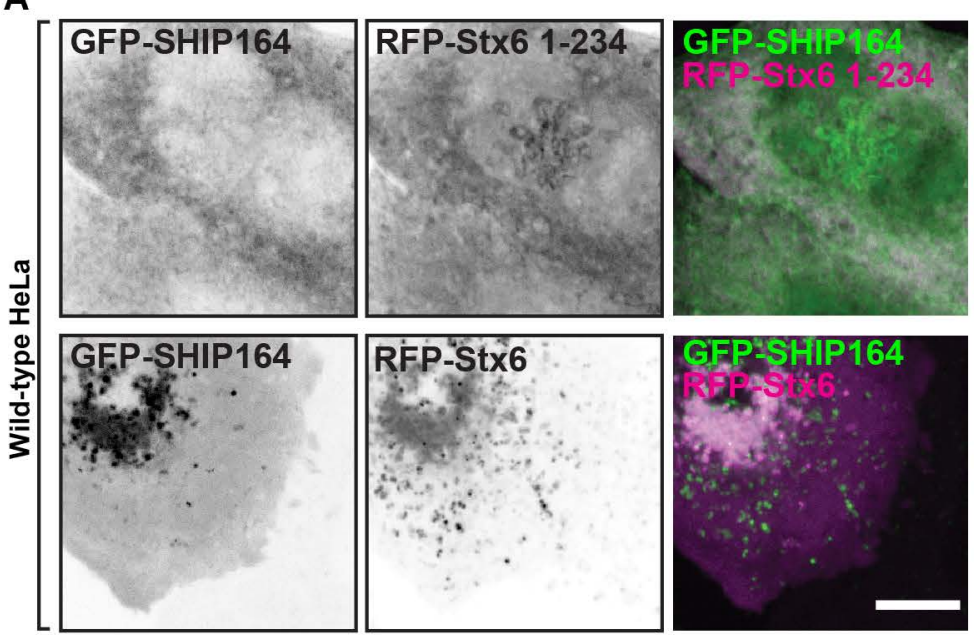

C

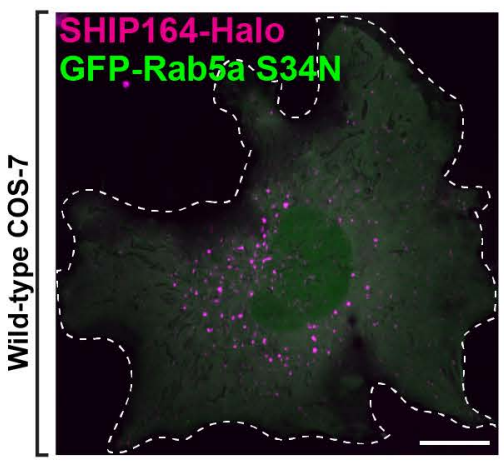

D

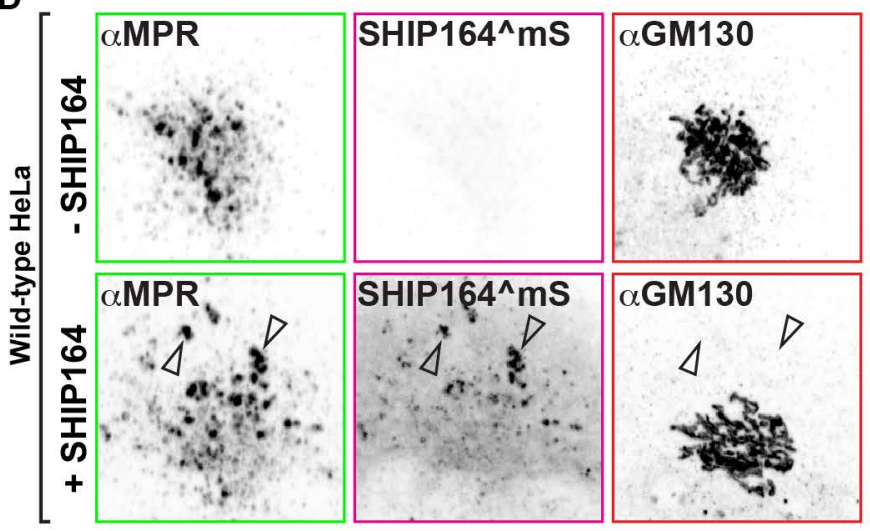

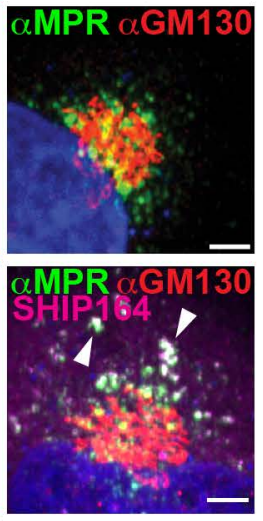

E

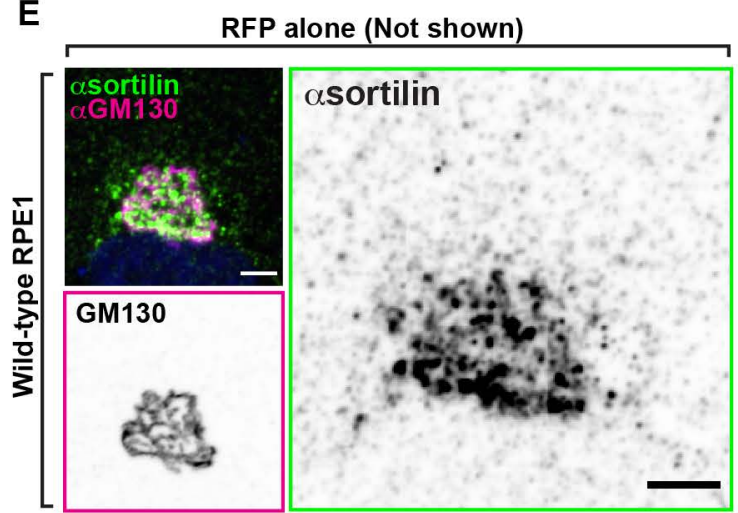

$\mathbf{G}$

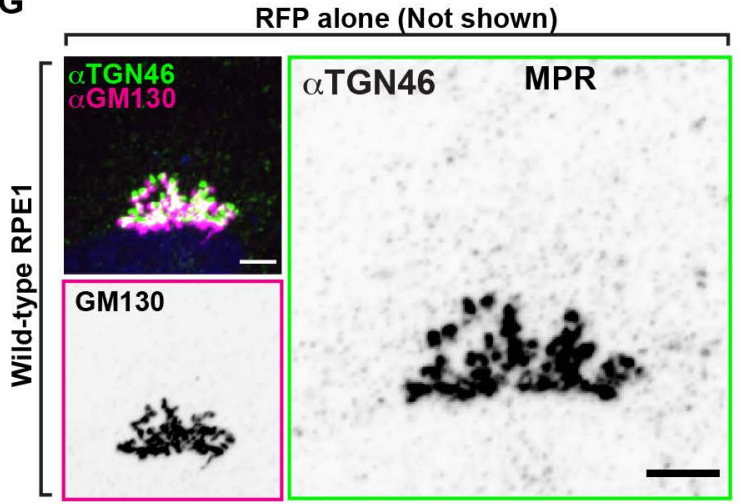

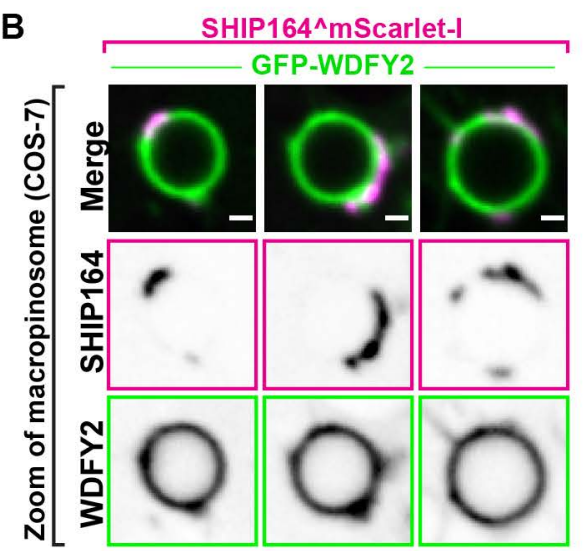

$\mathbf{F}$

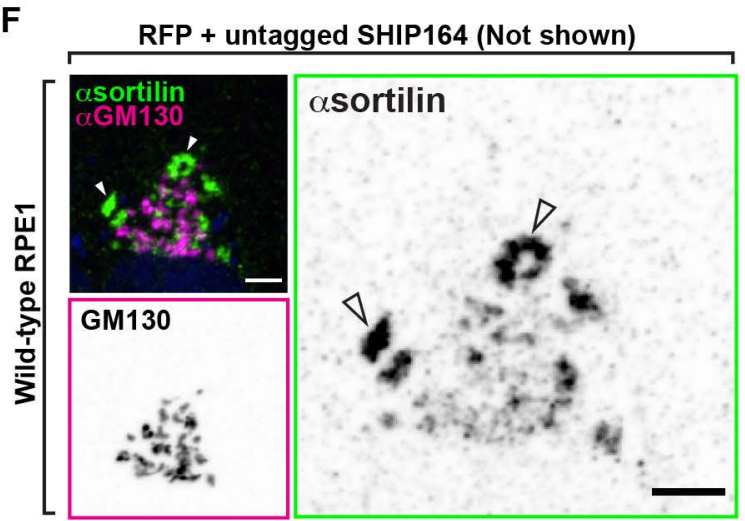

H

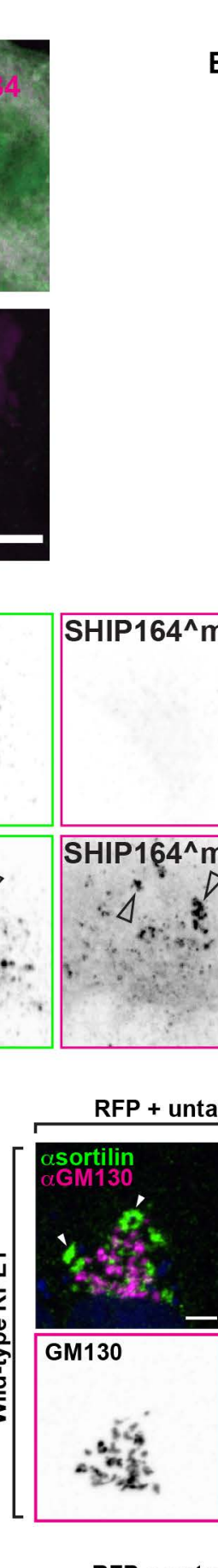


bioRxiv preprint doi: https://doi.org/10.1101/2021.11.04.467353; this version posted November 12, 2021. The copyright holder for this preprint (which was not certified by peer review) is the author/funder, who has granted bioRxiv a license to display the preprint in perpetuity. It is made available under aCC-BY 4.0 International license.

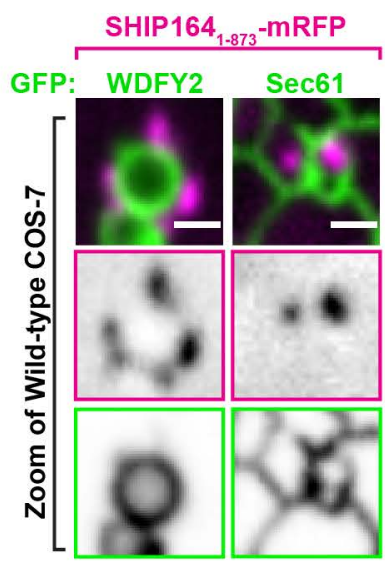

Supplemental Figure 3 
bioRxiv preprint doi: https://doi.org/10.1101/2021.11.04.467353; this version posted November 12, 2021. The copyright holder for this preprint (which was not certified by peer review) is the author/funder, who has granted bioRxiv a license to display the preprint in perpetuity. It is made available under aCC-BY 4.0 International license.

A

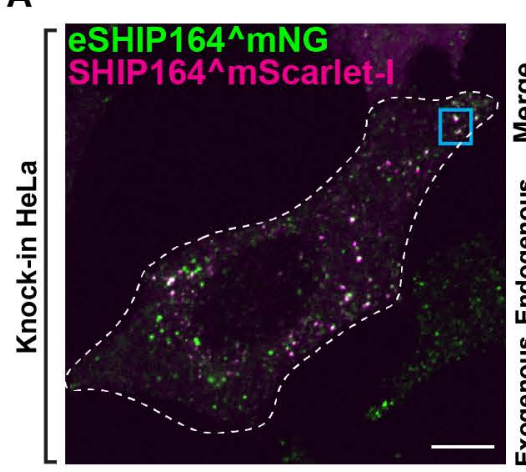

C

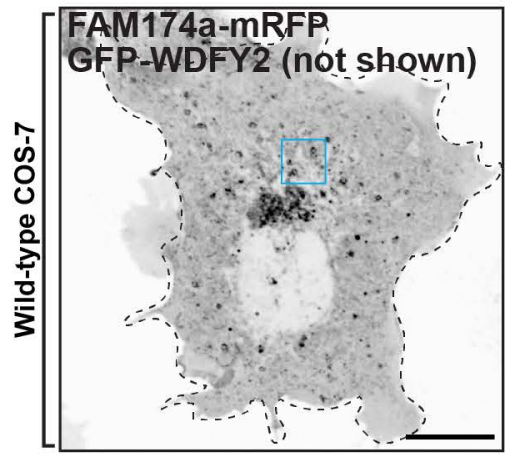

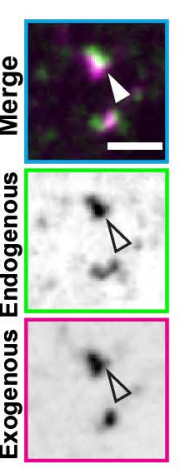

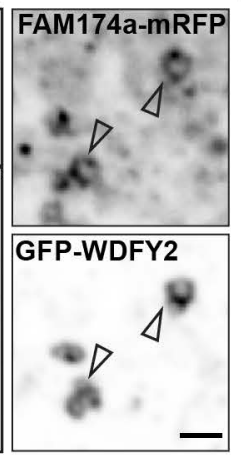

B
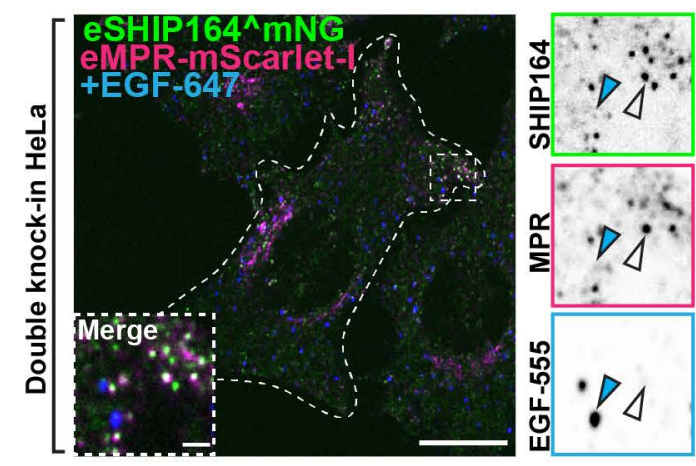

D

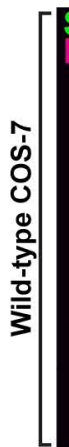

SHIP164-GFP

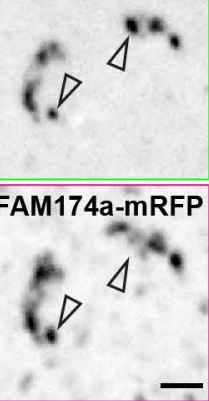

Supplemental Figure 4 
bioRxiv preprint doi: https://doi.org/10.1101/2021.11.04.467353; this version posted November 12, 2021. The copyright holder for this preprint (which was not certified by peer review) is the author/funder, who has granted bioRxiv a license to display the preprint in perpetuity. It is made available under aCC-BY 4.0 International license.

A
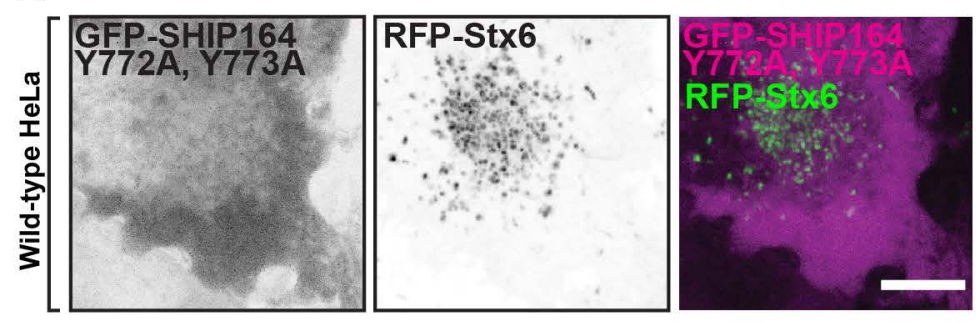

B

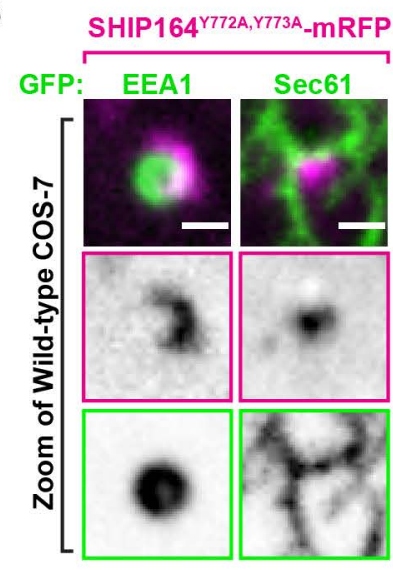

C
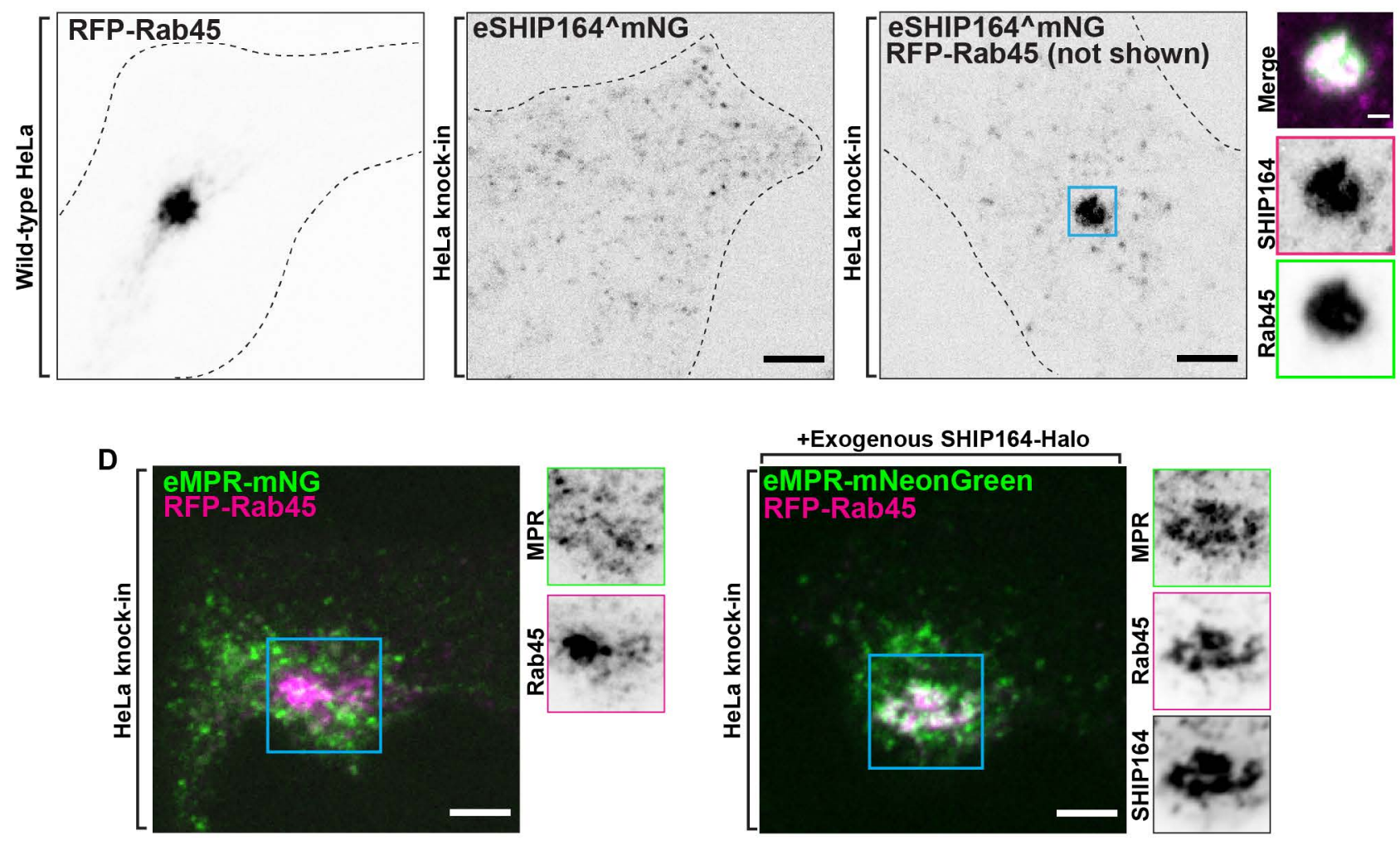

E
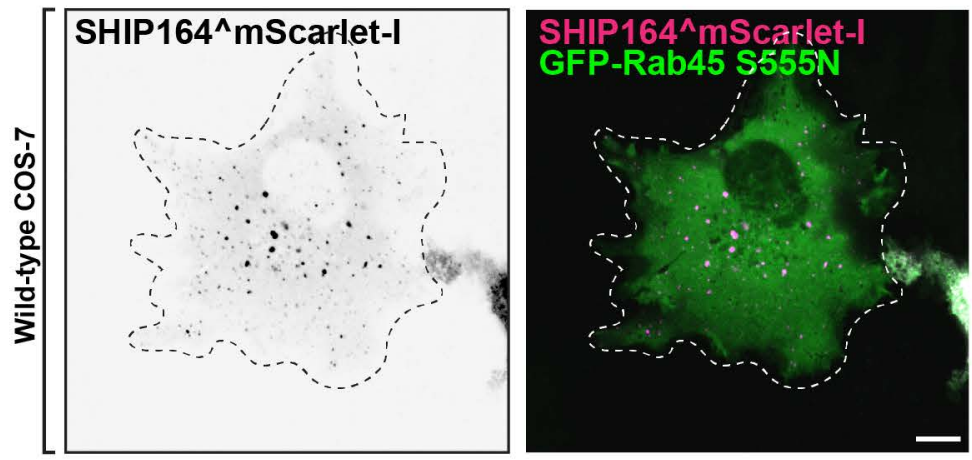

Supplemental Figure 5 
bioRxiv preprint doi: https://doi.org/10.1101/2021.11.04.467353; this version posted November 12, 2021. The copyright holder for this preprint (which was not certified by peer review) is the author/funder, who has granted bioRxiv a license to display the preprint in perpetuity. It is made available under aCC-BY 4.0 International license.

A

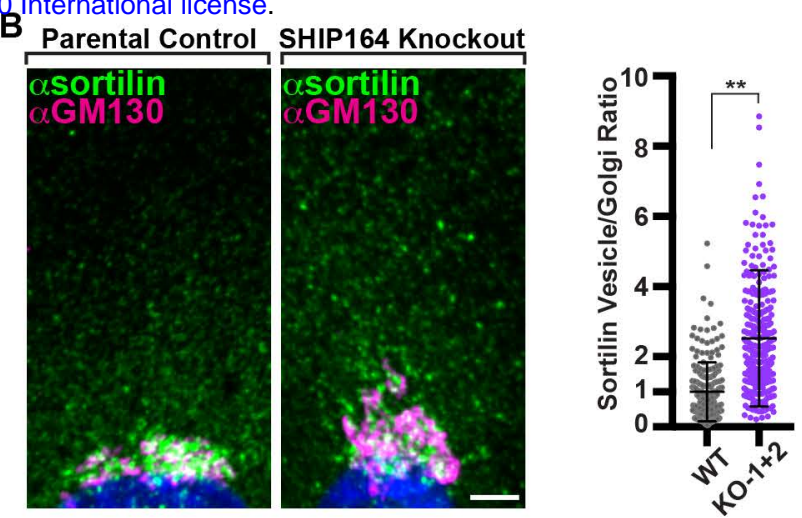

C

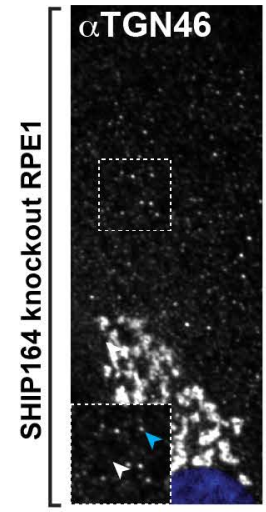

E
PAM Intron

\begin{tabular}{rl|} 
Wild-type & agcgtcc--attagggtgagact \\
Clone 1 & agcgtc---attagggtgagact \\
Clone 2 & agcgtcctcattagggtgagact \\
& ag****\# $\quad * * * * * * * * * * * * *$
\end{tabular}

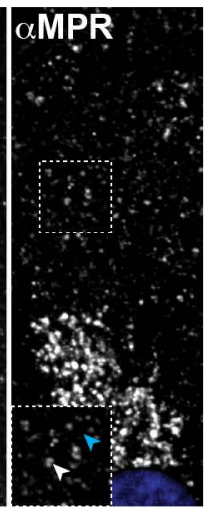

$\alpha$ TGN46 QMPR

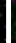
$+8$
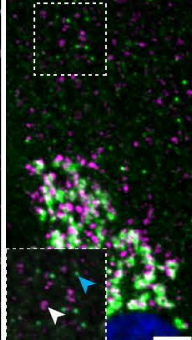

+untagged SHIP164

+RFP reporter (not shown)
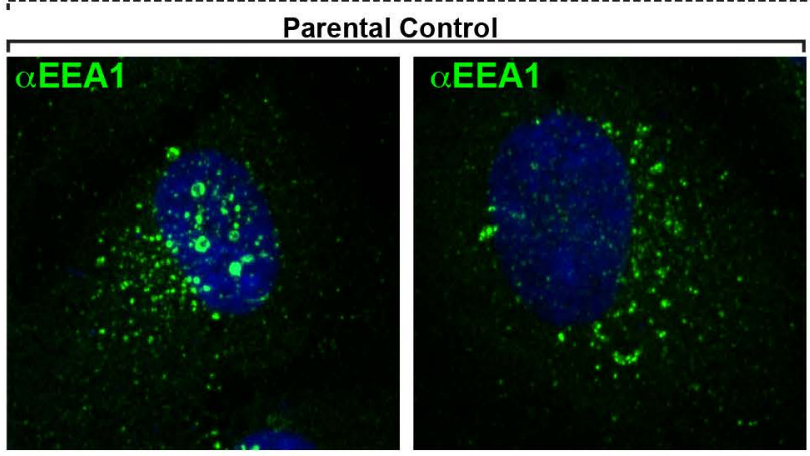

G

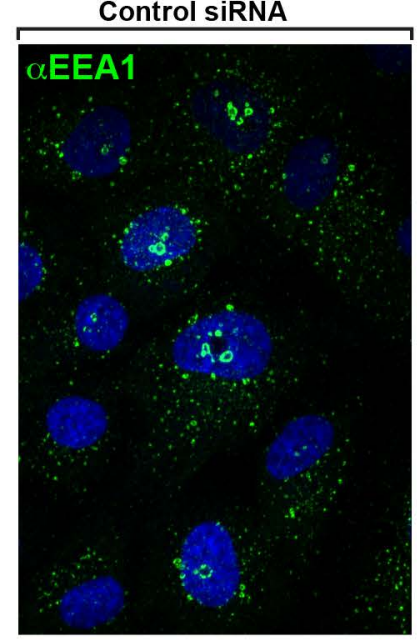

D

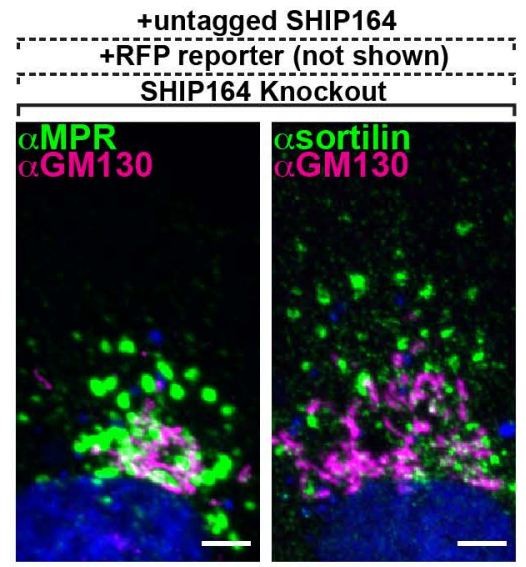

+untagged SHIP164

SHIP164 Knockout

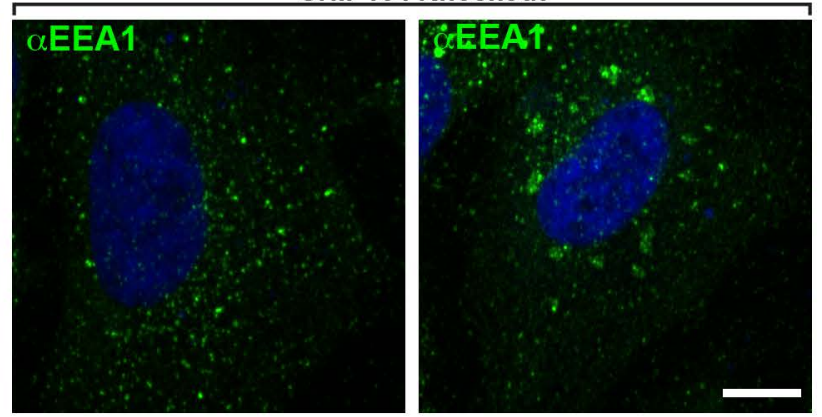

SHIP164 siRNA
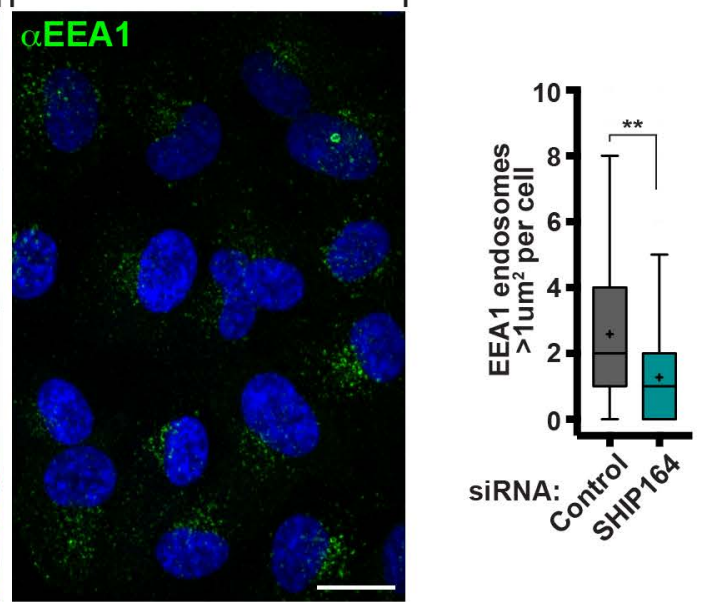

Supplemental Figure 6 
bioRxiv preprint doi: https://doi.org/10.1101/2021.11.04.467353; this version posted November 12, 2021. The copyright holder for this preprint (which was not certified by peer review) is the author/funder, who has granted bioRxiv a license to display the preprint in perpetuity. It is made available under ACC-BY 4.0 International license.

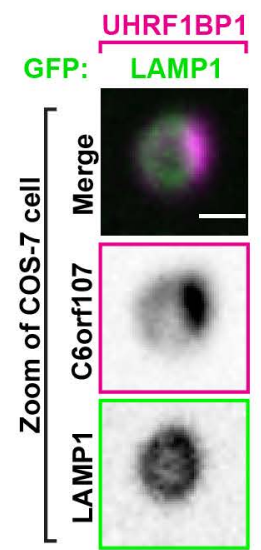

Supplemental Figure 7 